International Scientific-Technical and Production Journal

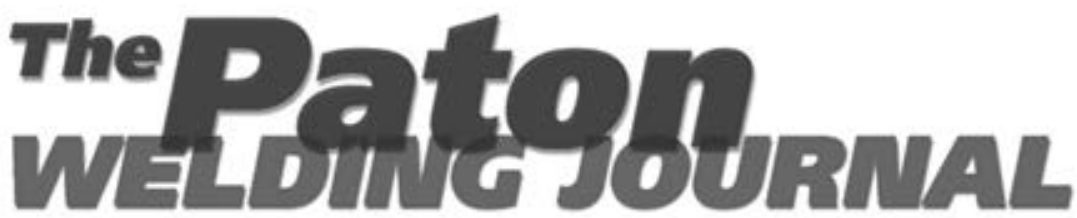

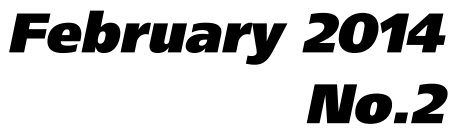

Published since 2000

English translation of the monthly «Avtomaticheskaya Svarka» (Automatic Welding) journal published in Russian since 1948

\section{Editor-in-Chief B.E.Paton EDITORIAL BOARD}

Yu.S. Borisov,

B.V. Khitrovskaya (exec. secretary) V.F. Khorunov, I.V. Krivtsun,

S.I. Kuchuk-Yatsenko ( vice-chief editor), V.I. Kyrian, Yu.N. Lankin,

V.N. Lipodaev (vice-chief editor), L.M. Lobanov, A.A. Mazur,

O.K. Nazarenko, I.K. Pokhodnya

V.D. Poznyakov, I.A. Ryabtsev, K.A. Yushchenko,

A.T. Zelnichenko (exec. director) (Editorial Board Includes PWI Scientists)

\section{INTERNATIONAL EDITORIAL COUNCIL \\ N.P. Alyoshin}

N.E. Bauman MSTU, Moscow, Russia

V.G. Fartushny

Welding Society of Ukraine, Kiev, Ukraine Guan Qiao

Beijing Aeronautical Institute, China V.I. Lysak

Volgograd State Technical University, Russia B.E. Paton

PWI, Kiev, Ukraine

Ya. Pilarczyk

Weiding Institute, Gliwice, Poland U. Reisgen

Welding and Joining Institute, Aachen, Germany O.I. Steklov

Welding Society, Moscow, Russia

G.A. Turichin

G.A. Turichin
St.-Petersburg State Polytechn. Univ., Russia M. Zinigrad

College of Judea \& Samaria, Ariel, Israel A.S. Zubchenko

OKB «Gidropress», Podolsk, Russia

E.O. Paton Electric Wers

E.O. Paton Electric Welding Institute of the NAS of Ukraine,

International Association «Welding"

Publisher
International Association «Welding»

Translators

A.A. Fomin, O.S. Kurochko,

I.N. Kutianova

Editor

N.A. Dmitrieva

D.I. Sereda, T.Yu. Snegiryova

\section{Address}

E.O. Paton Electric Welding Institute, International Association «Welding»

11, Bozhenko Str., 03680, Kyiv, Ukraine

11, Bozhenko Str., 03680, Kyiv, Ukraine

Tel.: (38044) 20060 16, 2008277

E-mail: journal@paton.kiev.ua

www.patonpublishinghouse.com

State Registration Certificate KV 4790 of 09.01.2001 ISSN 0957-798X

Subscriptions

$\$ 348,12$ issues per year air postage and packaging included. Back issues available.

All rights reserved.
This publication and each of the articles contained herein are protected by copyright.

Permission to reproduce material contained in this journal must be obtained in writing from the

\section{CONTENTS}

\section{SCIENTIFIC AND TECHNICAL}

Gajvoronsky A.A. Resistance to cold crack formation of $\mathrm{HAZ}$ metal of welded joint on high-strength carbon steels

Belyavin A.F., Kurenkova V.V. and Fedotov D.A. Fatigue

life of deposited repair welds on single-crystal

high-temperature nickel alloy under cyclic oxidation

Shelyagin V.D., Markashova L.I., Khaskin V.Yu., Bernatsky

A.V. and Kushnaryova O.S. Laser and laser-microplasma

alloying of surface of 38KhN3MFA steel specimens

Korzhik V.N., Borisova A.L., Gordan G.N., Lyutik N.P.,

Chajka A.A. and Kajda T.V. Peculiarities of structure of

coatings of $\mathrm{Fe}-\mathrm{Cr}-\mathrm{Al}$ system flux-cored wire produced

under conditions of supersonic electric arc metallization

INDUSTRIAL

Nesterenkov V.M. and Bondarev A.A. Electron beam welding of large-size thick-wall structures of magnesium alloys

Efimenko N.G., Atozhenko O.Yu., Vavilov A.V., Kantor A.G. and Udalova E.I. Structure and properties of welded joints of $15 \mathrm{Kh} 1 \mathrm{M} 1 \mathrm{FL}$ steel at repair of casting defects by transverse hill method

Korsunov K.A. and Ashikhmina E.A. Analysis of some physical and technical characteristics of ion-plasma coating $(\mathrm{TiZr}) \mathrm{N}$ on rotor blades of compressor of gas-turbine engine TV3-117

\section{INFORMATION}

Today's Foreign Trade Company «INPAT» of the E.O.

Paton Electric Welding Institute

«The Paton Welding Journal» abstracted and indexed in Ukrainian refereed journal «Source», RJ VINITI «Welding» (Russia), INSPEC, «Welding Abstracts», ProQuest (UK), EBSCO Research Database, CSA Materials Research Database with METADEX (USA), Questel Orbit Inc. Weldasearch Select (France); presented in Russian Science Citation Index \& «Google Scholar»; abstracted in «Welding Institute Bulletin» (Poland) \& «Rivista Italiana della Saldatura» (Italy); covered in the review of the Japanese journals "Journal of Light Metal Welding", "Journal of the Japan Welding Society», "Quarterly Journal of the Japan Welding Society», "Journal of Japan Institute of Metals», «Welding Technology». 


\title{
RESISTANCE TO COLD CRACK FORMATION OF HAZ METAL OF WELDED JOINT ON HIGH-STRENGTH CARBON STEELS
}

\author{
A.A. GAJVORONSKY \\ E.O. Paton Electric Welding Institute, NASU \\ 11 Bozhenko Str., 03680, Kiev, Ukraine. E-mail: office@paton.kiev.ua
}

\begin{abstract}
Influence of preheating temperature and heat input during surfacing on change of delayed fracture resistance of HAZ metal on high-strength steel at variation of carbon content in it from 0.55 to $0.75 \%$ was investigated. Effect of carbon content in steel on indices of critical stresses at HAZ metal delayed fracture was evaluated by Implant tests. Influence of a cooling rate on nature of metal fracture and typical rupture zone and parameters of structural constituents were studied and determined using the methods of scanning electron microscopy. It is determined that HAZ metal is predisposed to the delayed fracture in electric arc surfacing due to formation of quenched structures with high dislocation density and internal stresses in area of overheating. Increase of cooling rate and carbon content in steel promotes rise of fracture susceptibility and decrease level of critical stresses to $0.07 \sigma_{0.2}$. Formation of more plastic structures at reduction of the cooling rate in $600-500{ }^{\circ} \mathrm{C}$ temperature interval promotes increase of the delayed fracture resistance of HAZ metal on high-strength carbon steels to $\sigma_{\mathrm{cr}} \geq 0.45 \sigma_{0.2}$ level. A diagram of effect of carbon content in steel on HAZ metal resistance to the delayed fracture was plotted in form of $w_{6 / 5}=f(\mathrm{C})$. It is determined that the process of delayed fracture in HAZ metal on steel with carbon content not more than $0.60 \%$ can be prevented at cooling rate $w 6 / 5$ not more than $16{ }^{\circ} \mathrm{C} / \mathrm{s}, w 6 / 5 \leq 8{ }^{\circ} \mathrm{C} / \mathrm{s}$ with $0.60-0.65 \% \mathrm{C}$ and $w 6 / 5 \leq$ $\leq 5{ }^{\circ} \mathrm{C} / \mathrm{s}$ with $0.65-0.75 \% \mathrm{C}$. Under such conditions, the structures, having sufficiently high capability to microplastic strain without microcrack generation, are formed in the metal of HAZ overheating area. 18 Ref., 2 Tables, 11 Figures.
\end{abstract}

Keywords: electric arc surfacing, high-strength carbon steel, HAZ, preheating, heat input, delayed fracture, structure, rupture

Study of a phenomenon of delayed fracture of as-quenched metal under effect of constant loading was started as far back as the middle of the last century applicable to the conditions of heat treatment of quenching steels for providing of strength and service properties of the parts. Works [1-3] give the most complete explanation of physics of the delayed fracture process of quenched steel at loads, which are significantly lower than yield strength for given metal. It is also noted that the delayed fracture has exclusively brittle nature. In contrast to a classic brittle fracture, which takes place in short periods of time, the delayed fracture develops in the metal in a course of long period of time. At that, the processes of microplastic strain are developed in the local metal areas.

In welding the process of delayed fracture is realized at formation of cold cracks in the joints [4-6]. It is a well-known fact that the welded joints on high-strength steels are more susceptible to cold crack nucleation at formation in them of bainite-martensite structure, and increase of the carbon content in metal rises this susceptibility. Besides, saturation of weld metal with hydrogen, which diffuses in HAZ metal, takes palce in the process of welding. Presence of hydrogen intensifies the process of delayed fracture of the welded joints. It becomes more defined and receives own peculiarities.

Number of researchers [7-13] devoted their works to investigation of delayed fracture of welded joints on high-strength steels. Based on the results of these works, current formulation of the process of delayed fracture of welded joints on high-strength steels can be interpreted in the following way.

The nucleation of microcracks in the structure of as-quenched metal takes place locally in areas of accumulation of dislocations with high level of microstresses. As a rule, these are the areas along the grain boundaries, where metallic bonds are reduced by presence of different inclusions. The hydrogen dissolved in metal in the process of diffusion penetrates in these zones and reduces the level of surface energy necessary for microcrack nucleation. There are number of such zones and microcracks are nucleated simultaneous in several places. When the microcracks have nucleated, local relaxation of microstresses takes 
place. Microplastic strains on dislocation mechanism start to develop in the metal under effect of welding stresses formed in the joint during thermal-deformation cycle of welding. Movement of dislocations starts and hydrogen, traveling with them, accumulates again in the areas of their increased density blocking further slippage. Level of local microstresses in these areas of the structure rapidly increases, breaking of metallic bonds takes place, and microcrack propagates further. The microcracks, achieving their critical size, and in the presence of high level of stresses, can further propagate along a grain body and form a general microcrack in the welded joint metal. As a rule, such cracks are located in the field of main tensile stresses of the welded joint and their development is stopped on a boundary of compressive stresses.

Area of HAZ metal overheating [14-18] is the most dangerous place of the joint, where the nucleation of cold cracks has the highest possibility in arc welding of high-strength steel, the content of carbon in which exceeds $50 \%$. Significant changes of structure takes place in the metal due to the peculiarities of influence of thermal-deformation cycle of arc welding (surfacing) on a process of austenite homogenization and further $\gamma-\alpha$ transformation at cooling. As a result, a structure with increased dislocation density and high level of internal stresses is formed in the area of HAZ metal overheating. It shows that, even if content of diffusible hydrogen in the deposited metal is relatively low (to $2.2 \mathrm{~cm}^{3} / 100 \mathrm{~g}$ ), the critical stresses at delayed fracture make only $0.10-0.25$ of HAZ metal yield strength in welding of highstrength steels for wheel production with carbon content $0.58 \%$ (steel of grade 2, steel KS2). Improvement of the delayed fracture resistance requires providing of the conditions, at which not more than $50 \%$ of martensite is formed in HAZ metal structure and limiting the content of diffusible hydrogen in the deposited metal at the level not more than $0.3 \mathrm{ml} / 100 \mathrm{~g}[15,17]$.

According to GOST 10791, content of carbon in grade 2 steel makes $0.55-0.65 \%$. In present time, question about rise of carbon content up to $0.75 \%$ for increase of service properties of railway wheels is considered in Ukraine and CIS countries. Similar railway wheels are manufactured in USA (wheel type C, AARM 107), Japan (JIS E 5402) and China, and EU countries (R3, ISO $1005 / 6)$. At the same time, there are no experimental data on effect of carbon content on the delayed fracture resistance of HAZ metal of grade 2 steel.
The aim of present work lied in a performance of comparative investigations on determination of effect of rise of carbon content in KS2 steel (up to $0.75 \%$ ) on the delayed fracture resistance of HAZ metal in electric arc surfacing. Highstrength carbon steels of the composition (wt.\%) given below were used as the material for investigations:

- grade 2 steel (GOST 10791) - $0.58 \mathrm{C}$; $0.44 \mathrm{Si} ; 0.77 \mathrm{Mn} ; 0.10 \mathrm{Ni} ; 0.05 \mathrm{Cr} ; 0.012 \mathrm{~S}$; $0.011 \mathrm{P}$

- carbon structural steel 65G (GOST 1050) $0.065 \mathrm{C} ; 0.19 \mathrm{Si} ; 0.91 \mathrm{Mn} ; 0.18 \mathrm{Ni} ; 0.16 \mathrm{Cr}$; $0.017 \mathrm{~S} ; 0.010 \mathrm{P}$

- grade M76 steel (GOST 24182) - $0.74 \mathrm{C}$; $0.30 \mathrm{Si} ; 0.80 \mathrm{Mn} ; 0.10 \mathrm{Ni} ; 0.15 \mathrm{Cr} ; 0.012 \mathrm{~S}$; $0.011 \mathrm{P}$.

Methods of investigation. Quantitative evaluation of the delayed fracture resistance of HAZ metal was carried out using a well-known Implant method [6]. Conditions for preparation of specimens on high-strength carbon steel and performance of the experiments were similar to those in work [17]. The maximum loading stresses of the specimens $\sigma_{\mathrm{cr}}$, at which no delayed fracture was observed during $24 \mathrm{~h}$, were taken as an evaluation criterion.

Mechanized surfacing in $\mathrm{CO}_{2}$ using Sv-08G2S wire of $1.2 \mathrm{~mm}$ diameter was used in performance of the comparative investigations. Surfacing of the specimens was carried out using the following modes: $I_{\mathrm{w}}=160-180 \mathrm{~A}, U_{\mathrm{a}}=26-28 \mathrm{~V}, v_{\mathrm{w}}=8.1-$ $25 \mathrm{~m} / \mathrm{h}$. At that, heat input of surfacing was changed in $Q_{\mathrm{w}}=4.8-15 \mathrm{~kJ} / \mathrm{cm}$ range. Welding current was increased up to 220-240 A (at $v_{\mathrm{w}}=$ $=8.8 \mathrm{~m} / \mathrm{h}$ ) for receiving of higher value of heat input (up to $21 \mathrm{~J} / \mathrm{cm}$ ). Surfacing was carried out with preheating $\left(T_{\mathrm{pr}} \leq 250{ }^{\circ} \mathrm{C}\right)$. HAZ metal cooling rate $w$ of $600-500^{\circ} \mathrm{C}$ temperature interval changed in $w_{6 / 5}=3-37{ }^{\circ} \mathrm{C} / \mathrm{s}$ range, and $800-$ $100{ }^{\circ} \mathrm{C}$ cooling time $\tau$ made $\tau_{8 / 1}=110-1050 \mathrm{~s}$ at given conditions of surfacing. Table 1 provides for the main characteristics of thermal cycle of HAZ metal in surfacing of Implant specimens. Content of diffusible hydrogen $[\mathrm{H}]_{\mathrm{dif}}$ in the deposited metal, determined by method of «pencil» test using mixture of glycerin and distilled water as a locking fluid, made $0.75-0.90 \mathrm{ml} / 100 \mathrm{~g}$.

Ruptures of the Implant specimens was investigated by scanning electron microscopy methods ${ }^{*}$. Philips scanning electron microscope SEM-

\footnotetext{
* Investigations were carried out by L.I. Markashova, E.N. Berdnikova and T.A. Alekseenko.
} 
Table 1. Parameters of thermal cycle in HAZ metal of Implant specimens during surfacing $\left(T_{\max }=1250-1350{ }^{\circ} \mathrm{C}\right)$

\begin{tabular}{|c|c|c|c|c|}
\hline$Q_{\mathrm{w}}, \mathrm{kJ} / \mathrm{cm}$ & $T_{\mathrm{pr}},{ }^{\circ} \mathrm{C}$ & $w_{6 / 5},{ }^{\circ} \mathrm{C} / \mathrm{s}$ & $\tau_{8 / 5}, \mathrm{~s}$ & $\tau_{8 / 1}, \mathrm{~s}$ \\
\hline \multirow[t]{6}{*}{4.8} & 20 & $32-37$ & 6 & 110 \\
\hline & 50 & $27-32$ & 7 & 150 \\
\hline & 70 & $25-30$ & 8 & 170 \\
\hline & 100 & $20-25$ & 10 & 300 \\
\hline & 150 & $16-18$ & 12 & 650 \\
\hline & 200 & $8-10$ & 16 & 900 \\
\hline \multirow[t]{7}{*}{8.6} & 20 & $25-30$ & 8 & 170 \\
\hline & 50 & $20-25$ & 10 & 230 \\
\hline & 70 & $15-20$ & 11 & 250 \\
\hline & 100 & $12-15$ & 12 & 450 \\
\hline & 150 & $8-10$ & 14 & 760 \\
\hline & 200 & $5-7$ & 18 & 890 \\
\hline & 250 & $3-4$ & 25 & 1050 \\
\hline \multirow[t]{3}{*}{11.5} & 20 & $15-17$ & 14 & 210 \\
\hline & 50 & $12-14$ & 16 & 360 \\
\hline & 100 & $6-8$ & 20 & 850 \\
\hline 15.0 & 20 & $10-12$ & 17 & 290 \\
\hline 21.0 & 20 & $7-9$ & 22 & 940 \\
\hline
\end{tabular}

515, equipped with energy-dispersion spectrometer of LINK system, was used.

Results and discussion. In the beginning the results of investigation of the delayed fracture resistance of HAZ metal of grade 2 steel will be considered in more details in order to explain the properties of HAZ metal on high-strength steels

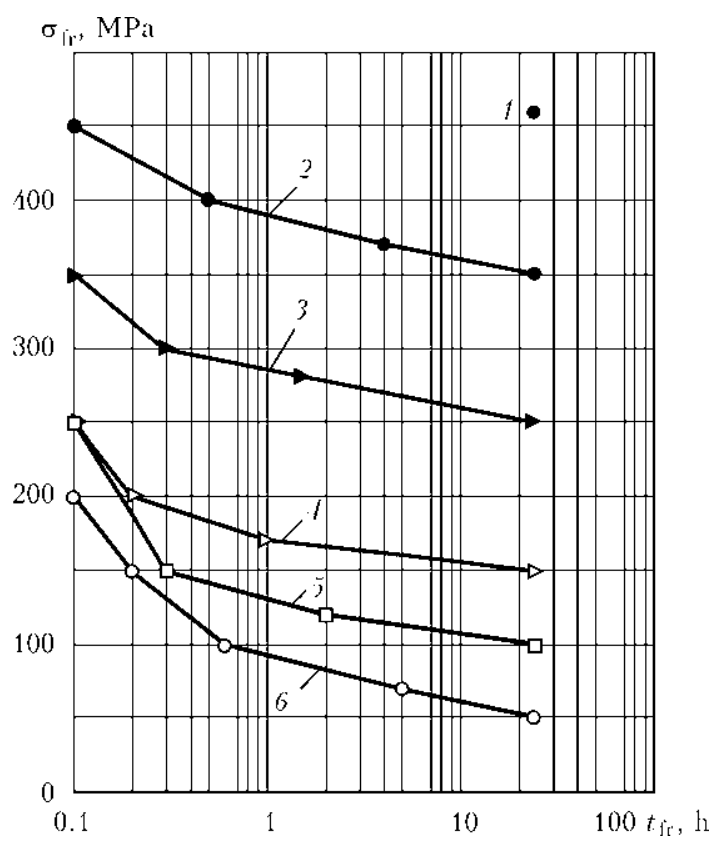

Figure 1. Effect of preheating temperature on delayed fracture resistance $\sigma_{\mathrm{fr}}$ of $\mathrm{HAZ}$ metal on KS2 steel at $Q_{\mathrm{w}}=$ $=4.8 \mathrm{~kJ} / \mathrm{cm}: 1-T_{\mathrm{pr}}=200 ; 2-150 ; 3-100 ; 4-70$; $5-50 ; 6-20{ }^{\circ} \mathrm{C}$

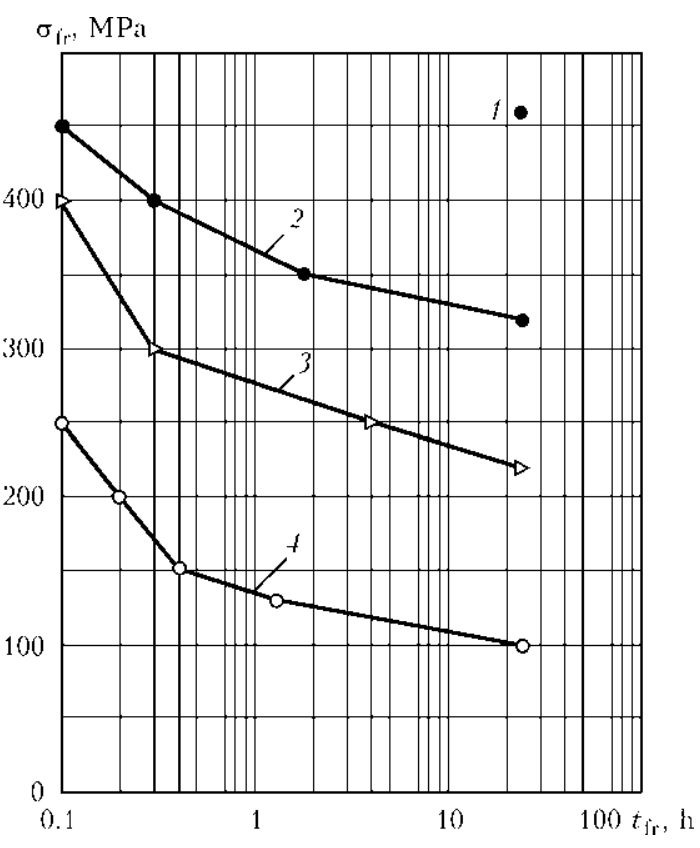

Figure 2. Effect of preheating temperature on delayed fracture resistance $\sigma \mathrm{fr}$ of $\mathrm{HAZ}$ metal on $\mathrm{KS} 2$ steel at $O_{\mathrm{w}}=$ $=8.6 \mathrm{~kJ} / \mathrm{cm}: 1-T_{\mathrm{pr}}=100 ; 2-70 ; 3-50 ; 4-20{ }^{\circ} \mathrm{C}$ with higher carbon content (steels $65 \mathrm{G}$ and M76). Figures 1 and 2 show the effect of preheating temperature on indices of critical stresses during testing of Implant specimens, the surfacing of which was carried out at 4.8 and $8.6 \mathrm{~kJ} / \mathrm{cm}$ heat input, respectively. Figure 3 shows a diagram of transformation of undercooled austenite in HAZ metal of KS2 steel in arc surfacing [15].

As can be seen from given material, structural condition of the metal in HAZ overheating area has significant effect on change of indices of the delayed fracture resistance $\sigma_{\mathrm{cr}}$. Martensite-bainite structure, the content of martensite in which exceeds $71 \%$, is formed in the metal of HAZ overheating area at cooling rate $\omega_{6 / 5} 25 \geq{ }^{\circ} \mathrm{C} / \mathrm{s}$.

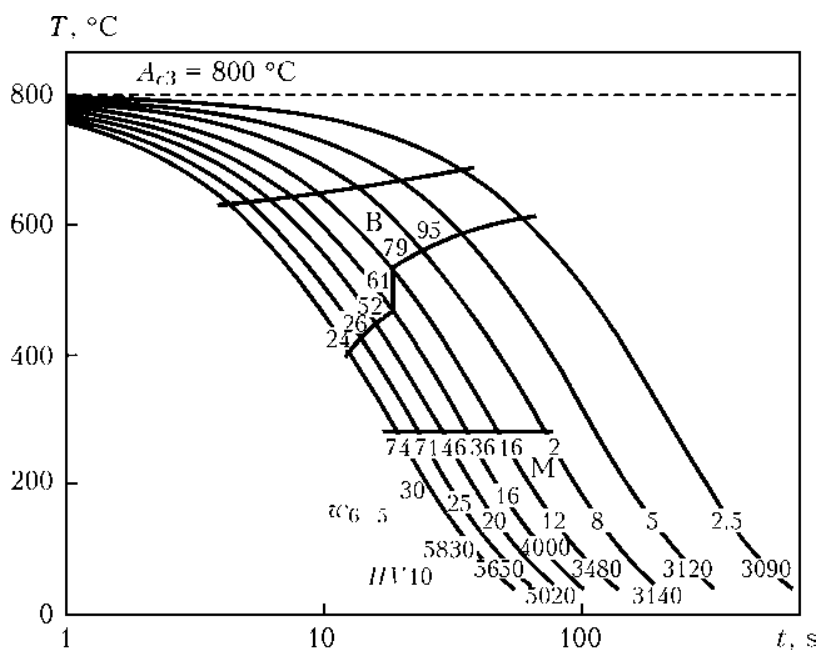

Figure 3. Diagram of transformation of undercooled austenite in HAZ metal on steel KS2 $(0.58 \% \mathrm{C})$ in arc surfacing at $w$ heat $=210{ }^{\circ} \mathrm{C} / \mathrm{s}$ and austenitizing time $t_{1}=$ $=7-10 \mathrm{~s}$ [15] 


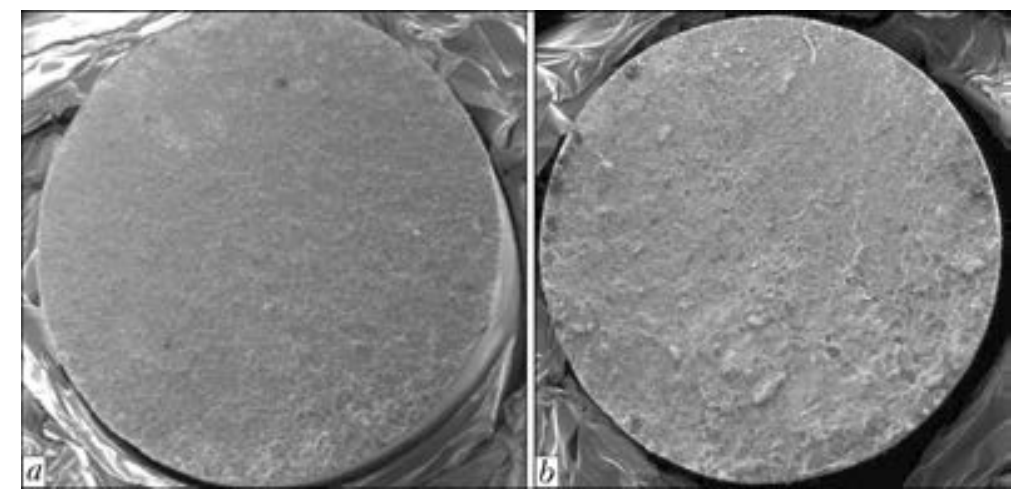

Figure 4. Ruptures $(\times 24)$ of Implant specimens of KS2 steel in surfacing at $8.6 \mathrm{~kJ} / \mathrm{cm}$ heat input without ( $a$ ) and with (b) preheating to $70{ }^{\circ} \mathrm{C}$

Martensite microhardness rises from $H V 0.1=$ $=4420 \mathrm{MPa}$ at $w_{6 / 5} 8{ }^{\circ} \mathrm{C} / \mathrm{s}$ up to $5660-$ $6060 \mathrm{MPa}$ at $25-30{ }^{\circ} \mathrm{C} / \mathrm{s}$. Integral hardness of metal makes $H V 10 \geq 5650 \mathrm{MPa}$. Therefore, HAZ metal has low resistance to nucleation and propagation of the microcracks, and critical fracture stresses make only $0.07 \sigma_{0.2}$ and $0.14 \sigma_{0.2}$, respectively, in surfacing without preheating at $Q_{\mathrm{w}}=$ $=4.8$ and $8.6 \mathrm{~kJ} / \mathrm{cm}$. In order to eliminate the development of delayed fracture process in the metal of HAZ overheating area under given conditions of surfacing, the external stresses should not exceed 50-100 MPa.

Using of preheating at $T_{\mathrm{pr}}=50{ }^{\circ} \mathrm{C}$ provides significant reduction of cooling rate to $w_{6 / 5} \geq$ $\geq 20{ }^{\circ} \mathrm{C} / \mathrm{s}$ ( see Table 1 ), and martensite-bainite structure with lower volume fraction of martensite $(50-74 \%)$ is also formed in HAZ metal. Critical stresses rise virtually 2 times, but still remain at the low level. Index $\sigma_{\mathrm{cr}}=0.14 \sigma_{0.2}$ in surfacing at $4.8 \mathrm{~kJ} / \mathrm{cm}$ heat input and it makes $\sigma_{\mathrm{cr}}=0.30 \sigma_{0.2}$ at $8.6 \mathrm{~kJ} / \mathrm{cm}$. At that realization of the process of delayed fracture of HAZ metal (time of fracture $t_{\mathrm{fr}}=0.1 \mathrm{~h}$ ) requires the external stresses of 250 and $400 \mathrm{MPa}$ value, respectively.

Application of preheating at $70{ }^{\circ} \mathrm{C}$ and higher promotes more significant increase of delayed fracture resistance of deposited HAZ metal, received at $8.6 \mathrm{~kJ} / \mathrm{cm}$, up to $\sigma_{\mathrm{cr}} \geq 0.45 \sigma_{0.2}$. The structure of HAZ metal under given conditions of surfacing $\left(T_{\mathrm{pr}}=70-100{ }^{\circ} \mathrm{C}\right)$ and depending on $w_{6 / 5}=12-20{ }^{\circ} \mathrm{C} / \mathrm{s}$ (see Table 1$)$ is represented by bainite-martensite mixture, the volume fraction of martensite in which does not exceed $50 \%$. When using surfacing at $4.8 \mathrm{~kJ} / \mathrm{cm}$, such conditions of structure formation correspond to application of preheating at $150-200{ }^{\circ} \mathrm{C}$, and critical stresses in fracture of HAZ metal increase up to $\sigma_{\mathrm{cr}} \geq 0.50 \sigma_{0.2}$. Testing of Implant specimens at higher load values failed due to beginning of a metal plastic flow and impossibility of realization of the delayed fracture process. Therefore, the critical stresses were conditionally taken equal $460 \mathrm{MPa}$ in surfacing with $Q_{\mathrm{w}}=8.6 \mathrm{~kJ} / \mathrm{cm}$ and $T_{\mathrm{pr}}=100{ }^{\circ} \mathrm{C}$, as well as $Q_{\mathrm{w}}=4.8 \mathrm{~kJ} / \mathrm{cm}$ and $T_{\mathrm{pr}}=200{ }^{\circ} \mathrm{C}$.

Fracture of HAZ metal of KS2 steel at all investigated variants of surfacing, described above, has brittle nature. Figure 4 shows ruptures of the Implant specimens, surfacing of which was carried out at $8.6 \mathrm{~kJ} / \mathrm{cm}$ heat input with or without preheating to $70{ }^{\circ} \mathrm{C}$, and Figure 5 displays typical fragments of fracture surface in areas of nucleation and propagation of microcracks. Loading at specimen fracture made $\sigma_{\mathrm{fr}}=(1.1-1.3) \sigma_{\mathrm{cr}}$.

Typical areas of fracture are observed on the rupture surfaces. They can be symbolically divided on local areas of nucleation of microcracks and their delayed propagation (zone I), areas of rapid propagation of microcrack to macrolevel (zone II) and areas of final rupture (zone III). Distribution of zones has local nature, nucleation and propagation of cracks take place simultaneously in several places, areas of fracture alternate. Microlevel investigations showed that nucleation of microcrack in HAZ for both variants of surfacing of KS2 steel has brittle nature and takes place along the grain boundaries (Figure 5, $a$, b). Further, the microcracks propagate along the boundaries as well as in grain body. The rupture in this zone is characterized as intergranular and transcrystalline cleavage. Size of cleavage facets is $D_{\mathrm{f}} \sim 30-100 \mu \mathrm{m}$.

Relationship of these types of rupture will change depending on HAZ metal structural condition. When surfacing without preheating, the volume fraction of intergranular cleavage makes $95 \%$, and with preheating at $70{ }^{\circ} \mathrm{C}$ it reduces to $30 \%$. Areas of quasi-brittle fracture and local areas of tough constituent with $D_{\mathrm{f}} \sim 0.5-2.0 \mu \mathrm{m}$ in amount up to $10 \%$ (Figure $5, c, d$ ) are also observed along the grain boundaries in preheating application.

Nature of the final rupture and size of structural elements differ from other zones of fracture. 
SCIENTIFIC AND TECHNICAL
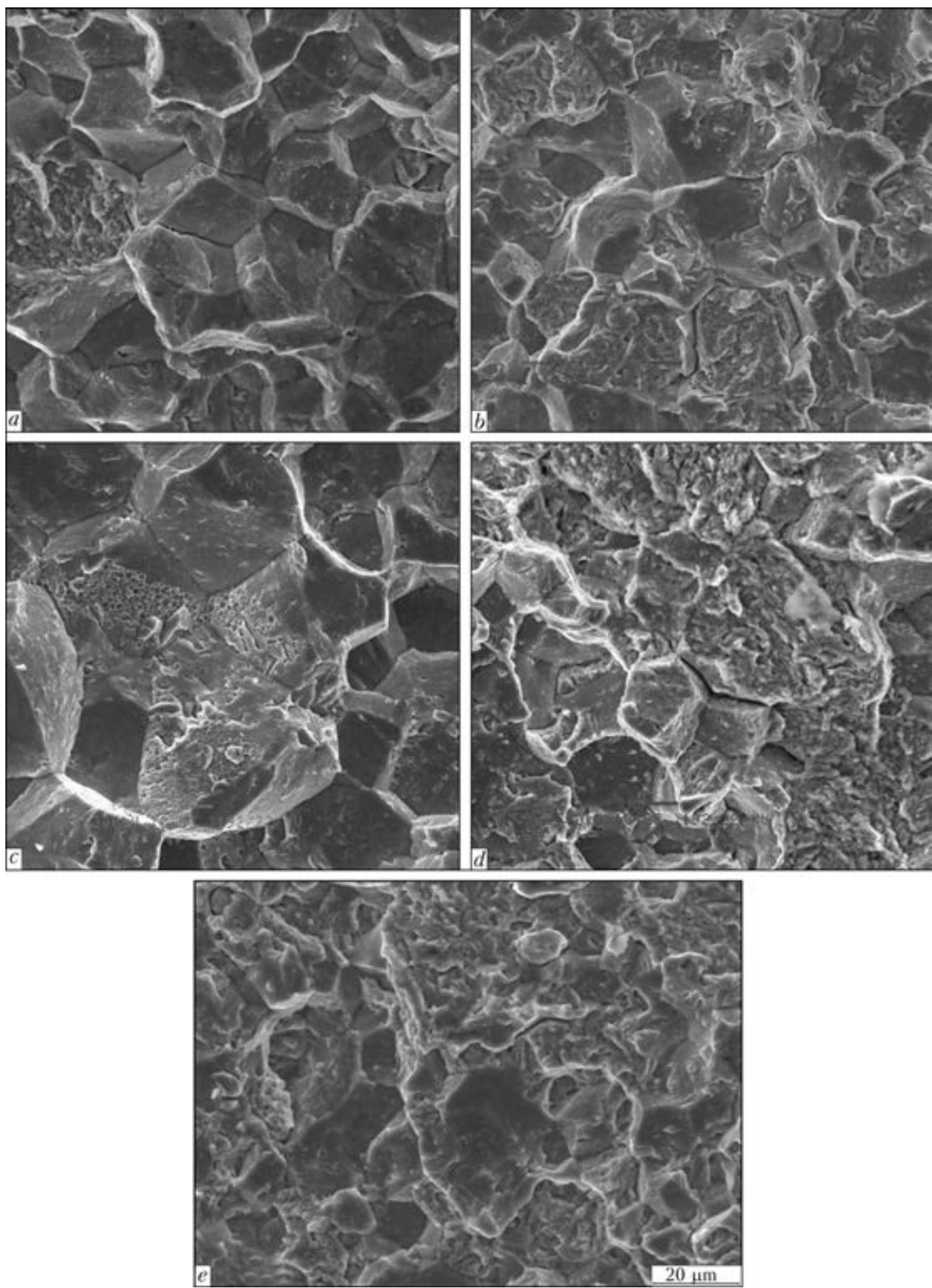

Figure 5. Fragments $(\times 1010)$ of fracture surface in area of nucleation $(a, b)$, propagation of microcrack $(c, d)$ and in zone of final rupture $(e)$ of HAZ metal on steel KS2 in surfacing with $Q_{\mathrm{w}}=8.6 \mathrm{~kJ} / \mathrm{cm}: a, c-T_{\mathrm{pr}}=20 ; b, d-70{ }^{\circ} \mathrm{C}$

It is similar for the both variants of surfacing. It is mainly intergranular quasi-brittle fracture with $D_{\mathrm{f}} \sim 10-20 \mu \mathrm{m}$ (Figure 5,e).

Increase of heat input of surfacing more than $8.6 \mathrm{~kJ} / \mathrm{cm}$ provides rise of resistance to the delayed fracture of HAZ metal on KS2 steel specimens (Figure 6). Thus, cooling rate reduces to $15-17{ }^{\circ} \mathrm{C} / \mathrm{s}$ in surfacing with $Q_{\mathrm{w}}=11.5 \mathrm{~kJ} / \mathrm{cm}$ without preheating. The same bainite-martensite structure as in surfacing with $Q_{\mathrm{w}}=11.5 \mathrm{~kJ} / \mathrm{cm}$ and $T_{\mathrm{pr}}=70^{\circ} \mathrm{C}$ is formed in the $\mathrm{HAZ}$ metal, and critical stresses make $200 \mathrm{MPa}$. But this $\sigma_{\mathrm{cr}}$ value is approximately 1.6 times lower than the similar index for surfacing with lower heat input at approximately the same rate of cooling in HAZ. Apparently, it is related with the development of process of growth of austenite grain in the metal of HAZ overheating area, which is more intensive in surfacing at higher heat input. However, even if this negative effect is taken into 
account, application of preheating at $50{ }^{\circ} \mathrm{C}$ in surfacing with $Q_{\mathrm{w}}=11.5 \mathrm{~kJ} / \mathrm{cm}$ eliminates propagation of the delayed fracture in HAZ metal on KS2 steel. It should also be noted that testing of Implant specimens in surfacing at higher heat input showed increase of time before fracture. Thus, delayed fracture of the specimens at $\sigma_{\mathrm{fr}}=$ $=2 \sigma_{\mathrm{cr}}$, surfaced with $Q_{\mathrm{w}}=8.6 \mathrm{~kJ} / \mathrm{cm}$ and $T_{\mathrm{pr}}=$ $=70{ }^{\circ} \mathrm{C}$, continued $0.1 \mathrm{~h}$, and fracture period at $Q_{\mathrm{w}}=11.5 \mathrm{~kJ} / \mathrm{cm}$ and $T_{\mathrm{pr}}=20{ }^{\circ} \mathrm{C}$ made $0.7 \mathrm{~h}$. This also can be related with growth of grain in HAZ metal and corresponding enlargement of path of propagation of microcrack along its boundary, location of which does not match with the field of action of main tensile stresses.

No development of the process of delayed fracture was registered in surfacing without preheating of $\mathrm{KS} 2$ steel $(0.58 \% \mathrm{C})$ at $15 \mathrm{~kJ} / \mathrm{cm}$ heat input. In this case, the rate of cooling in HAZ makes $10-12{ }^{\circ} \mathrm{C} / \mathrm{s}$, and bainite-martensite structure with volume fraction of martensite not exceeding $16 \%$ is formed. Hardness of metal in HAZ overheating areas makes $H V 10 \leq 3480 \mathrm{MPa}$. The microcracks are not nucleated in such a metal due to development of the processes of microplastic strain and relaxation of microstresses in the structure.

The delayed fracture of HAZ metal takes place at lower values of external stresses with the increase of carbon content in high-strength steel. Figure 7 represents the generalized results of Implant specimen testing. As can be seen from data presented, the increase of heat input up to $15 \mathrm{~kJ} / \mathrm{cm}$ and above in surfacing without preheating of $65 \mathrm{G}(0.65 \% \mathrm{C})$ and M76 $(0.74 \% \mathrm{C})$ steels promotes rise of critical stresses, but does not eliminate development of the process of delayed fracture in HAZ metal.

Specially carried out metallographic investigations ${ }^{*}$ showed that the structure of $65 \mathrm{G}$ structural steel in as-delivered condition is represented by bainite (Figure $8, a$ ), grain size is $16-24 \mu \mathrm{m}$ and integral hardness of metal makes $H V 10=$ $=2760 \mathrm{MPa}$. The bainite-martensite structure with volume fraction of martensite not exceeding $50 \%$ is formed in the metal of HAZ overheating area on steel $65 \mathrm{G}$ under effect of TCW at cooling rate $w_{6 / 5} \leq 7{ }^{\circ} \mathrm{C} / \mathrm{s}$, in contrast to steel $\mathrm{KS} 2$. Hardness of the metal with such a structure is not more than $4570 \mathrm{MPa}$. Size of grain in the metal of HAZ overheating area makes $63-94 \mu \mathrm{m}$. Increase of cooling rate up to $12-15{ }^{\circ} \mathrm{C} / \mathrm{s}$ promotes formation in $\mathrm{HAZ}$ metal of a structure with

* Investigations were carried out by V.A. Kostin, V.V. Zhukov and T.G. Solomijchuk.

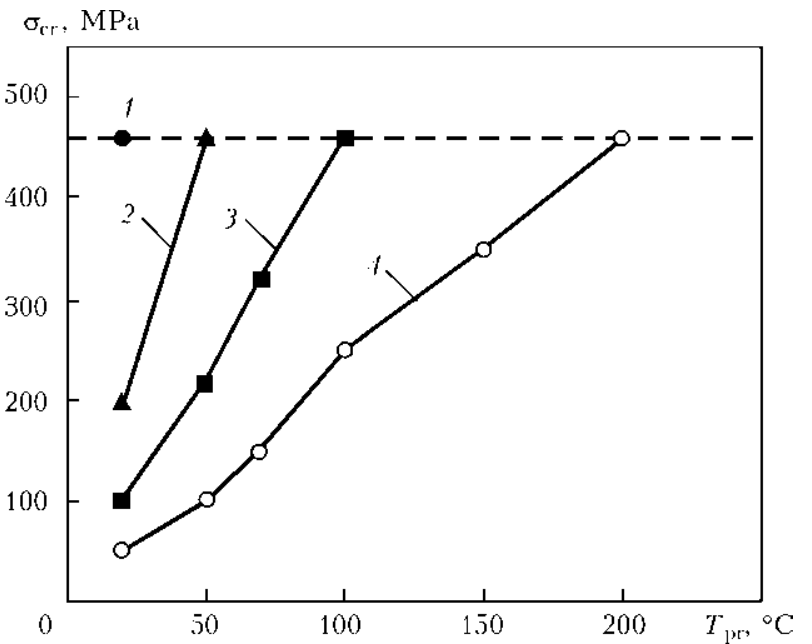

Figure 6. Effect of heat input of surfacing and preheating temperature on delayed fracture resistance of HAZ metal on steel $\mathrm{KS} 2(0.58 \% \mathrm{C}): 1-Q_{\mathrm{w}}=15.0 ; 2-11.5 ; 3-$ $8.6 ; 4-4.8 \mathrm{~kJ} / \mathrm{cm}$

volume fraction of martensite making more than $97 \%$. Lower bainite ( $2 \%)$ is also present in structure of the metal at given cooling rate. It is locally situated along the grain boundaries. Microhardness of martensite depending on cooling rate makes $H V 0.1=4250-7390 \mathrm{MPa}$, and integral
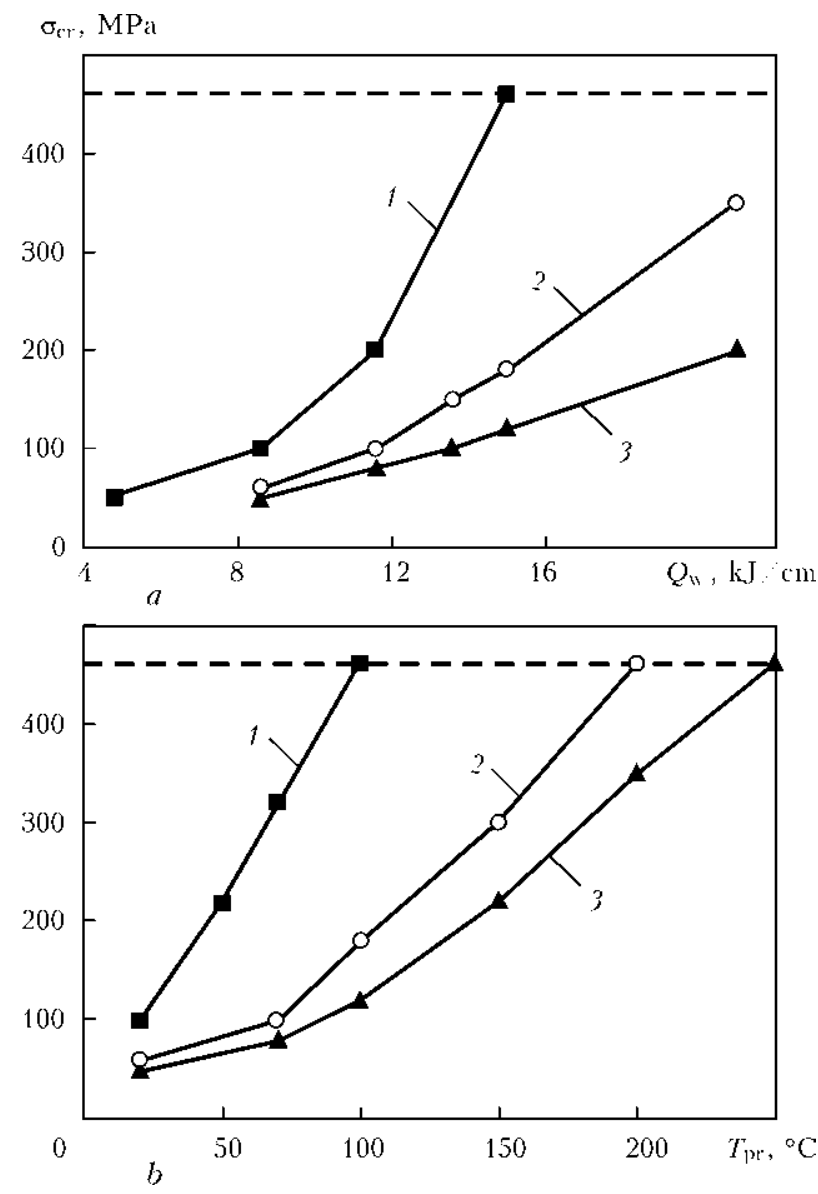

Figure 7. Effect of heat input of surfacing $(8.6 \mathrm{~kJ} / \mathrm{cm})(a)$ and temperature of preheating $\left(20{ }^{\circ} \mathrm{C}\right)(b)$ on resistance to delayed fracture of high-strength carbon steel: 1 - steel $\operatorname{KS} 2(0.58 \% \mathrm{C}) ; 2-65 \mathrm{G}(0.65 \% \mathrm{C}) ; 3-\operatorname{M} 76(0.74 \% \mathrm{C})$ 


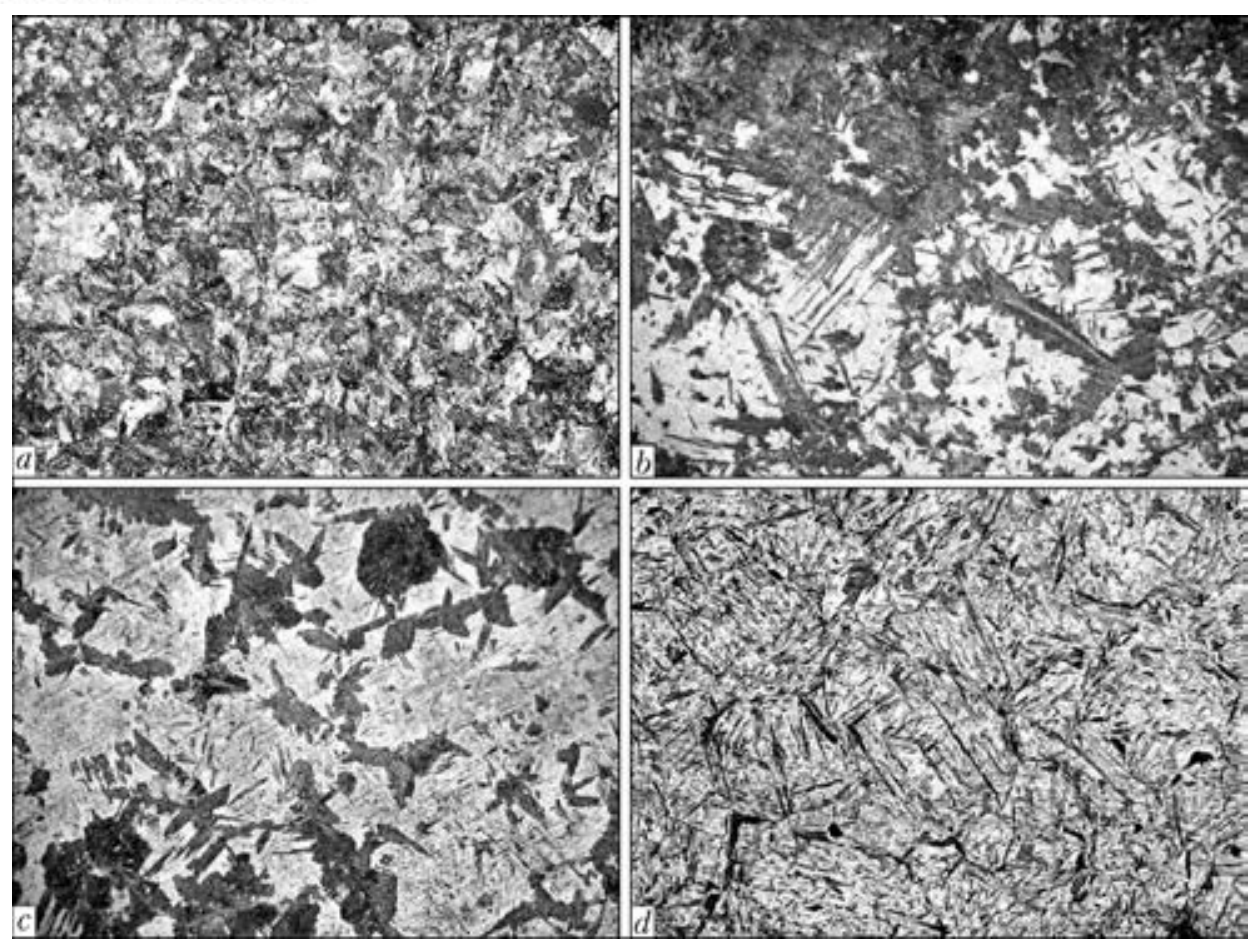

Figure 8. Microstructure of area of HAZ metal overheating on steel $65 \mathrm{G}(\times 500$, reduced 2 times $): a-$ as-delivered steel $(\times 200) ; b-w_{6 / 5}=5 ; c-8 ; d-20{ }^{\circ} \mathrm{C} / \mathrm{s}$

hardness of the metal is to $7200 \mathrm{MPa}$ (Figure 8, d). Microhardness of martensite makes 5600$6130 \mathrm{MPa}$ at $w_{6 / 5}=8{ }^{\circ} \mathrm{C} / \mathrm{s}$.

Structure of HAZ metal of $65 \mathrm{G}$ steel respectively influences the change of its resistance to delayed fracture. The critical stresses make more than $350 \mathrm{MPa}$ in formation in HAZ metal of relatively plastic bainite-martensite structure. The latter is formed at $w_{6 / 5} \leq 7{ }^{\circ} \mathrm{C} / \mathrm{s}$ that corresponds to application of heat input of surfacing on the level of $Q_{\mathrm{w}} \geq 21 \mathrm{~kJ} / \mathrm{cm}$ or $T_{\mathrm{pr}}>150{ }^{\circ} \mathrm{C}$ at $Q_{\mathrm{w}}=8.6 \mathrm{~kJ} / \mathrm{cm}$. At that, the increased resistance of HAZ metal to delayed fracture for steel $65 \mathrm{G}$ as well as for KS2 steel is provided at $\sigma_{\mathrm{cr}} \geq$ $\geq 0.45 \sigma_{0.2}$ during formation of the bainite-martensite structure, the volume fraction of martensite in which does not exceed $50 \%$. If structure with high content of martensite is formed in HAZ metal, its resistance to the delayed fracture reduces more than 3 times.

Study of ruptures of HAZ metal of $65 \mathrm{G}$ steel specimens, the generalized results of which are given in Figures 9 and 10 and Table 2, showed that the increase of heat input of surfacing from 13.6 to $21 \mathrm{~kJ} / \mathrm{cm}$, when cooling rate in $\mathrm{HAZ}$ metal reduces approximately from 15 to $7{ }^{\circ} \mathrm{C} / \mathrm{s}$, promotes significant changes in fracture nature. Similar to surfacing of KS2 steel, the microcracks in HAZ metal are nucleated and then slowly propagate along the boundaries as well as in grain body. The rupture in this zone is characterized as intergranular and transcrystalline cleavage (see Figure 10). Volume fraction of the intergranular cleavage, which makes $85 \%$ at $13.6 \mathrm{~kJ} / \mathrm{cm}$, reduces to $50 \%$ at $21 \mathrm{~kJ} / \mathrm{cm}$ with increase of the surfacing heat input. At that, size of facets on the surface of fracture increases from 25-50 to 50-100 $\mu \mathrm{m}$. Fraction of brittle intergranular cleavage is also reduced in the zone of accelerated propagation of microcrack (zone II), and local areas of tough constituent (up to $10 \%$ ) are observed along the grain boundaries.

If criterion of increased resistance to the delayed fracture of HAZ metal for studied KS2 and

Table 2. Structure of rupture during delayed fracture of HAZ metal on $65 \mathrm{G}$ steel

\begin{tabular}{|c|c|c|c|c|c|c|c|c|c|c|}
\hline \multirow{3}{*}{$Q_{\mathrm{w}}, \mathrm{kJ} / \mathrm{cm}$} & \multicolumn{4}{|c|}{ Zone I } & \multicolumn{6}{|c|}{ Zone II } \\
\hline & \multicolumn{2}{|c|}{ Brittle intergranular } & \multicolumn{2}{|c|}{ Brittle transcrystalline } & \multicolumn{2}{|c|}{ Brittle intergranular } & \multicolumn{2}{|c|}{ Brittle transcrystalline } & \multicolumn{2}{|c|}{ Tough } \\
\hline & $V, \%$ & $D_{\mathrm{f}}, \mu \mathrm{m}$ & $V, \%$ & $D_{\mathrm{f}}, \mu \mathrm{m}$ & $V, \%$ & $D_{\mathrm{f}}, \mu \mathrm{m}$ & $V, \%$ & $D_{\mathrm{f}}, \mu \mathrm{m}$ & $V, \%$ & $D_{\mathrm{f}}, \mu \mathrm{m}$ \\
\hline 13.6 & 85 & $25 / 50$ & 15 & $25 / 50$ & 60 & $30 / 50$ & 40 & $30 / 70$ & - & - \\
\hline 15.0 & 70 & $30 / 70$ & 30 & $30 / 70$ & 40 & $30 / 70$ & 60 & $40 / 70$ & - & - \\
\hline 21.0 & 50 & $50 / 100$ & 50 & $50 / 100$ & 20 & $30 / 100$ & 70 & $40 / 70$ & 10 & $0.5 / 2.0$ \\
\hline
\end{tabular}




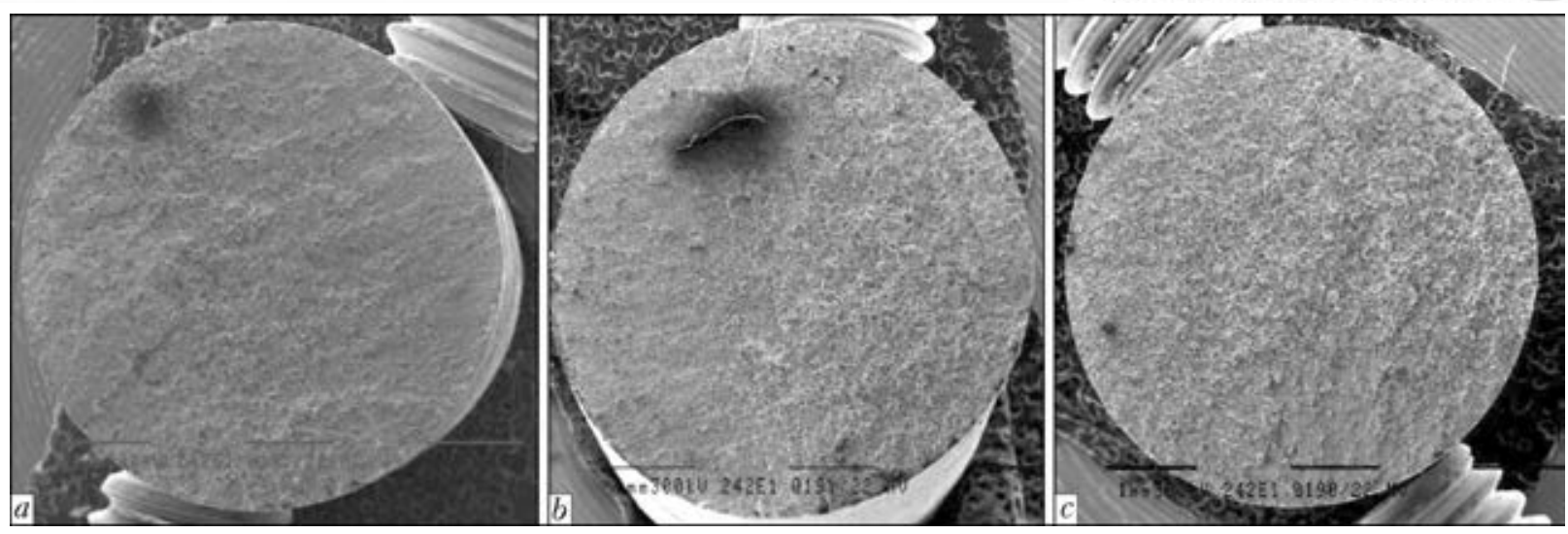

Figure 9. Ruptures $(\times 15)$ of Implant specimens on steel $65 \mathrm{G}$ in surfacing without preheating: $a-Q_{\mathrm{w}}=13.6 ; b-15.0$; $c-21.0 \mathrm{~kJ} / \mathrm{cm}$

$65 \mathrm{G}$ steels, carbon content in which does not exceed $0.65 \%$, was provided in formation of the bainite-martensite structure, the volume fraction of martensite in which does not exceed $50 \%$, then properties of M76 steel $(0.74 \% \mathrm{C})$ differ from previous ones. Temperature of beginning of austenite to martensite transformation $\left(T_{\mathrm{b} . \mathrm{M}}\right)$ in HAZ metal of steel M76 under effect of arc surfacing thermal cycle makes $240-250{ }^{\circ} \mathrm{C}$, depending on development of transformations in transitional region, and it is more than $40{ }^{\circ} \mathrm{C}$ lower of $T_{\text {b.M }}$ temperature for $\mathrm{KS} 2(0.58 \% \mathrm{C})$ and $65 \mathrm{G}$
$(0.65 \%$ C) steels. Microhardness of the structure martensite constituent, depending on cooling rate, is at the level of $H V 0.1=5030-7880 \mathrm{MPa}$. Obviously, that the local microstresses in martensite structure of M76 steel will be significantly higher than in steels with lower content of carbon. Therefore, nucleation and propagation of microcracks should take place at lower volume fraction of martensite in the structure and at lower values of external stresses. It is verified by the results of testing of Implant specimens (see Figure 7). As can be seen, the increaed delayed
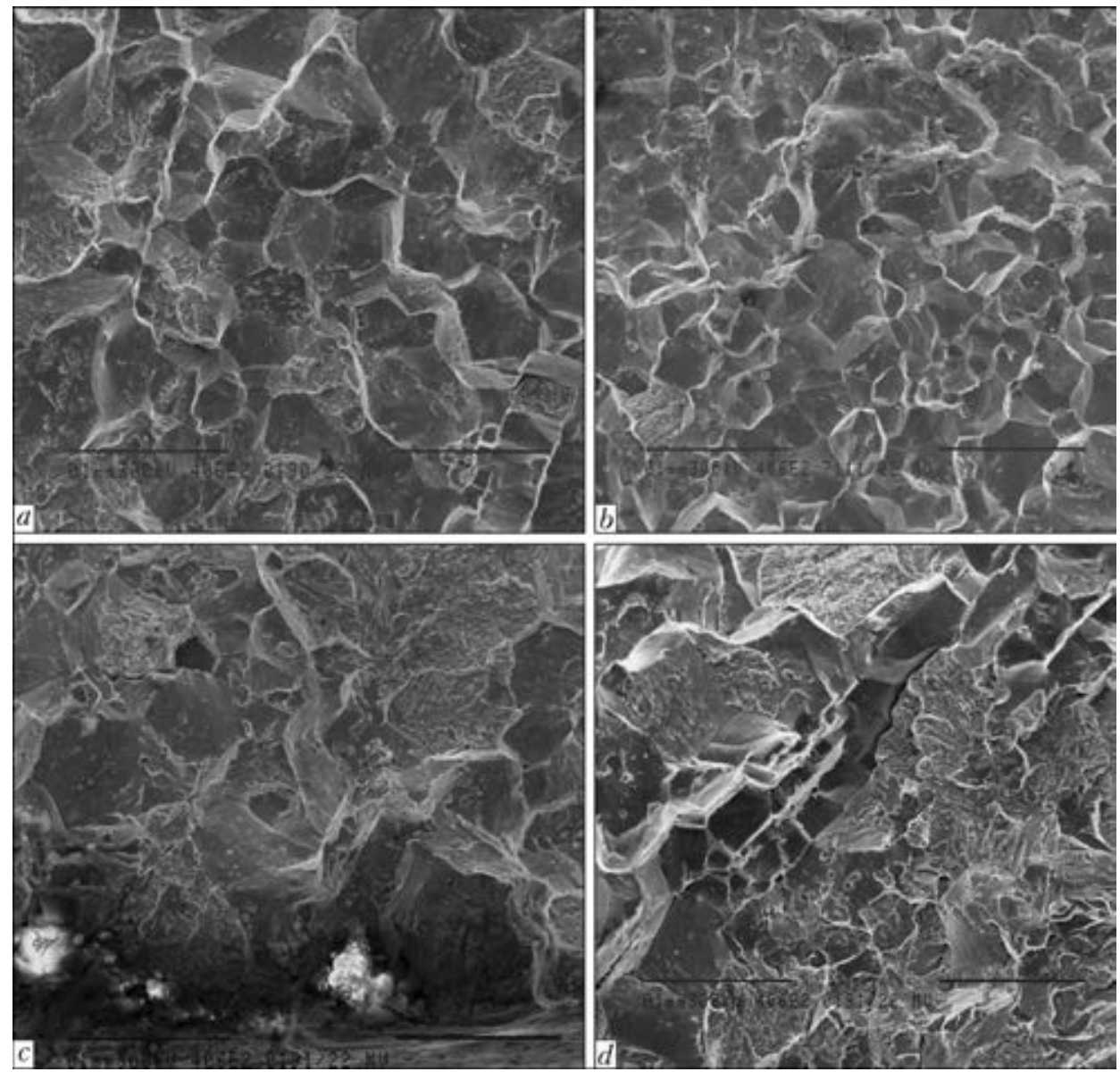

Figure 10. Fragments $(\times 406)$ of fracture surface in area of nucleation $(a, c)$ and propagation $(b, d)$ of microcrack in HAZ metal on steel $65 \mathrm{G}$ in surfacing with $Q_{\mathrm{w}}=13.6(a, b)$ and $21.0(c, d) \mathrm{kJ} / \mathrm{cm}$ 
fracture resistance of HAZ metal on steel M76 at $\sigma_{\mathrm{cr}} \geq 0.45 \sigma_{0.2}$ level can be provided using preheating temperature above $200{ }^{\circ} \mathrm{C}$, when the rate of cooling makes not more than $5-7{ }^{\circ} \mathrm{C} / \mathrm{s}$. It was determined that the bainite-martensite structure is formed at this cooling rate, volume fraction of martensite in it does not exceed $10 \%$ and its microhardness $H V 0.1=5030-6200 \mathrm{MPa}$. Lower bainite with $3360-3780 \mathrm{MPa}$ microhardness is the prevailing structure at $w_{6 / 5} \leq 12{ }^{\circ} \mathrm{C} / \mathrm{s}$. No delayed fracture of HAZ metal on M76 steel takes place at $T_{\mathrm{pr}}=250{ }^{\circ} \mathrm{C}$, when $\omega_{6 / 5}=3-4{ }^{\circ} \mathrm{C} / \mathrm{s}$ and content of martensite in the structure is not more than $2 \%$.

Generalizing the results of investigations given above, the effect of carbon content in KS2 steel on HAZ metal resistance to delayed fracture can be represented in form of diagram $w_{6 / 5}=$ $=f(\mathrm{C})$. Three typical areas of HAZ metal susceptibility to delayed fracture (Figure 11) are outlined:

1. Area of active development of the process of delayed fracture in HAZ metal. If the cooling rate $w_{6 / 5}$, indicated by upper curve in the diagram, is exceeded, then the hardening structures, susceptible to nucleation and propagation of the cold cracks at presence of sufficiently low external stresses $\left(\sigma_{\mathrm{cr}}<0.30 \sigma_{0.2}\right)$, will be formed in HAZ metal. The structures, in which the volume fraction of martensite is more than $50 \%$, are formed at carbon content in wheel steel in the limits of $0.55-0.65 \%$, and structure with $10 \%$ of martensite and more is developed at 0.65 $0.75 \% \mathrm{C}$. In this area the process of nucleation of microcracks and their development to macrolevel is realized during $0.1 \mathrm{~h}$, and its elimination is virtually impossible.

2. Area of increased delayed fracture resistance of HAZ metal. Nucleation and propagation of microcracks are complicated due to formation of

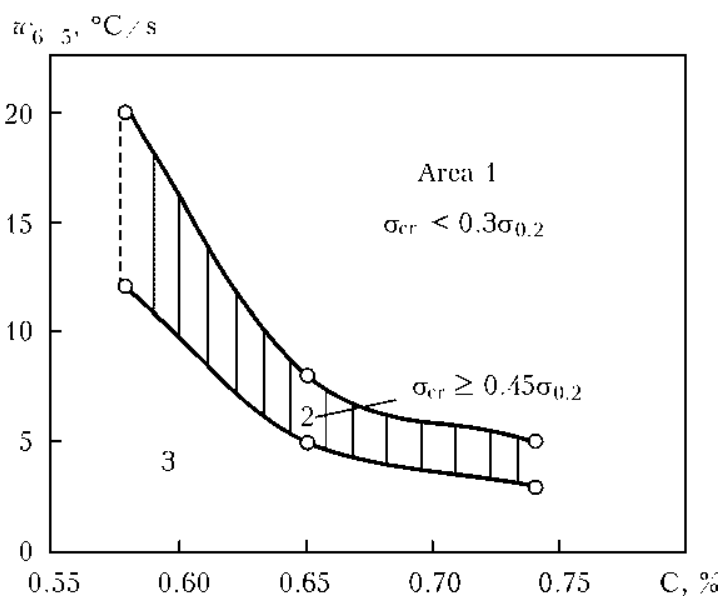

Figure 11. Effect of content of carbon in KS2 steel on delayed fracture resistance of HAZ metal relatively plastic structures. This is HAZ metal structure, in which the volume fraction of martensite makes more than 28-36\%, but does not exceed $50 \%$ at carbon content in KS2 steel up to $0.65 \%$. The structure includes from 4 to $10 \%$ of martensite at $0.65-0.75 \% \mathrm{C}$. The nucleation of microcracks is possible only under condition of presence of stresses at the level of $\sigma_{\mathrm{cr}} \geq 45 \sigma_{0.2}$ with continuous cooling of metal in low-temperature area $\left(T \leq T_{\mathrm{b} . \mathrm{M}}\right)$, when the processes of microplastic strain take place in completely formed as-quenched structure. This area of cooling rates is limited by two curves in the diagram. The process of delayed fracture in this case is realized during longer period of time (more than $0.7 \mathrm{~h}$ ). Delayed fracture of the deposit HAZ metal can be prevented by slowing its cooling in the area of martensite transformation temperatures $(T \leq$ $\left.\leq T_{\mathrm{b} . \mathrm{M}}\right)$. Practically, it can be performed using controlled thermal cycle of surfacing.

3. Area, in which the process of delayed fracture of KS2 steel in electric arc surfacing is not realized. When providing the cooling rate, which does not exceed the lower boundary of indicated area of increased resistance, the structures, having sufficiently high susceptibility to microplastic strain without microcrack nucleation, are formed in the HAZ. The cooling rate is $w_{6 / 5} \leq$ $\leq 10{ }^{\circ} \mathrm{C} / \mathrm{s}$ at content of carbon in $\mathrm{KS} 2$ steel at the level of $0.60 \%, w_{6 / 5} \leq 5{ }^{\circ} \mathrm{C} / \mathrm{s}$ at $\mathrm{C} \leq 0.65 \%$ and $w_{6 / 5} \leq 3{ }^{\circ} \mathrm{C} / \mathrm{s}$ at $\mathrm{C} \leq 0.75 \%$.

It should also be noted that the diagram given in Figure 11 meets the conditions of electric arc surfacing, when content of diffusible hydrogen in the deposited metal does not exceed 0.75$0.90 \mathrm{ml} / 100 \mathrm{~g}$. When its content increases, that depends on methods and parameters of surfacing, system of alloying of surfacing consumables and methods of their preparation etc., the special technological measures on reduction of its negative effect [17] should be applied.

Practical recommendations on selection of temperature of preheating and heat input of surfacing are realized in technologies for retailoring of worn flanges of solid-rolled wheels of freight cars. Today, the repair enterprises of railway transport of Ukraine during repair of wheels, made from KS2 steel, use a technology of restoration applying submerged dual-arc surfacing developed at the E.O. Paton Electric Welding Institute of the NASU in cooperation with Design Bureau «Ukrzaliznytsya» Company. Surfacing is carried out using Sv-08KhM wire at heat input $11-13 \mathrm{~kJ} / \mathrm{cm}$. Mandatory elements of the technology are application of preheating of wheel treads to $150{ }^{\circ} \mathrm{C}$ and delayed cooling of the wheels 
after surfacing in thermal chambers, where they are soaked during $5 \mathrm{~h}$ (cooling rate makes around $50{ }^{\circ} \mathrm{C} / \mathrm{h}$ ). High quality of deposited metal and safety of wheels in operation is achieved with fulfilment of set of requirements, made to the surfacing technologies, in particular, to process equipment, consumables, procedure and modes of surfacing and maintaining of thermal cycle during restoration.

\section{Conclusions}

1. High-strength steel, content of carbon in which makes $0.55-0.75 \%$, have increased susceptibility to the delayed fracture of HAZ metal in electric arc surfacing due to formation of hardening structures with increased dislocation density and high level of local internal stresses. Structural condition of the metal, which depends on carbon content and conditions of cooling in surfacing, makes significant effect on the processes of nucleation and propagation of microcracks in the metal of HAZ overheating area. The increase of carbon content in steel and cooling rate in $600-500{ }^{\circ} \mathrm{C}$ temperature interval provokes rise of susceptibility to the delayed fracture of HAZ metal, and level of critical stresses reduces to $0.07 \sigma_{0.2}$.

2. Formation of more plastic structures with volume fraction of martensite not exceeding $50 \%$ promotes increase of the delayed fracture resistance of HAZ metal on grade 2 steel at carbon content $0.55-0.65 \%$ up to $\sigma_{\mathrm{cr}} \geq 0.45 \sigma_{0.2}$ level of stresses. The volume fraction of martensite in HAZ metal structure should make not more than 4-10\% at $0.75 \%$ C. Nucleation and propagation of microcracks in surfacing under such conditions of structure formation can be prevented by slowing down the cooling of HAZ metal in area of temperatures of martensite transformation $\left(T \leq T_{\mathrm{b} . \mathrm{M}}\right)$.

3. Diagram in form of $w_{6 / 5}=f(\mathrm{C})$ was plotted for showing the influence of carbon content in KS2 steel on HAZ metal resistance to the delayed fracture. It was determined that the structures, having sufficiently high capability to microplastic strain without generation of microcracks, are formed in the metal of HAZ overheating area for KS2 steel, content of carbon in which is $0.55-$ $0.60 \%$ at cooling rate $w_{6 / 5} \leq 16{ }^{\circ} \mathrm{C} / \mathrm{s}\left(w_{6 / 5} \leq\right.$ $\leq 8{ }^{\circ} \mathrm{C} / \mathrm{s}$ at $0.60-0.65 \% \mathrm{C}$ and $w_{6 / 5} \leq 5{ }^{\circ} \mathrm{C} / \mathrm{s}$ at $0.65-0.75 \% \mathrm{C}$.

1. Alekseeva, L.E., Sarrak, V.I., Suvorova, S.O. et al. (1975) About two ways of residual microstress relaxation in martensite of steel. Metallofizika, Issue 61, 79-84.

2. Sarrak, V.I., Filippov, G.A. (1976) Delayed fracture of steel after tempering. Fiz.-Khimich. Mekhanika Materialov, 2, 44-54.

3. Panasyuk, V.V. (1991) Mechanics of quasibrittle fracture of materials. Kiev: Naukova Dumka.

4. Shorshorov, M.Kh. (1965) Physical metallurgy of welding of steel and titanium alloys. Moscow: Nauka.

5. Makara, A.M., Mosendz, N.A. (1971) Welding of high-strength steels. Kiev: Tekhnika.

6. Makarov, E.L. (1981) Cold cracks in welding of alloyed steels. Moscow: Mashinostroenie.

7. Filippov, G.A., Sarrak, V.I. (1980) Local hydrogen distribution and internal stresses in structure of quenched steel. Fizika Metallov i Materialovedenie, 49(1), 121-125.

8. Sterenbogen, Yu.A. (1986) Some factors determining the HAZ metal resistance of martensite steels to cold cracking. Avtomatich. Svarka, 6, 5-8.

9. Kasatkin, O.G. (1994) Peculiarities of hydrogen embrittlement of high-strength steels in welding. Ibid., 1, 3-7.

10. Pokhodnya, I.K., Shvachko, I.V. (1997) Physical nature of hydrogen induced cold cracks in structural steel welded joints. Ibid., 5, 3-12.

11. Shvachko, V.I., Ignatenko, A.V. (2007) Model of transportation of hydrogen with dislocations. The $\mathrm{Pa}^{-}$ ton Welding J., 2, 24-26.

12. Skulsky, V.Yu. (2009) Peculiarities of kinetics of delayed fracture of welded joints of hardening steels. Ibid., 7, 12-17.

13. Ignatenko, A.V., Pokhodnya, I.K., Paltsevich, A.P. (2012) Dislocation model of hydrogen-enhanced localizing of plasticity in metals with bcc lattice. Ibid., 3, 15-19.

14. Gajvoronsky, A.A., Poznyakov, V.D., Sarzhevsky, V.A. et al. (2010) Influence of thermodeformational cycle of hardfacing on the structure and properties of railway wheels at their reconditioning. Ibid., 5, $15-18$.

15. Gajvoronsky, A.A., Zhukov, V.V., Vasiliev, V.G. et al. (2014) Structural changes in overheating zone of HAZ metal of railway wheels in arc surfacing. Ibid., 1, 13-19.

16. Gajvoronsky, A.A., Poznyakov, V.D., Markashova, L.I. et al. (2012) Influence of deposited metal composition on structure and mechanical properties of reconditioned railway wheels. Ibid., 8, 16-22.

17. Gajvoronsky, A.A. (2013) Influence of diffusible hydrogen on delayed cracking resistance of high-carbon steel welded joints. Ibid., 5, 14-20.

18. Poznyakov, V.D., Kiriakov, V.M., Gajvoronsky, A.A. et al. (2010) Properties of welded joints of rail steel in electric arc welding. Ibid., 8, 16-20.

Received 11.10.2013 


\title{
FATIGUE LIFE OF DEPOSITED REPAIR WELDS ON SINGLE-CRYSTAL HIGH-TEMPERATURE NICKEL ALLOY UNDER CYCLIC OXIDATION
}

\author{
A.F. BELYAVIN, V.V. KURENKOVA and D.A. FEDOTOV \\ $\mathrm{RC} \ll$ Pratt\&Whitney-Paton» \\ 68 Gorky Str., Kiev, Ukraine. E-mail: vkurenkova@pwpaton.com
}

\begin{abstract}
In modern gas-turbine units increase of gas working temperature leads to shortening of blade service life. For this reason their repair becomes a priority. Retailoring of single-crystal blade tip by hardfacing is a rather complicated task. In order to select suitable filler material, thermal cycling tests of samples of deposited welds on CMSX-4 alloy with a single-crystal structure have been performed. Evolution of the structure under the conditions of high-temperature cyclic oxidation is considered. Selection of filler material, which ensures high temperature resistance and stability of weld metal structure, was optimized. These requirements are satisfied by $\mathrm{Co}-\mathrm{Ni}$-based material, which was earlier tried out and proved to be very good in complex technology of repair of a blade from ZMI-3U alloy. The technology includes airfoil tip retailoring by hardfacing with subsequent deposition on the item surface of a high-temperature metal coating by electron beam deposition to ensure the required service properties of the item. 18 Ref., 4 Tables, 10 Figures.
\end{abstract}

Key words: single-crystal alloy, hardfacing, dendritic growth, stray grains, raft structure, heat-affected zone, cyclic oxidation, oxidation resistance, coating, spinel, yttrium oxide

In connection with a significant increase of gas working temperature (by approximately $150{ }^{\circ} \mathrm{C}$ ) and rising level of thermal stress in blades of commercial gas-turbine unit (GTU) a need arose of development of new approaches to repair and deposition of coatings, which would ensure turbine blade protection from high-temperature gas corrosion and would increase resistance to thermal fatigue cracking, thus extending blade working life.

Gas temperature at the outlet of combustion chamber of a modern commercial GTU is equal to approximately $1420{ }^{\circ} \mathrm{C}$, accordingly, turbine inlet temperature is $1180-1200{ }^{\circ} \mathrm{C}$ for $45-47 \mathrm{MW}$ GTU.

Blade tip belongs to low-duty areas, where temperature is higher than $1000{ }^{\circ} \mathrm{C}$ and can reach $1050-1150{ }^{\circ} \mathrm{C}$ [1]. Service of gas turbines operating at a high temperature is characterized by non-uniform heating of blade airfoil surface in gas flow. In connection with non-symmetrical operation of combustion chambers gas flow temperature is non-uniform, leading to blades exposure to different temperatures at their rotation in the turbine and coming under the flame plume. Non-uniform heating leads to increase of internal thermal stresses: compressive stresses at temperature rise and tensile stresses at its lowering, causing thermal fatigue crack initiation in the depos-

(C) A.F. BELYAVIN, V.V. KURENKOVA and D.A. FEDOTOV, 2014 ited weld metal. Thus, thermal fatigue cracks parallel to blade axis can form at blade tip, in addition to corrosion and erosion damage (as a result of contact with labyrinth seal).

The main purpose of these studies consisted in selection of filler material having sufficient oxidation and corrosion resistance at working temperatures for repair (retailoring) of airfoil tip of a single-crystal blade (made from CMSX-4 alloy), that enables formation of defect free deposited welds. Deposited material should also match the material of the base and high-temperature electron beam coating deposited at the end of complex blade repair.

Materials and methods of investigation. The base for the blades was carbon-free second generation single-crystal alloy CMSX-4 (analog of JS32 alloy) of the following composition, wt. $\%$ : $\mathrm{Ni}-9 \mathrm{Co}-6.5 \mathrm{Cr}-$ $6 \mathrm{~W}-0.6 \mathrm{Mo}-6.5 \mathrm{Ta}-5.6 \mathrm{Al}-1 \mathrm{Ti}-3 \mathrm{Re}-0.1 \mathrm{Hf}$, which is characterized by high strength, structural stability and high creep resistance [2].

Samples (4 pcs), cut out of the blade root of GTE first stage were used in experiments. The surface for hardfacing of each sample was treated by endless abrasive belt KK711 R40 in PWS $3 / 200 \mathrm{DH}$ grinder.

Pulsed argon-arc surfacing was performed using HOBART 120 power source and three types of filler wire of 0.8 to $1.2 \mathrm{~mm}$ diameter. The process was conducted by moving the electrode in the direction normal to the prevailing direction of single-crystal growth $<001>$. At hardfacing the samples were clamped in the vise to ensure the hardfacing plane (110). Usually five beads 
Table 1. Composition of base and filler materials, wt.\%

\begin{tabular}{|c|c|c|c|c|c|c|c|c|c|c|c|c|c|c|c|}
\hline $\begin{array}{c}\text { Base alloy } \\
\text { and filler } \\
\text { wire variants }\end{array}$ & $\mathrm{Ni}$ & Co & $\mathrm{Cr}$ & $\mathrm{Al}$ & $\mathrm{Ti}$ & W & Mo & $\mathrm{Ta}$ & $\operatorname{Re}$ & $\mathrm{Nb}$ & Hf & $\mathrm{Si}$ & $\mathrm{Fe}$ & $\mathrm{C}$ & $\begin{array}{c}\Sigma \mathrm{Al} \\
\mathrm{Ti}\end{array}$ \\
\hline CMSX-4 & Base & 9.0 & 6.5 & 5.6 & 1.0 & 6.0 & 0.6 & 6.5 & 3.0 & - & 0.1 & - & - & - & 6.6 \\
\hline PWA 795 & 15.0 & Base & 20.0 & 4.4 & 0.2 & 9.0 & - & 3.0 & - & - & 1.1 & $\begin{array}{c}0.045^{-} \\
0.1 Y^{-}\end{array}$ & - & 0.35 & 4.6 \\
\hline FSX 414 & 10.0 & Same & 29.0 & - & - & 7.5 & - & - & - & $0.5 \mathrm{Mn}$ & - & - & $<1.0$ & 0.25 & - \\
\hline IN 625 & Base & 1.0 & 21.5 & 0.4 & 0.4 & - & 9.0 & - & - & 3.65 & - & 0.5 & $0.5 \mathrm{Mn}$ & 0.1 & $<0.8$ \\
\hline
\end{tabular}

were deposited on samples. After deposition of each bead, the surface was scraped by a metal brush. After hardfacing the samples were annealed in vacuum at $950{ }^{\circ} \mathrm{C}(2 \mathrm{~h})$ to relieve welding stresses.

Evaluation of deposited weld quality was performed visually with application of liquid-penetrant inspection, and on microsections using scanning electron microscope CamScan-4, fitted with energy-dispersive analyzer ENERGY 200 (with INCA software). Deposited weld microhardness was measured in Micro-Duromat 4000E instrument at 10-20 g load.

To perform comparative assessment of oxidation resistance of the studied filler materials CMSX-4 alloy samples with deposited beads were tested for cyclic oxidation in CM FURNACES Bloomfield-1710BL (c) unit in the following mode: heating up to $1150{ }^{\circ} \mathrm{C}$ for $5 \mathrm{~min}+$ soaking at maximum temperature for $50 \mathrm{~min}+$ cooling to $50{ }^{\circ} \mathrm{C}$ for $5 \mathrm{~min}$ [3]. This mode is used for assessment of thermal-fatigue life of coated samples. Testing conditions were quite hard and only slightly different from temperature conditions of operation of blades in real engines. Upper test temperature was close to the real temperature $\left(1050-1150{ }^{\circ} \mathrm{C}\right)$ on blade airfoil surface in modern GTU.

Oxidation resistance was assessed by the weight method by relative change (reduction) of sample weight by plotting kinetic oxidation curves, as well as by the depth of frontal and local oxidation during the time of testing (400 thermal cycles) of deposited welds obtained using various filler materials. It is recommended to apply the method of direct measurements of corrosion depth at non-uniform oxidation process. Sample of CMSX-4 base alloy was also subjected to thermal cycling tests as a reference.

Oxidation resistance of deposited welds was first of all determined visually - by examination of samples after each 50 thermal cycles to detect intensive oxidation areas, and relative change of deposited weld mass was determined by comparison to initial condition (in view of complex con- figuration of samples) - by the gravimetric method.

In order to ensure oxidation and corrosion resistance of deposited material, preference was given to high-chromium (with about 20 wt.\% Cr) filler materials based on nickel or cobalt. Four variants of alloys for hardfacing were considered: IN 625/FSX 414; PWA 795; IN 625; FSX 414 (Table 1).

Deposited weld structure was studied on microsections in as-deposited condition and after completion of thermal cycling tests.

Experimental. The criteria for assessment of weld quality were absence of cracks or other defects, initiating at weld formation under the conditions of following the orientation of the substrate and direction of welding source motion (normal to prevailing direction of single-crystal growth).

As was noted in [4], surfacing of single crystal blades has several significant special features. Basic criteria for deposited weld quality and structural perfection of growth single-crystal structure are orientation uniformity of the weld and line of fusion with the base metal; absence of stray grains (SG) in the weld [5]; and absence of solidification cracks or other defects.

It is established that by controlling the weld pool shape at argon TIG process, it is possible to ensure a flat solidification front, on which conditions are created for directional solidification, allowing preservation of prevailing growth direction of the single crystal up to $1 / 2-2 / 3$ of full weld height minimum. Minimum speed of pulsed argon-arc surfacing and power input of the process prevent formation of SG, and, consequently, of intergranular cracks on the solidification front.

As is seen from cross-sectional structures of welds, deposited with application of various materials, before and after thermal cycling tests (Figure 1), the formed deposited welds had quite dense defect-free structures, which differed as a result of application of alloys of various alloying 


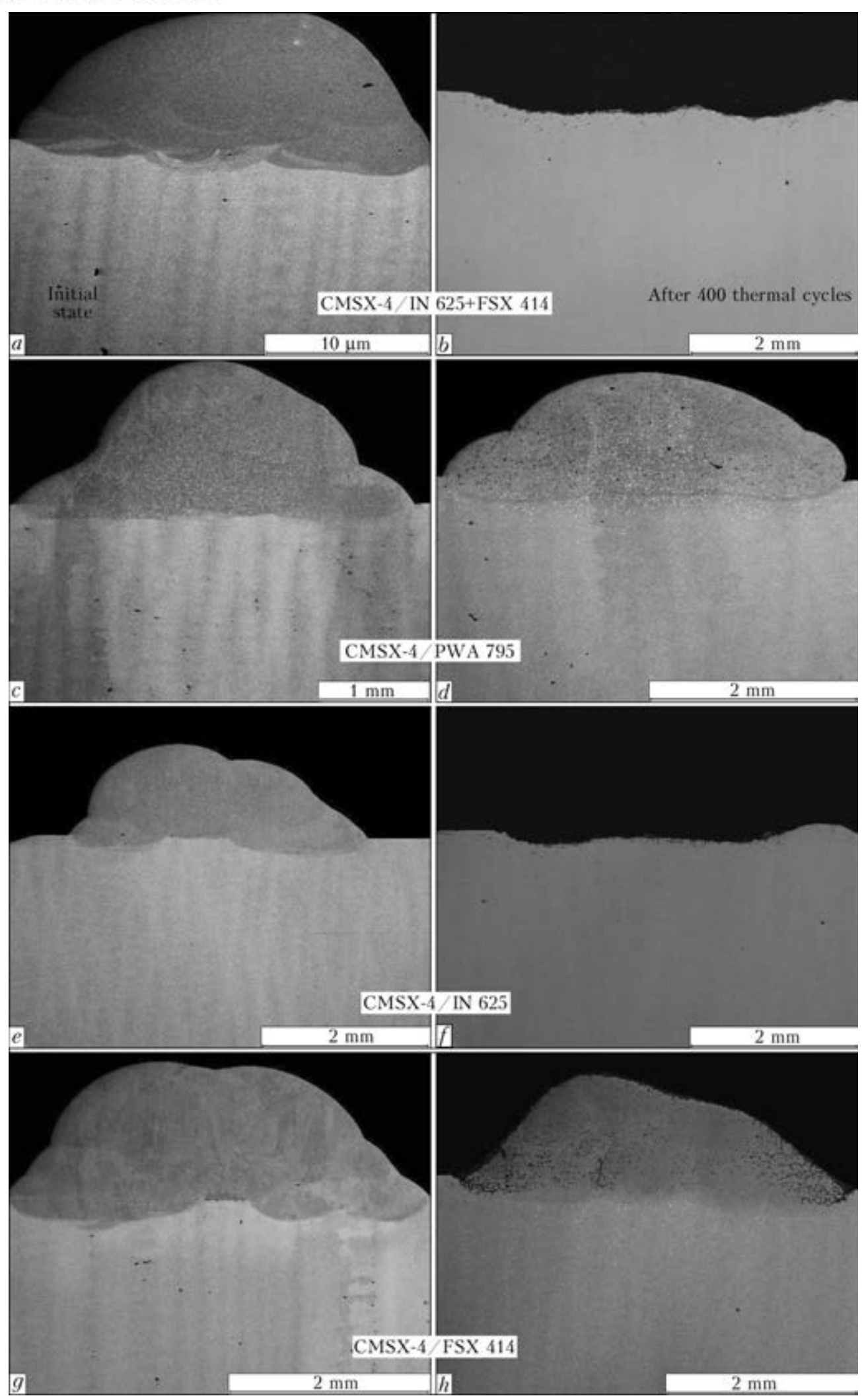

Figure 1. Structure of deposited welds on CMSX-4 samples with application of different fillers before $(a, c, e, f)$ and after $(b, d, f, h)$ thermal cycling tests

systems, namely oxidation-resistant nickel alloy IN 625 and cobalt corrosion-resistant alloys PWA 795 and FSX 414. In weld fusion zone, equal to 30-100 $\mu \mathrm{m}$, structural perfection of growth single-crystal structure and epitaxial growth of the single crystal in the deposited weld were visible (Figure 2).

At investigation of various weld sections, including root sections (with overheating at the start of the process), a significant influence of 


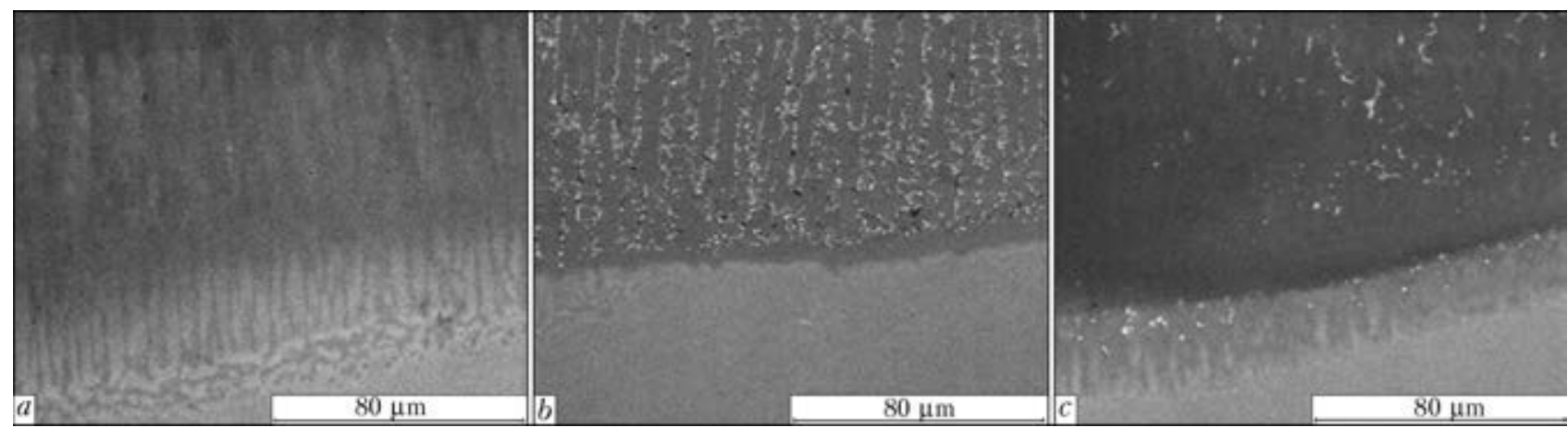

Figure 2. Microstructure of fusion line of welds made on CMSX-4 alloy samples using fillers IN 625 ( $a$ ), PWA 795 (b) and FSX 414 (c)

filler material on deposit integrity and quality was found, namely: stray grains appeared, as a rule, at formation of a curvilinear solidification front. At application of nickel alloys as filler materials, solidification cracks formed along the boundaries of such grains during solidification or postweld heat treatment both on fusion line and in the weld proper (Figure 3, $a, c$ ). This was not observed in case of application of cobalt filler materials (Figure $3, b, d$ ). Even in the presence of defects in the base (subgrains with high-angle boundaries, pores, etc., see Figure $3, b, d$ ) formation of coarse SG on the fusion line did not lead to initiation and propagation of intercrystalline cracks. This is attributable to the fact that in cobalt alloys there is no phenomenon of solidphase dispersion strengthening (characteristic for high nickel alloys), i.e. precipitation of particles of strengthening $\gamma^{\prime}$-phase from the solid solution induces dispersion hardening cracks in deposited welds.

For clear understanding of the process of deposited layer oxidation and degradation on the single crystal we, first of all, considered the evolution of base microstructure as a result of longterm high-temperature impact. Structure of initial single-crystal alloy CMSX-4 is $\gamma$-solid solution, strengthened by $\gamma^{\prime}$-phase particles of $0.2-$ $0.5 \mu \mathrm{m}$ size, the volume fraction of which is equal to approximately $71.5 \%[6]$ (Figure $4, a, c, e$ ). After long-term high-temperature cyclic testing, as a result of diffusion processes in single-crystal alloy, particles of strengthening $\gamma^{\prime}-\mathrm{Ni}_{3} \mathrm{Al}$ phase coagulate with a change in morphology, and in-

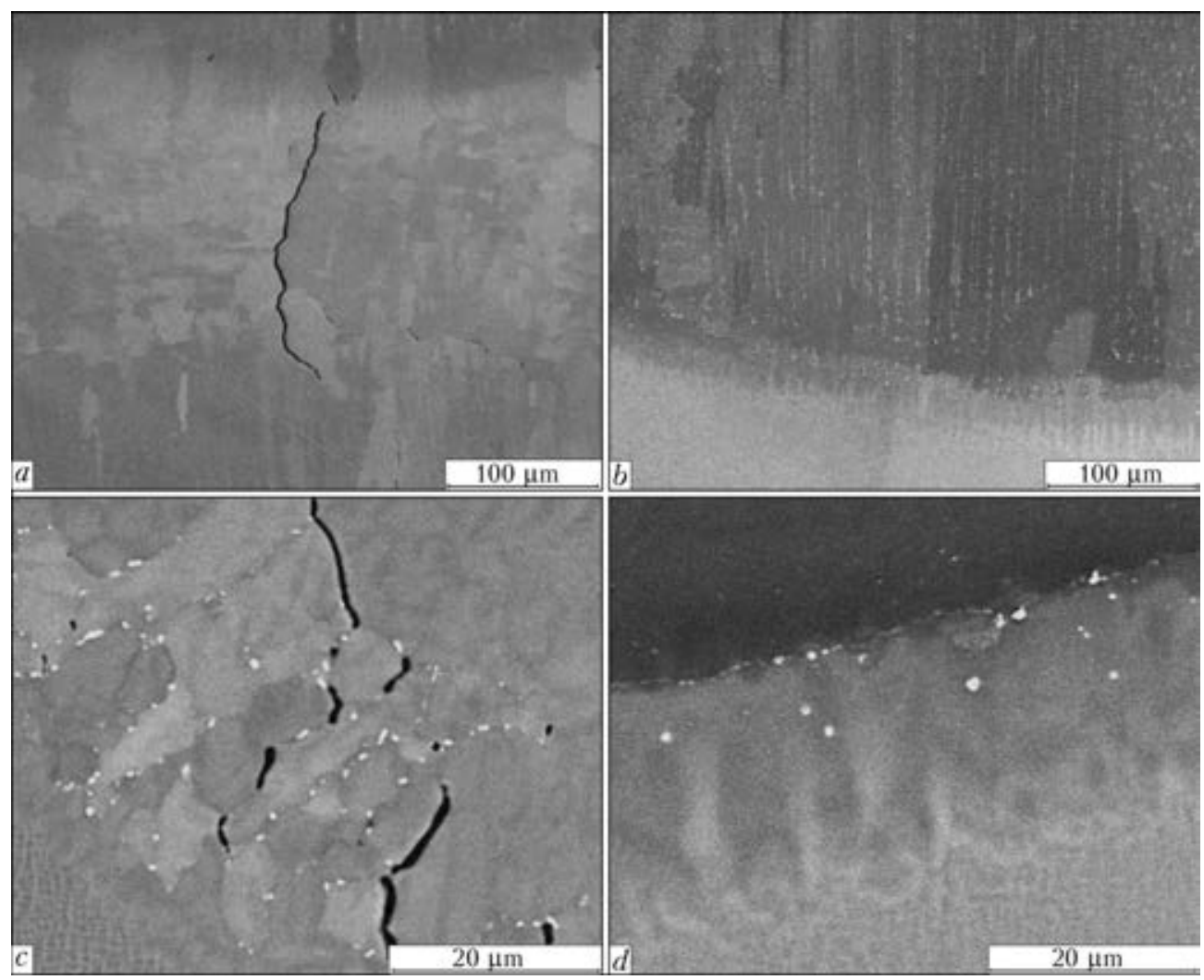

Figure 3. Defects in the structure of welds deposited with application of filler materials on nickel $(a, c)$ and cobalt $(b$, d) base 

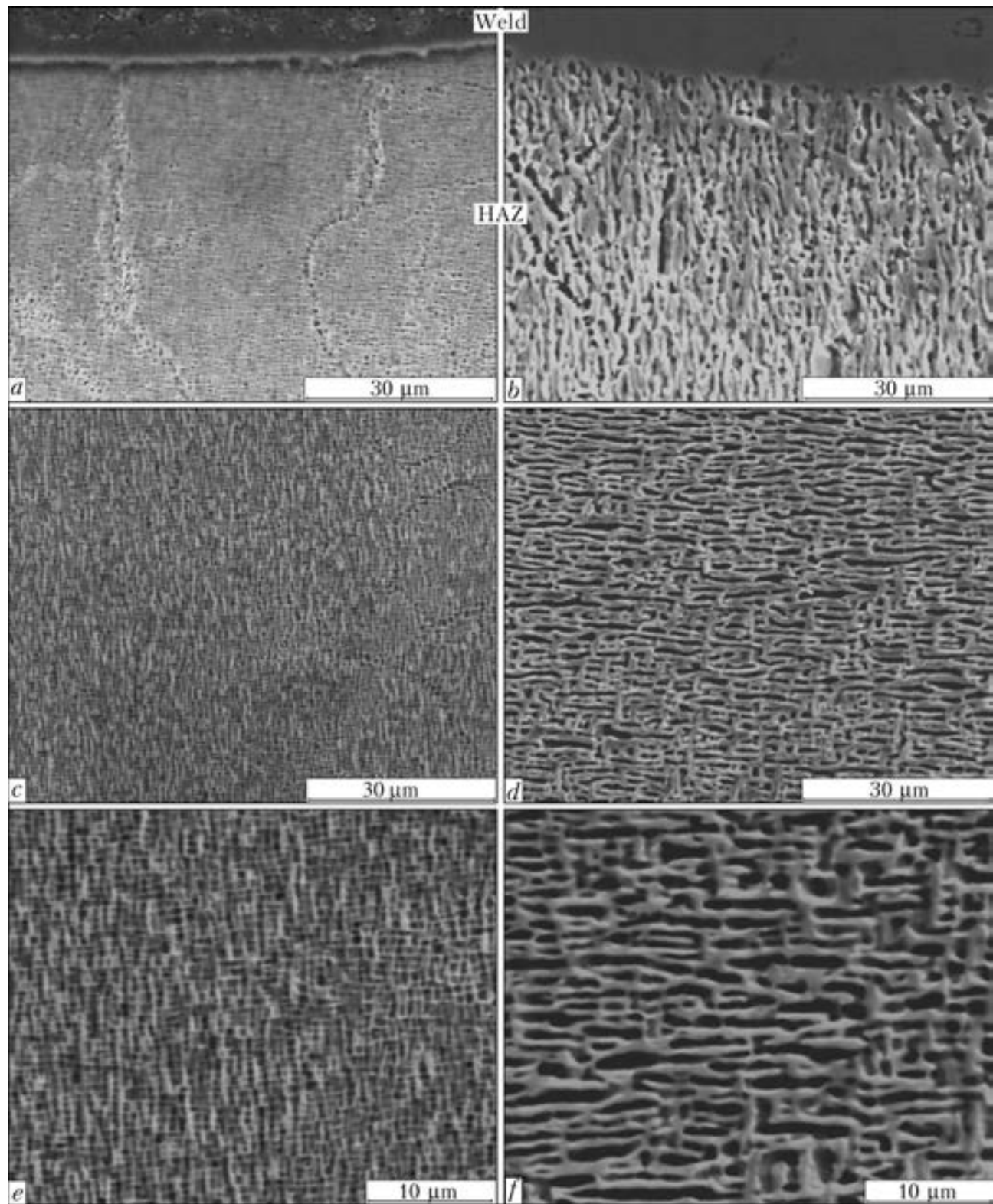

Figure 4. Evolution of $\left(\gamma-\gamma^{\prime}\right)$-microstructure of CMSX-4 alloy before $(a, c, e)$ and after $(b, d, f)$ thermal cycling tests

tergrow, forming so-called raft structure of parallel plates up to $10 \mu \mathrm{m}$ long (Figure $4, b, d, f$ ). The negative misfit (discrepancy between crystalline lattice periods of the main structural $\gamma$ and $\gamma^{\prime}$-phases) is one of the causes for internal stress initiation [7]. Under the impact of these stresses and temperature gradient (changes of thermal stress sign at heating-cooling) in the case of thermal cyclic testing cuboidal particles of $\gamma^{\prime}$-phase coalesce in a specific way by intergrowing into plates or rods, which are oriented along $<101>$ direction with equal probability (Figure 4, $d, f$ ) $[6,8]$.

Raft structure under the conditions of external load application thermodynamically is a more equilibrium system, as the level of interphase surface energy in it is lower than in the structure with cubic dispersed precipitates of $\gamma^{\prime}$-phase. In single crystals in the absence of carbide phases and with minimum amount of eutectic $\gamma^{\prime}$-phase, raft structure is more perfect and less prone to local changes. In addition, it ensures a lower rate of material softening, namely improves creep resistance, and preventing dislocation motion through the layer $[8,9]$.

As shown in [10], material deformation at thermal impact under thermal cycling conditions develops by the mechanism of active tensioncompression. At long repetition of compressiontension cycle this causes formation of a substructure, fabourable for crack initiation, particularly at the stage of cooling and increase of tensile stresses. An important feature of single crystal deformation is preservation of initial crystallographic orientation of blade axis at multiple cyclic heating and cooling. 
During pulsed hardfacing of single-crystal alloy a HAZ is formed. In this region (30 to $50 \mu \mathrm{m}$ depth) temperature impact results in partial dissolution of strengthening $\gamma^{\prime}$-phase (see Figure 4, $a$ ). During thermal impact at cyclic oxidation not only repeated precipitation of $\mathrm{Ni}_{3} \mathrm{Al}$ intermetallic phase, but also its evolution towards enlargement and coarsening occur in the considered volume. However, after 400 thermal cycles no intergrowing of strengthening phase plates or formation of raft structure were observed in the HAZ $\left(\gamma+\gamma^{\prime}\right)$ microstructure, that was clearly seen in all other regions of base material ( $\mathrm{Fi}^{-}$ gure $4, b, d, f)$.

Dependence of sample weight change under the conditions of thermal cycling tests $(50 \leftrightarrow$ $\leftrightarrow 1150{ }^{\circ} \mathrm{C}$ ) is given in Figure 5. CMSX-4 base alloy is a high-temperature thermally stable material. Its oxidation intensity at thermal cycling is low (compared to some of the considered filler materials), that points to a relatively small angle of inclination of exponential oxidation curve.

After 400 thermal cycles the depth and nature of oxidation product distribution both in base material (CMSX-4 alloy) and in weld material was determined (Figure 6). After oxidation at $t_{\max }=1150{ }^{\circ} \mathrm{C}$ of $\mathrm{CMSX}-4$ alloy its scale consists of two layers: outer layer of $4 \mu \mathrm{m}$ thickness of complex spinel based on nickel $\mathrm{Ni}, \mathrm{Co}(\mathrm{Cr}, \mathrm{Al})_{2} \mathrm{O}_{4}$, and inner layer of $5 \mu \mathrm{m}$ thickness based on $\mathrm{Al}_{2} \mathrm{O}_{3}$ oxide. Aluminium oxide based film is predominantly continuous and determines the alloy oxidation resistance (Figure $7, a$ ). On the other hand, at rapid cooling of the alloy under cyclic oxidation conditions $\mathrm{Al}_{2} \mathrm{O}_{3}$ protective film cracks and delaminates. At each repeated cycle the film $\left(\mathrm{Al}_{2} \mathrm{O}_{3}\right.$ oxide $)$ forms again, but with smaller aluminium content in it. The latter is consumed from subsurface layers of base alloy, leading to depletion of its stock and lowering of base oxidation temperature resistance [11]. At protective film spallation formation of nickel oxide film and spinel-based suboxide film at the depth of the order of $120 \mu \mathrm{m}$ at frontal oxidation to the depth of $8^{-10 \mu \mathrm{m}}$ was observed on sample surface in some locations.

At longer testing time samples with deposited welds, made with application of IN 625 nickel filler, oxidized more intensively at high temperature than those made with cobalt filler. During the total time of thermal cycling tests (400 thermal cycles) deposited welds burnt out completely: material was oxidized, and oxidation products spalled off at cooling, that was observed both visually and on microsections (see Figure 1, $b, f$ and Figure $7, b)$. HAZ under the degraded

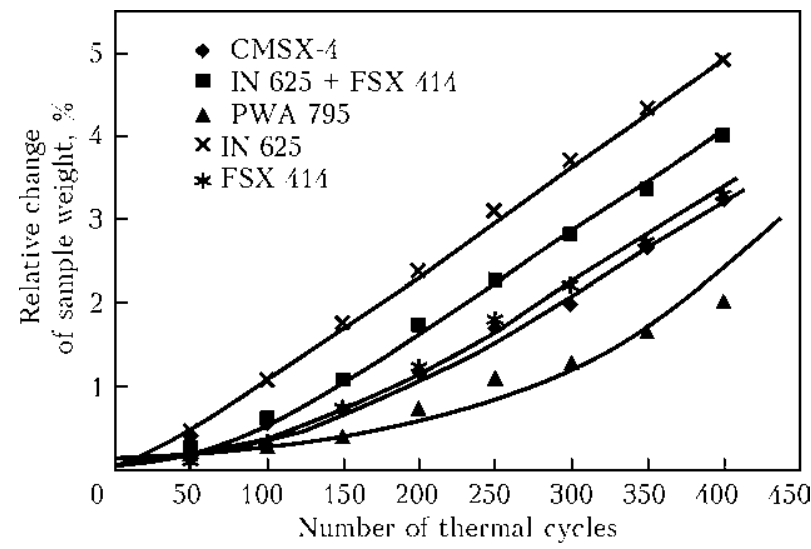

Figure 5. Kinetics of oxidation of various filler materials and CMSX-4 alloy

weld was also subjected to internal oxidation (Figure 7,b): areas of local and frontal damage of alloy surface and precipitation of a large number of discrete oxide and coarse nitride phases were observed, that is indicative of an essential degradation of base material under the weld.

Selection of IN 625 alloy as filler material for single crystal hardfacing was predetermined by its high fatigue resistance, rupture strength, satisfactory creep resistance, oxidation resistance, weldability and adaptability to fabrication. However, these properties of the alloy are preserved at limit service temperature of $900-950{ }^{\circ} \mathrm{C}$. Alloying of IN 625 alloy by titanium, molybdenum and niobium ensures its oxidation resistance. However, at more than 3 wt.\% Mo (IN 625 alloy contains 9 wt.\% Mo) its oxidation resistance drops, as at heating above $900{ }^{\circ} \mathrm{C}$ molybdenum oxide $\mathrm{MoO}_{2}$ is volatile.

Chromium included in IN 625 composition in the amount of $21.5 \mathrm{wt} \%$ provides reliable protection from oxidation and corrosion at temperature of 950 to $1000{ }^{\circ} \mathrm{C}$, forming $\mathrm{Cr}_{2} \mathrm{O}_{3}$ film. $\mathrm{Cr}_{2} \mathrm{O}_{3}$ protective properties decrease with temperature rise (above $1000{ }^{\circ} \mathrm{C}$ ) in air, as $\mathrm{Cr}_{2} \mathrm{O}_{3}$ transformation into volatile $\mathrm{CrO}_{3}$ oxide takes place. Ac-

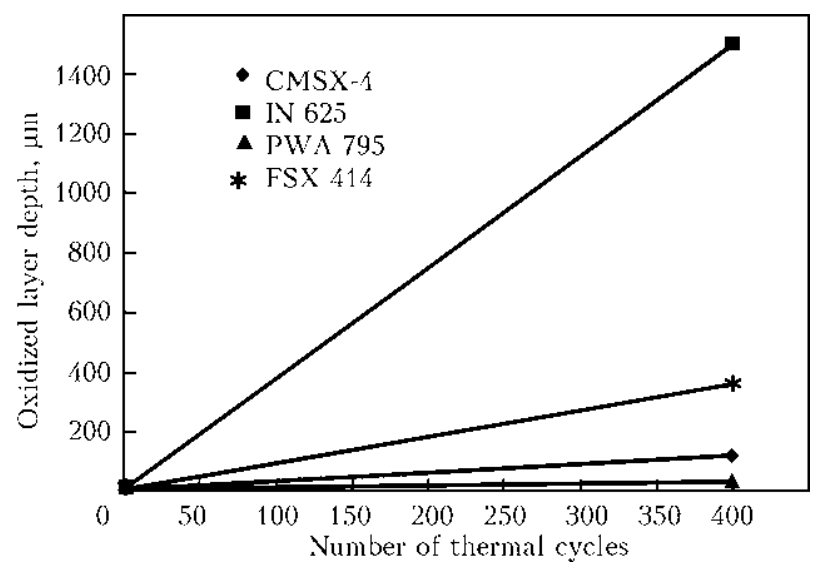

Figure 6. Dependence of thickness of scale film on deposited weld surface on various fillers after thermal cycling tests 


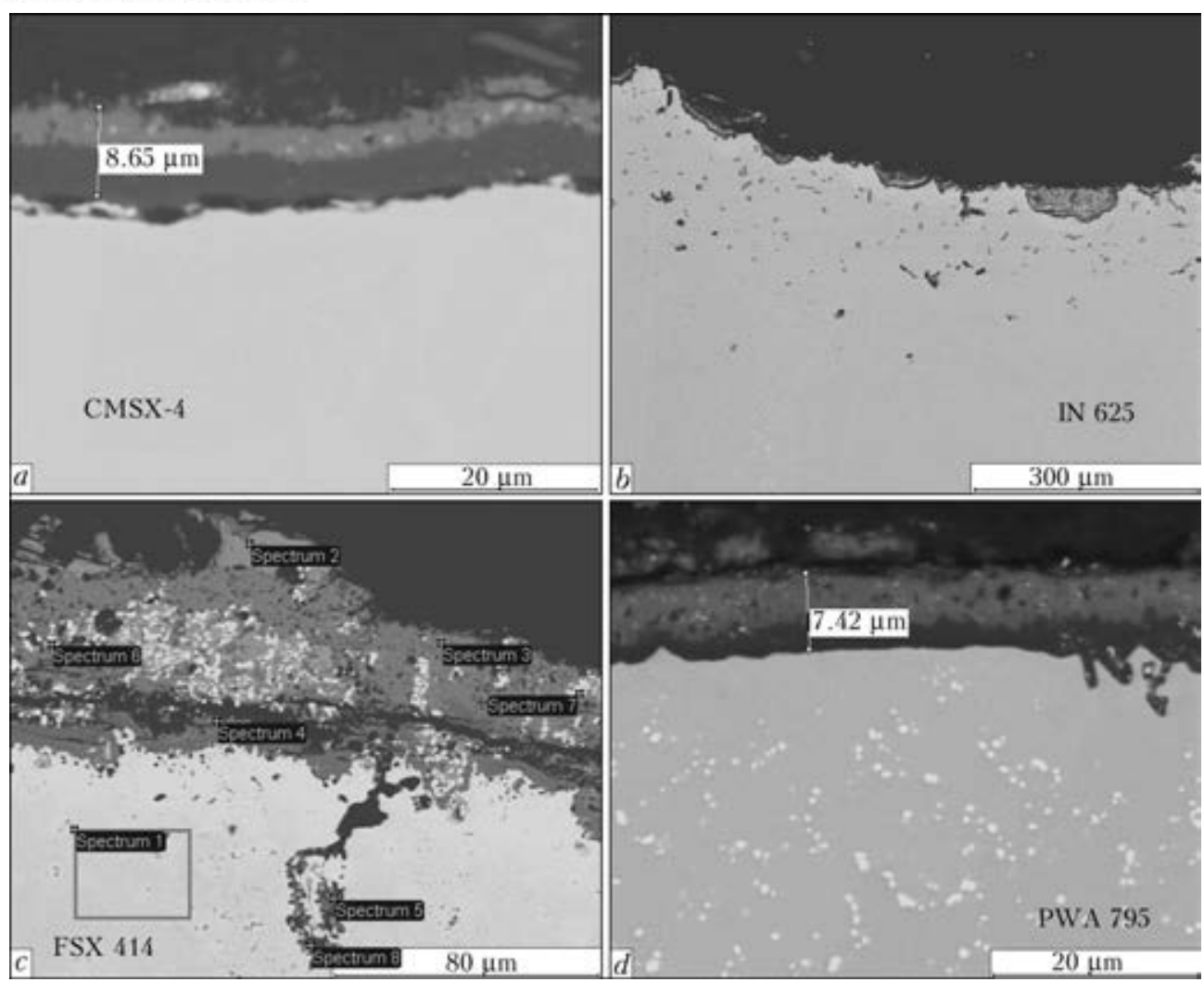

Figure 7. Oxide film on the surface of base metal $(a)$ and deposited welds $(b-d)$ formed using various filler materials after 400 thermal cycles

cordingly, at maximum testing temperature of $1150{ }^{\circ} \mathrm{C}$, surface layer of spinel and protective film, based on chromium oxide (III) adjacent to weld metal, break up. Reduction of sample weight at oxidation at temperature above $1100^{\circ} \mathrm{C}$ is also related to possible scale evaporation.

Welds formed by cobalt-based fillers have successfully resisted $400 \mathrm{~h}$ of cyclic testing at $1150{ }^{\circ} \mathrm{C}$. Kinetic curves of sample oxidation are located in the plot lower part (see Figure 5), that is indicative of a lower oxidation rate compared to nickel fillers.

Table 2. Composition of deposited weld formed with application of filler wire FSX 414 after 400 thermal cycles, wt.\% (see Figure $7, c)$

\begin{tabular}{||c|c|c|c|c|c|c||}
\hline \hline Spectrum & $\mathrm{C}^{*}$ & $\mathrm{O}$ & $\mathrm{Cr}$ & $\mathrm{Co}$ & $\mathrm{Ni}$ & $\mathrm{W}$ \\
\hline 1 & - & 0.26 & 20.84 & 56.96 & 14.16 & 7.77 \\
\hline 2 & - & 21.68 & 2.27 & 54.92 & 20.89 & 0.25 \\
\hline 3 & - & 31.58 & 35.96 & 26.84 & 2.87 & 2.75 \\
\hline 4 & - & 32.93 & 39.39 & 23.61 & 4.08 & - \\
\hline 5 & 12.39 & 37.91 & 45.79 & 2.67 & 2.86 & 0.38 \\
\hline 6 & 5.32 & 19.07 & 4.06 & 25.42 & 9.18 & 40.94 \\
\hline 7 & - & 28.78 & 27.21 & 26.65 & 3.10 & 14.26 \\
\hline 8 & 24.66 & 18.28 & 46.94 & 5.92 & 3.31 & 0.89 \\
\hline
\end{tabular}

*Here and in Table 4 carbon for determination of structural phase type is given qualitatively because of instrument malfunction (scale on the sample).
Application of FSX 414 alloy as filler material allowed forming a quite dense oxidation-resistant deposited weld on CMSX-4 alloy (see Figure 1, $h$ and Figure $7, c$ ). Main alloying component of FSX 414 cobalt alloy ( 29 wt.\% Cr) ensured reliable oxidation resistance of deposited material at increased temperature. Matrix solution of FSX 414 alloy is strengthened by addition of tungsten (7.5 wt.\%) and dispersion-strengthened by carbides predominantly of $\mathrm{Me}_{23} \mathrm{C}_{6}$ type (0.10.15 wt.\% C). Other types of carbides (based on tantalum and hafnium from base alloy) were also present in the bottom part of the already formed weld.

Thickness of frontal oxidation products on the surface of metal of weld from FSX 414 alloy after testing was 40 to $80 \mu \mathrm{m}$, and internal oxidation depth was $400 \mu \mathrm{m}$ (Figure 7,c). Heterogeneous morphology of oxide film on weld surface from cobalt-, chromium- and nickel-based spinels and localized penetration of oxidation products along grain boundaries to $50 \mu \mathrm{m}$ depth were observed (see Table 2). As follows from weld microstructure, after 400 thermal cycles of testing the most intensive oxidation occurred in the point of interaction of three components, namely base alloy, deposited material, and furnace atmosphere proper. In the lateral zones of weld adjacent to the base, i.e. in zones of the most active interdiffusion, local formation of oxidation products 


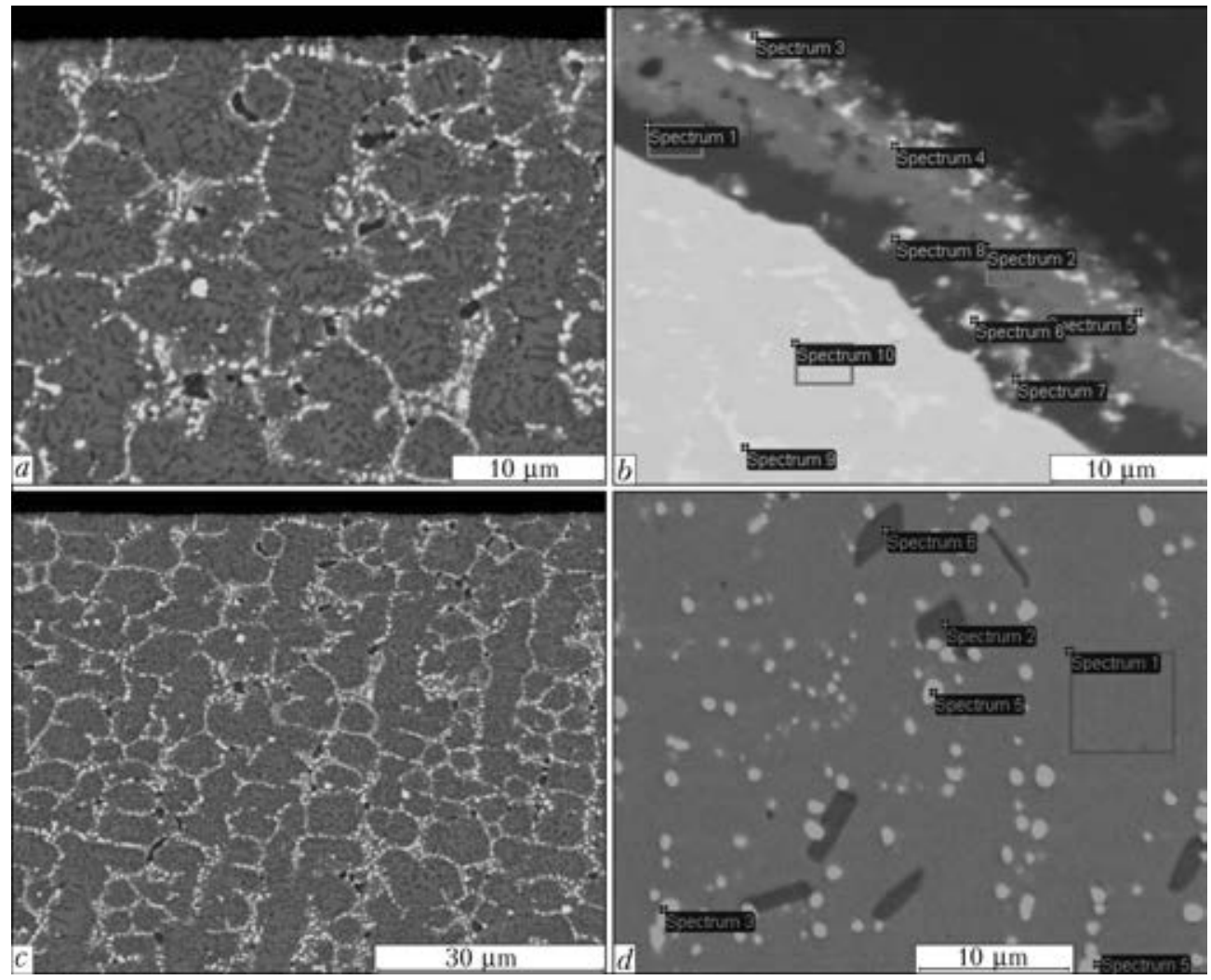

Figure 8. Evolution of the structure of filler material PWA 795 before $(a, c)$ and after $(b, d)$ thermal cycling tests

(oxides, nitrides) in the metal of weld and HAZ was observed (see Figure 1, $h$ ). Contrarily, weld center and the region of interphase boundary of deposited metal and base were not prone to oxidation and material degradation, respectively. Thus, at thermal cycling oxidation the deposit material - FSX 414 alloy - demonstrated satisfactory results on oxidation resistance, and the weld deposited with it on CMSX-4 single-crystal alloy was mostly preserved (even in the presence of polycrystalline structure on the fusion line, see Figure $3, b$ ).

As is seen from Figure 5, kinetic curve of oxidation of a sample with a deposit from PWA 795 alloy $\quad(\mathrm{Co}-15 \mathrm{Ni}-20 \mathrm{Cr}-4.4 \mathrm{Al}-8.7 \mathrm{~W}-2.7 \mathrm{Ta}-$ $1 \mathrm{Hf}-0.045 \mathrm{Y}-0.35 \mathrm{C}$ ) is the lowest. This material turned out to be the most oxidation-resistant by the results of high-temperature cyclic testing. Application of cobalt-based alloy ensured minimum oxidation rate of deposited weld (see Figure 1, $c)$, which preserved its configuration after 400 thermal cycles of testing (see Figure 1, $d, h$ ).

In the structure of initial weld, deposited with PWA 795 alloy, oriented columnar dendritic growth of solidified metal along single crystal direction [001] is clearly traced over the entire solidification front (see Figure 1, $c, d$ ). At preservation of a plane solidification front epitaxial growth of deposited metal was observed on the fusion line, when dendrites of excess solid solu- tion based on deposited metal solidify inheriting the lattice of base metal grains (see Figure 2, $b$ ). As regards the fine structure of weld metal, it has a three-phase structure. Its base is matrix $\gamma$-solid solution and carbide phase network, fringing fine dendrites (Figure $8, a, c$ ). As a rule, MeC type carbides based on hafnium, tantalum, zirconium, etc. form at solidification from liquid.

After thermal cyclic testing the depth of frontal oxidation over the entire surface of weld based on PWA 795 alloy was equal to $9-10 \mu \mathrm{m}$. Protective film was dense and had a two-layer structure, and good adhesion to deposited weld metal was noted (see Figure $7, d$ and Figure $8, b$ ). The inner layer adjacent to the base by its chemical composition corresponded to protective $\mathrm{Al}_{2} \mathrm{O}_{3}$ film, and outer layer - to spinel of $(\mathrm{Ni}, \mathrm{Co})$ $(\mathrm{Cr}, \mathrm{Al})_{2} \mathrm{O}_{4}$ type with $\mathrm{Al}_{2} \mathrm{O}_{3}, \mathrm{TaO}$ and $\mathrm{Y}_{2} \mathrm{O}_{3}$ inclusions (Table 3) [11, 12].

Microhardness of weld metal deposited with PWA 795 alloy (Figure 9) reflects the changes which occur on deposit/base interphase during cyclic oxidation. After surfacing microhardness of weld metal reached $4800 \mathrm{MPa}$, that is due to strengthening of matrix solution by interdendrite network of carbide phases. During testing diffusion processes run actively in the weld metal, causing partial dissolution of secondary strengthening phases, in particular, $\mathrm{MeC}$ carbides based on tantalum and hafnium which were trans- 
SCIENTIFIC AND TECHNICAL

Table 3. Composition of oxide film on the surface of welds deposited with application of filler wire PWA 795 after 400 thermal cycles, wt.\% (see Figure $8, b$ )

\begin{tabular}{|c|c|c|c|c|c|c|c|c|c|c|}
\hline Spectrum & $\mathrm{O}$ & $\mathrm{Al}$ & $\mathrm{Ti}$ & $\mathrm{Cr}$ & Co & $\mathrm{Ni}$ & $\mathrm{Y}$ & $\mathrm{Hf}$ & $\mathrm{Ta}$ & W \\
\hline 1 & 50.86 & 46.85 & - & 0.64 & 1.14 & 0.51 & - & - & - & - \\
\hline 2 & 40.90 & 25.05 & - & 6.03 & 18.05 & 9.97 & - & - & - & - \\
\hline 3 & 28.74 & 1.73 & 1.07 & 0.82 & 2.11 & 1.18 & 13.25 & 28.91 & 18.59 & 3.61 \\
\hline 4 & 35.93 & 10.94 & 0.59 & 3.76 & 10.34 & 5.59 & 5.73 & 3.86 & 15.30 & 7.96 \\
\hline 5 & 39.92 & 17.73 & 1.08 & 5.42 & 14.65 & 8.10 & - & 3.33 & 9.34 & 0.43 \\
\hline 6 & 36.56 & 20.56 & 2.33 & 0.96 & 1.25 & 0.46 & - & 6.55 & 29.53 & 1.82 \\
\hline 7 & 42.26 & 30.38 & 1.22 & 0.49 & 1.03 & 0.18 & - & 6.27 & 17.06 & 1.13 \\
\hline 8 & 45.11 & 24.28 & 2.09 & 1.68 & 2.13 & 1.18 & - & 5.54 & 16.59 & 1.40 \\
\hline 9 & - & 1.20 & 2.10 & 9.21 & 18.87 & 7.57 & - & 20.18 & 36.89 & 3.98 \\
\hline 10 & - & 3.81 & - & 21.07 & 45.19 & 18.67 & - & - & 0.71 & 10.55 \\
\hline
\end{tabular}

formed into globular discrete forms. Lowering of weld microhardness to $3200 \mathrm{MPa}$ is associated with it. Smoothing of the curve on the graph along the fusion line is indicative of the processes of diffusion and homogenizing of deposit material composition.

Increased oxidation resistance of the deposit from PWA 745 cobalt alloy is achieved due to optimum selection of deposited material composition, containing, in addition to basic elements, also other alloying elements, such as 2.7 wt.\% Ta, 1 wt.\% Hf and 0.045 wt.\% Y. Let us consider the influence of (contribution) of each of the cobalt alloy components to functional characteristics of the deposit of single-crystal nickel alloy CMSX-4.

Alloying system $(\mathrm{Co}-\mathrm{Ni}-\mathrm{Cr}-\mathrm{Al}-\mathrm{W})$ of filler PWA 795 alloy has high thermal structural stability (compared to other nickel fillers) in the temperature range of $800-1100{ }^{\circ} \mathrm{C}$, as here $\gamma \rightarrow$ $\rightarrow \gamma^{\prime}$ phase transformation at cooling in the range of $900-700{ }^{\circ} \mathrm{C}$ is eliminated. Such a phase transformation is associated with volume changes, particularly increase of temperature coefficient of linear expansion of material, leading to high ther-

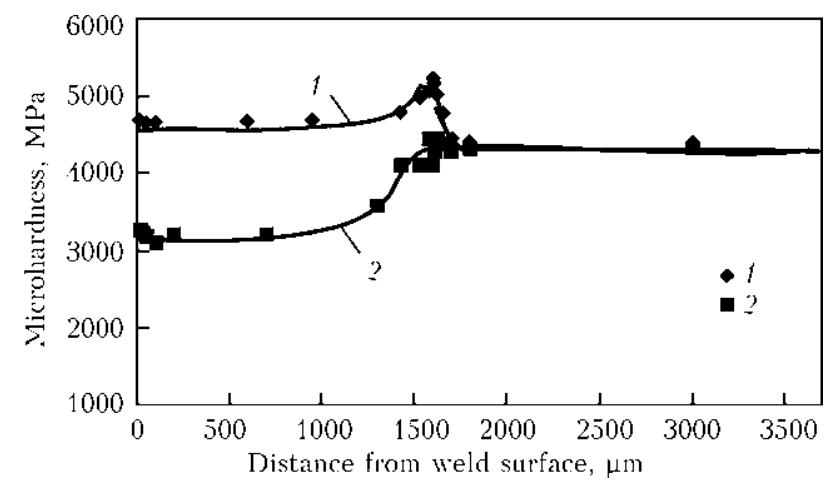

Figure 9. Microhardness of weld metal deposited by PWA 795 filler on single-crystal alloy CMSX-4 before (1) and after (2) thermal cycling tests mal stresses, which arise in the oxide film at cooling $[9,12]$. Cobalt, being the base of PWA 795 filler material, increases chromium solubility (its content is $20 \mathrm{wt. \%}$ ) in the matrix, hindering formation of brittle chromium phase $\alpha$-Cr, which forms in nickel systems jointly with $\gamma^{\prime}-\mathrm{Ni}_{3} \mathrm{Al}$ and lowers material creep resistance. On the whole, $\alpha$-Cr particles have a negative effect on mechanical properties, for instance, on fatigue resistance. On the other hand, chromium and aluminium improve oxidation resistance of the deposit.

Presence of about 15 wt.\% Ni stabilizes FCC lattice of cobalt-based solid solution, and chromium and tungsten (8.7 wt.\%) strengthen the solid solution, respectively.

Tantalum and hafnium in the amount of 2.7 and 1 wt.\% jointly present in material composition, improve mechanical properties of nickel-cobalt alloys, strengthening $\gamma$-solid solution (tantalum) and refining the carbide phase morphology.

Although low-carbon compositions of filler materials are mostly applied for single crystal surfacing, in the case of PWA 795 alloy carbon content reaches 0.35 wt.\%. However, presence of this component does not promote development of diffusion processes on the fusion line, in view of formation of carbide phases of $\mathrm{MeC}$ type, i.e complete binding of carbon into a chemical compound. At a rather wide range of mutual solubility and high formation temperature, $\mathrm{MeC}$ carbides have the shape close to a round one. Carbides, being located along dendrite/grain boundaries and inside dendrite cells, have the modifying functions, promote grain refinement and prevent recrystallization at high temperature. They strengthen both the grain proper, and its boundaries, slowing down diffusion processes and dislocation migration, and thus increasing the alloy thermal stability. From this viewpoint 
Table 4. Composition of weld metal deposited with application of PWA 795 filler wire after 400 thermal cycles, wt.\% (see Figure 8, $d$ )

\begin{tabular}{|c|c|c|c|c|c|c|c|c|c|}
\hline Spectrum & $\mathrm{C}$ & $\mathrm{Al}$ & $\mathrm{Ti}$ & $\mathrm{Cr}$ & Co & $\mathrm{Ni}$ & Hf & $\mathrm{Ta}$ & $\mathrm{W}$ \\
\hline 1 & 2.52 & 3.83 & - & 20.36 & 43.55 & 18.09 & 0.73 & 0.46 & 10.46 \\
\hline 2 & 6.36 & 13.84 & 0.39 & 9.89 & 33.76 & 29.96 & - & 2.07 & 3.73 \\
\hline 3 & 11.54 & 0.60 & 2.51 & 4.89 & 10.10 & 4.30 & 22.56 & 40.90 & 2.59 \\
\hline 4 & 8.98 & 0.64 & 2.72 & 4.03 & 8.39 & 3.24 & 26.80 & 42.92 & 2.27 \\
\hline 5 & 9.65 & 0.46 & 2.86 & 3.92 & 8.69 & 3.34 & 22.57 & 46.67 & 1.85 \\
\hline 6 & 5.05 & 14.13 & 0.48 & 9.86 & 34.77 & 29.69 & - & 1.56 & 4.45 \\
\hline
\end{tabular}

(Ta, Hf, W)C carbides in deposited metal are the main strengthener at the temperature of up to $1200{ }^{\circ} \mathrm{C}$ and higher. TaC monocarbide prevailing in the weld is strongly bound to the matrix compared to other carbide phases.

Alloying of PWA 795 alloy by hafnium in the amount of 1 wt.\% causes a relative reduction of volume fraction of carbide precipitates of pin morphology. The first to form particles of (Hf, $\mathrm{Ti}) \mathrm{C}$ carbides are additional solidification centers and promote precipitation of carbides in a more favourable form as discrete faceted particles, that was observed by us after testing (see Figure 8, $d$; Table 4). Hafnium alloying improves weld metal oxidation resistance [9].

Aluminium present in the deposit material (4.4 wt.\%) has an important role in ensuring high-temperature resistance of deposited welds. First, in weld metal it guarantees formation of $\mathrm{Al}_{2} \mathrm{O}_{3}$ film during oxidation, preserving its protective properties at temperature above $1000{ }^{\circ} \mathrm{C}$. Secondly, when studying the initial structure of deposited weld metal, regular precipitates of $\beta$ (Ni, Co)Al intermetallic phase of $0.5-0.7 \mu \mathrm{m}$ size ensuring material oxidation resistance, are observed alongside strengthening carbide phases in matrix solution. Intermetallic phase present in PWA 795 alloy has a high stability in the cobalt matrix compared to nickel-base alloys at temperature above $1000{ }^{\circ} \mathrm{C}$. This is attributable to slow diffusion of aluminium and yttrium to the surface during soaking at high temperature. During testing this phase coagulates, being preserved in the greater part of the deposited weld and being a reserve of aluminium in weld composition (see Figure 8, $d$ and Table 4) [13].

It is known that yttrium in the amount of 0.34-0.40 wt.\% (alongside rare-earth elements - cerium, lanthanum, gadolinium) has an effective protective effect at high temperature oxidation [14].

Earlier considered reduction of the weight of samples deposited by alloys without yttrium is due to the fact that during cooling at each test cycle the scale cracks and delaminates. Poor ad- hesion of the film to the substrate is related to presence of pores, which form as a result of condensation of vacancies at scale-substrate boundary, forming as a result of element diffusion from metal into oxide film. Yttrium addition into nickel (cobalt) alloys leads to a considerable reduction of oxide film microporosity [15]. Lowering of defect rate in $\mathrm{Cr}_{2} \mathrm{O}_{3}$ film due to yttrium penetration into it was established [16]. This element reduces the diffusion flow of oxygen ions due to a large atomic radius, precipitating predominantly on vacancies, dislocations, subgrains and grain boundaries. This results in retardation of diffusion processes and oxidation resistance of protective film grows accordingly.

Owing to a higher chemical activity of yttrium to oxygen than that of base metal, including chromium and aluminium, yttrium binds the coming oxygen, releasing a relatively large amount of reserve chromium in the surface layers, and thus ensuring scale resistance of deposit metal.

Alloying by yttrium leads to formation of a zone containing highly-dispersed $\mathrm{Y}_{2} \mathrm{O}_{3}$ oxide particles in the subsurface layer of scale. Yttrium presence suppresses on the alloy or in the weld formation of $\mathrm{NiO}$ and $\mathrm{NiWO}_{4}$ oxides, not having any protective properties, owing to stabilization of $\mathrm{Cr}_{2} \mathrm{O}_{3}, \mathrm{Al}_{2} \mathrm{O}_{3}$ and $\mathrm{Ni}(\mathrm{Cr}, \mathrm{Al}) \mathrm{O}_{4}$ spinel. Penetration of yttrium into them and dissolution of $\mathrm{Y}_{2} \mathrm{O}_{3}$ oxide results in formation of $(\mathrm{Cr}, \mathrm{Y})_{2} \mathrm{O}_{3}$ and $\mathrm{Ni}(\mathrm{Cr}, \mathrm{Al}, \mathrm{Y}) \mathrm{O}_{4}$ oxides. A confirmation of yttrium penetration into the oxides are their unusually large lattice parameter values: for $(\mathrm{Cr}$, $\mathrm{Y}_{2} \mathrm{O}_{3} a=5.42-5.43 \mathrm{~nm}$, and for $\mathrm{Ni}(\mathrm{Cr}, \mathrm{Al}) \mathrm{O}_{4}$ $a=8.35 \mathrm{~nm}$.

Protective capacity of the oxides is also due to smaller number of faults in their crystalline lattice, greater force of ion binding, smaller coefficient of self-diffusion in it, as well as formation of a surface protective oxide film with a denser structure than that of $\mathrm{NiO}$ and $\mathrm{NiWO}_{4}$ oxides.

Yttrium is used to improve oxidation resistance of alloys of various types and coatings, on which protective $\mathrm{Al}_{2} \mathrm{O}_{3}$ film forms during oxida- 
tion. It is capable of improving the alloy oxidation resistance. If the alloy contains enough chromium, then at oxidation and formation of $\mathrm{Cr}_{2} \mathrm{O}_{3}$ oxide, yttrium improves its oxidation resistance not only at static, but also at cyclic oxidation (particularly for cobalt alloys) [9, 11].

At cyclic oxidation of the alloy with yttrium (as in our case) the protective film mainly preserves its integrity and has a good adhesion to the substrate being protected. At a high affinity to oxygen yttrium actively diffuses to the interphase (with an oxidizing medium) and forms oxides [17]. These Y-containing particles are localized near the protective $\mathrm{Al}_{2} \mathrm{O}_{3}$ film, i.e. in the zone with a high activity of oxygen and aluminium (chromium) and are readily enriched in chromium, thus leading to formation of $\mathrm{YAlO}_{3}$ and $\mathrm{YAl}_{5} \mathrm{O}_{12}$ yttrium granates. These are exactly the compounds that grow into protective $\mathrm{Al}_{2} \mathrm{O}_{3}$ film and ensure a reliable adhesion of the film to the substrate [13].

Thus, the high oxidation resistance of the deposited material - PWA 795 alloy - is determined by optimum alloying of cobalt base and its modifying by active components (yttrium and hafnium) [18]. In this composition yttrium ensures a high adhesion of oxide film to deposit material. At sufficient reserve of yttrium and low rate of yttrium diffusion to the surface in the cobalt alloy a high stability of $\mathrm{Ni}(\mathrm{Co}) \mathrm{Y}$ intermetallic compared to $\mathrm{Ni}-\mathrm{Co}-\mathrm{Cr}-\mathrm{Al}$ alloys is also ensured that determines the deposited metal oxidation resistance. Yttrium stabilizes the oxide films of aluminium oxide and chromium oxide on the alloy surface, that ensures increased oxidation resistance and allows in some cases elimination of protective coatings on turbine blades.

Hafnium has a positive influence on strength and ductility properties of deposited alloy. Modifying role of hafnium was manifested in that during oxidation disperse $\mathrm{HfO}_{2}$ particles «decorated» the inner boundaries of $\alpha-\mathrm{Al}_{2} \mathrm{O}_{3}$ film (see
Figure 8, $b$ and Table 3 ). This boundary strengthening has a positive effect on creep resistance of oxide film [18].

The question of complex repair includes not only re-tailoring airfoil upper tip by hardfacing, but also subsequent operations of product mechanical (abrasive) treatment, formation of airfoil upper tip (whisker), finish two-step heat treatment of the product, including application of a protective coating. An urgent task under these conditions is that of protection of working surface of single-crystal blades operating at 1100$1200{ }^{\circ} \mathrm{C}$ and made from Re-containing single-crystal alloys with limit content of alloying elements. Alloying of high-temperature nickel alloys by refractory metals and reduction of the number of elements providing satisfactory oxidation resistance of GTU hot section products, as well as carbon elimination from the composition, requires application of protective coatings safeguarding against high-temperature oxidation.

At selection of coating compositions it is necessary to take into account base alloy composition and coating oxidation resistance, which is determined not only by integral content of aluminium, chromium, cobalt, etc., time of its performance loss by the following mechanism: $\gamma+\beta(\mathrm{NiAl}) \rightarrow$ $\rightarrow \gamma+\beta+\gamma^{\prime}\left(\mathrm{Ni}_{3} \mathrm{Al}\right) \rightarrow \gamma+\gamma^{\prime}$, but also by the restoration ability of the film of spinel $\alpha-\mathrm{Al}_{2} \mathrm{O}_{3}+$ $+\alpha-\mathrm{Cr}_{2} \mathrm{O}_{3}$ or $\mathrm{Ni}(\mathrm{Cr}, \mathrm{Al})_{2} \mathrm{O}_{4}$, and a set of physical, chemical and mechanical properties.

In parallel with deposition on single-crystal alloy CMSX-4, work was performed on deposition of PWA 795 material on equiaxially solidified alloy ZMI-3U with subsequent deposition of oxidation-resistant coating of $\mathrm{Co}-\mathrm{Ni}-\mathrm{Cr}-\mathrm{Al}-$ $\mathrm{Y}$ system. Investigation results demonstrated a good matching of substrate material and repair deposit with protective coating layer. Interphases were dense, defect-free, without pronounced developed diffusion zones (Figure 10).

In order to confirm the above established advantages of application of PWA 795 deposition

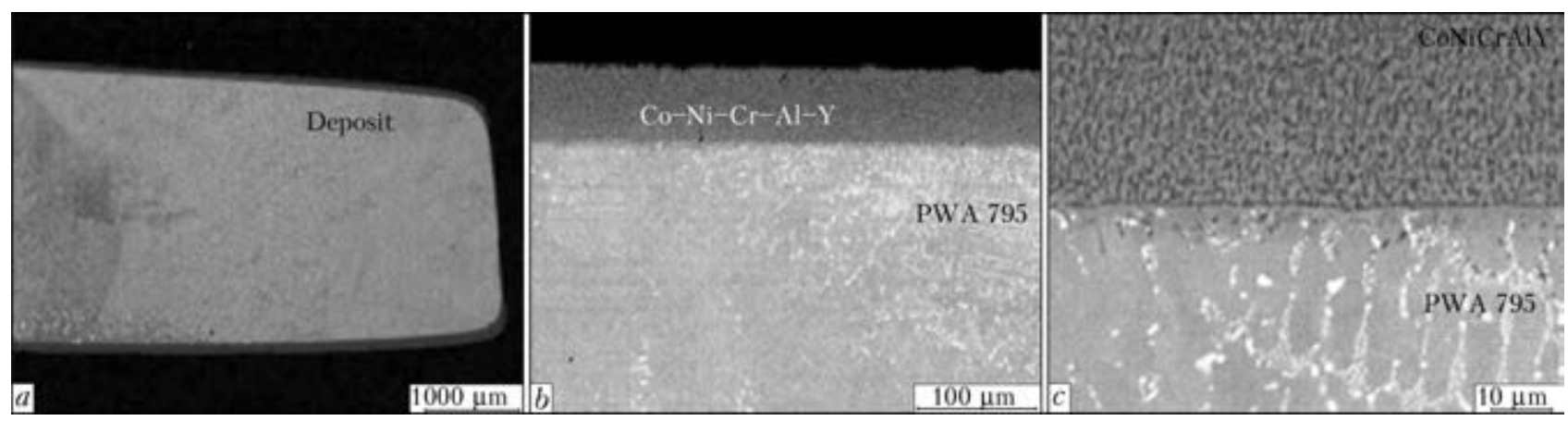

Figure 10. Microstructure of the tip of GKT-10-4 blade re-tailored by TIG hardfacing process with deposited protective coating 
on single-crystal CMSX-4 alloy, it is rational to perform comprehensive repair of the blade with subsequent electron beam deposition of thermal barrier NiCoCrAlY $/ \mathrm{ZrO}_{2}-\mathrm{Y}_{2} \mathrm{O}_{3}$ coating.

\section{Conclusions}

1. For comparative assessment of oxidation resistance of filler materials deposited on single-crystal alloy CMSX-4, thermal cycling tests were performed (at $t_{\max }=1150{ }^{\circ} \mathrm{C}$, cycle time $-1 \mathrm{~h}$ ) on samples with deposited welds and on base alloy sample.

2. IN 625 alloy is a good material for repair of items by deposition of oxidation-resistant alloys at working temperature of parts of up to $950{ }^{\circ} \mathrm{C}$. At higher temperatures and strict thermal cycling loading modes the produced welds burn out completely. Therefore, application of oxidation-resistant coatings on blades with such repair does not ensure satisfactory protection from oxidation at high service temperatures of high-heat GTU.

3. In terms of oxidation kinetics, PWA 795 filler material turned out to be the most oxidation-resistant, ensuring minimum oxidation rate of deposited weld. Thickness of frontal oxide film on weld surface did not exceed $10 \mu \mathrm{m}$ at local oxidation depth of not more than $30 \mu \mathrm{m}$. Oxide film forming on PWA 795 alloy has a doublelayer structure and ensures good protection of deposited metal from high-temperature oxidation. Good adhesion of the film to weld metal is noted, which is due to the alloying complex of the alloy and its yttrium content.

4. Tantalum and hafnium bind carbon (0.35 wt.\%) into $\mathrm{MeC}$ carbide phases and improve their morphology, perfecting carbide strengthening mechanism, accordingly. Tantalum present in the alloy in the amount of $2.7 \mathrm{wt} . \%$ influences thermal stability of deposit material, and hafnium improves weld metal ductility, owing to dispersion of carbide particles along grain boundaries and their spheroidization.

5. Presence of aluminium and nickel in cobalt filler material promotes formation of $\beta-(\mathrm{Ni}$, Co)Al-phase in the weld, ensuring material oxidation resistance. This phase is preserved in the greater part of the weld also after 400 test thermal cycles.

6. Cobalt-based filler materials ensure satisfactory oxidation resistance at high $\left(1150{ }^{\circ} \mathrm{C}\right)$ test temperature. Welds formed with application of cobalt filler materials, are not prone to development of cracks caused by dispersion hardening (similar to nickel ones) even in the presence of stray grains, forming during solidification. Selection of cobalt-based filler is also justified in that the main strengthening phase in it - carbides - are more stable than $\gamma^{\prime}$-phase (in nickel alloys) and they dissolve to a smaller degree at $1150{ }^{\circ} \mathrm{C}$.

1. Shukin, S., Annerfeldt, M., Bjorkman, M. (2008) Siemens SGT-800 industrial gas turbine enhanced to 47 MW. In: Proc. of ASME Turbo Expo 2008 on Power for Land, Sea and Air (June 9-13, 2008, Germany), 1-6.

2. Wilson, B.C., Hickman, J.A., Fuchs, G.E. (2003) The effect of solution heat treatment on a single-crystal Ni-based superalloy. JOM, 3, 35-40.

3. Wortman, D.J., Duderstadt, E.C., Nelson, W.A. (1990) Bond coat development for thermal barrier coating. Transact. of ASME. J. Eng. Gas Turbines Power, 12(10), 527-530.

4. Belyavin, A.F., Fedotov, D.A., Kurenkova, V.V. et al. (2013) Restoration of single-crystal blades using argon-arc surfacing and deposition of thermal-barrier coating. Pt 1. Sovr. Elektrometallurgiya, 1, 49-57.

5. Anderson, T.D., DuPont, J.N. (2010) Stray grain formation and solidification cracking susceptibility of single crystal Ni-base superalloy CMSX-4. Met. and Materials Transact. A, 41(1), 181-195.

6. Shalin, R.E., Svetlov, I.L., Kachanov, E.B. et al. (1997) Single crystals of nickel heat-resistant alloys. Moscow: Mashinostroenie.

7. Sieborgen, D., Brehm, H., Wunderlich, F. et al. (2001) Temperature dependence of lattice parameter, misfit and thermal expansion coefficient of matrix, $\gamma^{\prime}$ phase and superalloy. Z. Metallkd, 92, 58-61.

8. Caron, P., Lavigne, O. (2011) Recent studies at ONERA on superalloys for single crystal turbine blades. $J$. Aerospace Lab., Issue 3, 11, 1-14.

9. Kablov, E.N. (2001) Cast blades of gas turbine engines. Moscow: MISiS.

10. Tikhomirova, E.A., Azizov, T.N., Sidokhin, E.F. (2012) On thermal fatigue of heat-resistant alloys. Aviats. Materialy i Tekhnologii, 3, 3-5.

11. Kolomytsev, P.T. (1979) Heat-resistant diffusion coatings. Moscow: Metallurgiya.

12. Jackson, R.D. (2009) The effect of bond coat oxidation on the microstructure and endurance of two thermal barrier coating systems: Dis.

13. Toscano, J. (2008) Influence of composition and processing on the oxidation behavior of MCrAlYcoatings for TBC applications. Energy \& Environment, 28, 187.

14. Nikitin, V.N. (1987) Corrosion and protection of gas turbine blades. Leningrad: Mashinostroenie.

15. Tien, I.K., Rand, W.H. (1972) The effect of active element addition in void formation during oxidation. Ser Metal, 1, 55-57.

16. Michels, H.T. (1976) The effect of dispersed reactive metal oxides on the oxidation resistance of nickel$20 \%$ chromium alloys. Met. Transact., 3, 379-388.

17. Malashenko, V.S., Shelkovoj, A.N., Grabin, V.V. et al. (2000) Life of condensation thermal barrier coatings in current heat-resistant nickel alloy. Problemy Spetselektrometallurgii, 1, 23-24.

18. Liu, J. (2007) Mechanism of lifetime improvement in thermal barrier coatings with $H f$ or $Y$ modification of CMSX-4 superalloy substrates: Dis.

Received 25.10.2013 


\title{
LASER AND LASER-MICROPLASMA ALLOYING OF SURFACE OF 38KhN3MFA STEEL SPECIMENS
}

\author{
V.D. SHELYAGIN, L.I. MARKASHOVA, V.Yu. KHASKIN, A.V. BERNATSKY and O.S. KUSHNARYOVA \\ E.O. Paton Electric Welding Institute, NASU \\ 11 Bozhenko Str., 03680, Kiev, Ukraine. E-mail: office@paton.kiev.ua
}

\begin{abstract}
Considered are the technologies of laser and laser-microplasma alloying of surface layers of 38KhN3MFA structural steel specimens with introduction of powder filler materials based on tungsten and chromium carbide, promoting increase of physical-chemical properties of the parts, manufactured from these steels. Structural transformations, concentration variations and reasons of crack formation in treated surface layers were investigated at different modes of alloying using the methods of light microscopy and analytic scanning electron microscopy. It is shown that susceptibility to crack formation in laser and laser-microplasma alloying of specimens of 38KhN3MFA steel is caused, first of all, by structural (size of crystalline particles, coefficient of their shape) and concentration variations, related with redistribution of the elements, in particular, chromium, that results in formation of grain boundary concentration gradients. Absence of microcracks in a fusion zone at laser-microplasma method of alloying allows making a conclusion about perspective of application of this method for surface treatment of parts, manufactured from 38KhN3MFA steel. 6 Ref., 9 Figures.
\end{abstract}

Key words: structural steel, treated surfaces, laser alloying, structure

General tendencies for development of current machine building lie in intensifying of the production processes due to increase of main technological parameters (temperature, pressure, concentration of reacting substances, etc.). This provides for a rise of requirements to safe operation of equipment, mechanisms and machines. Constant reduction of weight and dimensions of mechanisms and increase of their power result in rise of loads and stresses in the parts, that, in turn, require development and shifting to new, safer structural materials.

Today, bulk alloying of steels becomes uneconomical due to large consumption of expensive materials [1]. However, level of service properties of the unalloyed steels is not sufficient for their application in current industry. One of the solutions is an application of surface alloying of steels and alloys, that allows receiving the necessary surface properties at minimum consumption of alloying elements.

Most of the traditional methods of surface alloying are based, as a rule, on the processes of diffusion saturation with elements from gaseous or liquid phase in combination with heat (chemical-heat) treatment [2]. However, application of traditionally used chemical-heat or bulk heat treatment is not sufficient in number of cases for receiving of set level of service properties.
Therefore, the development of surface engineering at present stage, considering the problems related with strengthening technologies applied now, assumes creation of new level technological processes allowing modification of a surface layer, changing of its structure and properties [3]. At that, the preference during modification of metal surfaces is given to the methods of strengthening treatment using as a heat source the concentrated energy flows, namely ion, laser, ultrasonic, electron beam and others.

Considering the fact that laser technologies allow successfully solving a problem of development of materials with set complex of properties by means of directed formation of necessary structure along the whole volume of metal, there is a possibility in application of laser treatment for strengthening of local volumes, in particular, surface layers of treated material. Application of such an approach of laser alloying develops the possibility for formation of surfaces characterizing by high level of hardness, heat, wear and corrosion resistance. Thus, present work is dedicated to the investigation of surface alloying of steel and surface structures being formed under different conditions of irradiation in order to optimize the technological modes of laser alloying.

Materials and methods of investigation. Laser and laser-microplasma surface alloying of end face of circular specimens from 38KhN3MFA structural steel were carried out in course of investigations. Chemical composition of 


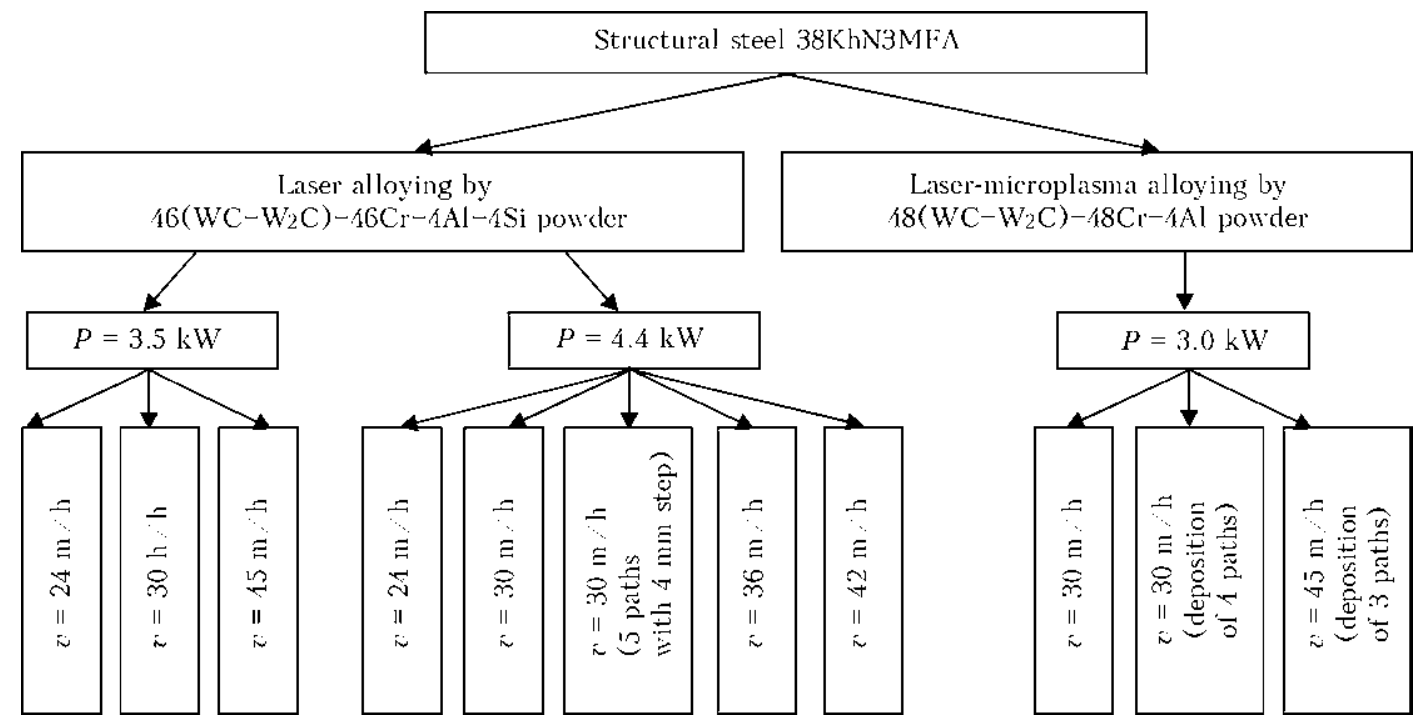

Figure 1. Flow-chart of investigated specimens

38KhN3MFA steel (GOST 4543-71) is as follows, wt.\%: $0.33-0.40 \mathrm{C}$; $0.17-0.37 \mathrm{Si} ; 0.25-$ $0.50 \mathrm{Mn} ; 3.0-3.5 \mathrm{Ni} ; 1.2-1.5 \mathrm{Cr} ; 0.35-0.45 \mathrm{Mo}$; $0.10-0.18 \mathrm{~V} ;<0.3 \mathrm{Cu} ;<0.025 \mathrm{~S} ;<0.025 \mathrm{P}$.

Mechanical properties of $38 \mathrm{KhN} 3 \mathrm{MFA}$ steel at $T=20{ }^{\circ} \mathrm{C}(\operatorname{rod}$ diameter $25 \mathrm{~mm})$ are $\sigma_{\mathrm{t}}=$ $=1180 \mathrm{MPa} ; \sigma_{0.2}=1080 \mathrm{MPa} ; \delta=12 \% ; \psi=$ $=50 \% ; K C U=780 \mathrm{~kJ} / \mathrm{m}^{2}$. Mechanical mixture of $0-40 \mu \mathrm{m}$ fraction powders of the following composition, wt.\%: $46\left(\mathrm{WC}-\mathrm{W}_{2} \mathrm{C}\right)+46 \mathrm{Cr}+$ $+4 \mathrm{Al}+4 \mathrm{Si}$, was used in laser alloying, and $48\left(\mathrm{WC}-\mathrm{W}_{2} \mathrm{C}\right)+48 \mathrm{Cr}+4 \mathrm{Al}$ composition was applied in laser-microplasma alloying.

ROFIN-SINAR Nd:YAG-laser DY044 (Germany) with irradiation wave length $\lambda=1.06 \mu \mathrm{m}$ was used for laser alloying. Equipment and technologies of laser-plasma alloying were developed at the E.O. Paton Electric Welding Institute. A laboratory bench was assembled on the basis of three-coordinated manipulator «Lastochka-1».

Laser irradiation was transferred using optic fiber of $600 \mu \mathrm{m}$ diameter and $20 \mathrm{~m}$ length manufactured from quartz glass. The laser irradiation from optic fiber came to a collimator, where it was transformed with the help of the system of optical elements and received the necessary geometry, and then was transmitted to focusing quartz lens of $50 \mathrm{~mm}$ diameter with focal distance $F=200 \mathrm{~mm}$. Treatment was carried out with variation of laser irradiation power in $P=3.0$ $4.4 \mathrm{~kW}$ limits, treatment speed $v=24-45 \mathrm{~m} / \mathrm{h}$ and value of irradiation defocusing $\Delta F=30$ $45 \mathrm{~mm}$. More detailed state of the investigated specimens is represented in a flow diagram ( $\mathrm{Fi}^{-}$ gure 1).

The experiments on laser alloying were carried out on scheme given in work [4]. At that, stationary specimen was located on object table and laser head was fixed on movable carriage of the manipulator. Structure of laser head allowed performing treatment of the specimen with axial feed of laser irradiation and filler powder mixture. The latter was transported in a nozzle part of the head using argon and dosing at that was carried out by vibrating feeder of the E.O. Paton Electric Welding Institute production. The laser head was fixed at $10^{\circ}$ angle to vertical axis in order to prevent entering of irradiation reflected from surface of melt pool into optical path.

The laser head and microplasmatron were based on a stationary support during performance of the experiments on laser-microplasma alloying. The specimens were fixed in the clamps positioned on movable carriage of the three-coordinated manipulator (Figure 2). End face of the specimen in form of ring was linearly alloyed at longitudinal movement of the carriage. At that, the melt pool of up to $2 \mathrm{~mm}$ depth was formed on the specimen surface. Mechanical mixture of

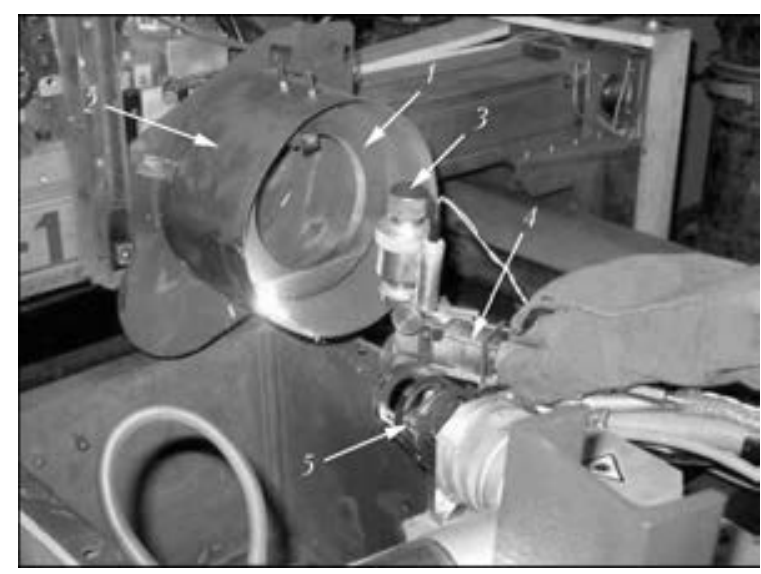

Figure 2. Bench for surface laser-microplasma alloying: 1 specimen fixed in clams; 2 - protective cover; 3 - powder measuring hopper; 4 - microplasmatron; 5 - laser focusing head 
powders was fed in it by a jet of laminar argon plasma. Power supply of the plasmatron was carried out using MPU-4 power source at 40-50 A current and around $32 \mathrm{~V}$ voltage. The distance from microplasmatron nozzle to treatment zone made 12-150 $\mathrm{mm}$. Convergence angle of axes of laser irradiation and mictroplasma jet made $30-45^{\circ}$.

Metallographic investigations for determination of general dependence of formation of surface structure in alloyed layers, received by different methods (laser and laser-microplasma alloying), were carried out by light microscopy method on Versamet-2. Content of elements in solid solution and in separate inclusions was investigated using analytical scanning microscopy method on Philips SEM-515 unit (Holland).

Nature of laser alloying effect. Carried investigations of process of laser alloying showed that active local heating of filler material, promoting formation of vapor-gas phase over liquid phase surface (melt pool), takes place at power irradiation densities of $10^{5}-10^{6} \mathrm{~W} / \mathrm{cm}^{2}$. At that, the latter includes the turbulent flows resulting in mixing of base and filler materials [4]. Besides, movement of laser beam results in difference of surface tension forces in central and tail parts of the melt pool. That in combination with effect of vapor pressure and turbulent flows of the melt promotes relatively uniform distribution of filler material through the whole depth of melt pool and formation of alloyed layer.

Increase of power density of laser irradiation above $10^{6} \mathrm{~W} / \mathrm{cm}^{2}$ leads to shifting in a keyhole penetration mode, characterized by formation vapor-gas channel in the melt pool [4,5]. The latter results in such unfavorable effects as burning out of chemical elements of filler material, formation of pores and cavities (due to collapse of vapor-gas pockets on the surface, with formation of wormholes inside the treated layer due to small time of liquid phase existence), increase of HAZ and transfer zone, slopping of base metal into the alloyed layer. Thus, for elimination of indicated defects, the power density of irradiation in a heating spot was limited approximately to (810) $\cdot 10^{5} \mathrm{~W} / \mathrm{cm}^{2}$ during performance of the experiments.

Reduction of power density of irradiation below $(2-4) \cdot 10^{4} \mathrm{~W} / \mathrm{cm}^{2}$ resulted in absence of uniformly remelted layer of metal.

Investigations of structure. The metallographic investigations were carried out in different areas, namely alloyed layer $\rightarrow$ fusion zone $\rightarrow$ base metal of each of 11 specimens (differ by parameters of technological modes).

Laser treatment of the surface was performed with $P=3.5 \mathrm{~kW}$ power at different alloying speed $v=24-45 \mathrm{~m} / \mathrm{h}$ as well as with increased power up to $4.4 \mathrm{~kW}$ at $v=24-42 \mathrm{~m} / \mathrm{h}$. Lasermicroplasma treatment was carried out with constant power $P=3 \mathrm{~kW}$ and varying alloying speed (it was changed from 30 to $45 \mathrm{~m} / \mathrm{h}$ ) at deposition of different number of paths.

Laser alloying. It was determined that thickness of surface alloyed layer changed from 1.55 to $2.10 \mathrm{~mm}$ in laser alloying (with $P=3.5$ as well as $4.4 \mathrm{~kW}$ ) at increase of alloying speed $(v=24,30,45 \mathrm{~m} / \mathrm{h})$. Metal of the surface alloyed layer has a well-defined structure of elongated shape $(h \times l)$ of crystalline particles (where $h$ is the width, and $l$ is the crystalline particle elongation), size of which on average make $h \times$ $\times l=15 \times 85 \mu \mathrm{m}$ at $v=24 \mathrm{~m} / \mathrm{h}, 20 \times 80 \mu \mathrm{m}$ for $v=30 \mathrm{~m} / \mathrm{h}$ and $15 \times 100 \mu \mathrm{m}$ with $v=45 \mathrm{~m} / \mathrm{h}$ (Figure 3, $a$ ). Thus, change of shape coefficients $\kappa$ of crystalline particles is observed [6], the values of which on average are 5 for $24 \mathrm{~m} / \mathrm{h}, 3$ for $30 \mathrm{~m} / \mathrm{h}$, and it rises up to 6 with increase of speed of laser alloying to $45 \mathrm{~m} / \mathrm{h}$. Increase of microhardness in the alloyed layer on average by $30-36 \%$ was also registered depending on rise of speed from 24 to $45 \mathrm{~m} / \mathrm{h}$ at $P=3.5 \mathrm{~kW}$.

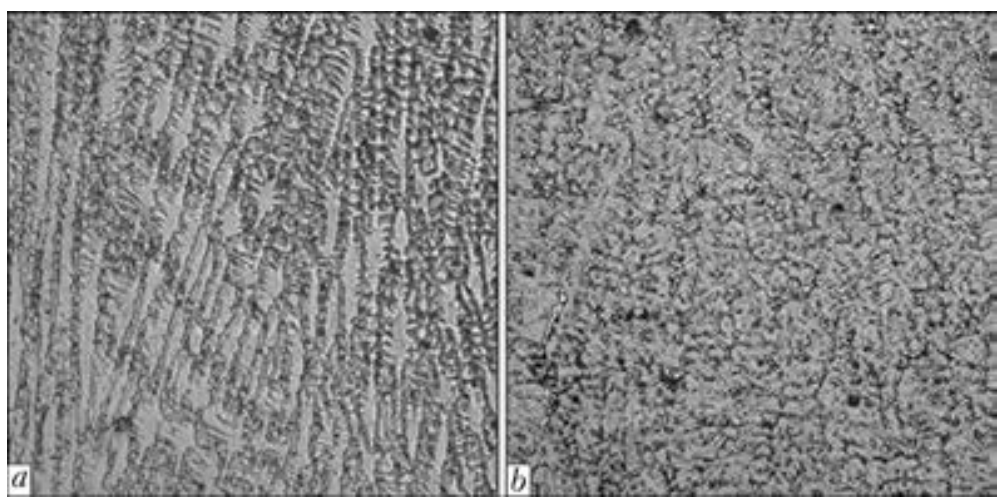

Figure 3. Microstructure $(\times 500)$ of surface layers of structural steel 38KhN3MFA under conditions of laser $(a)$ and laser-microplasma $(b)$ alloying 


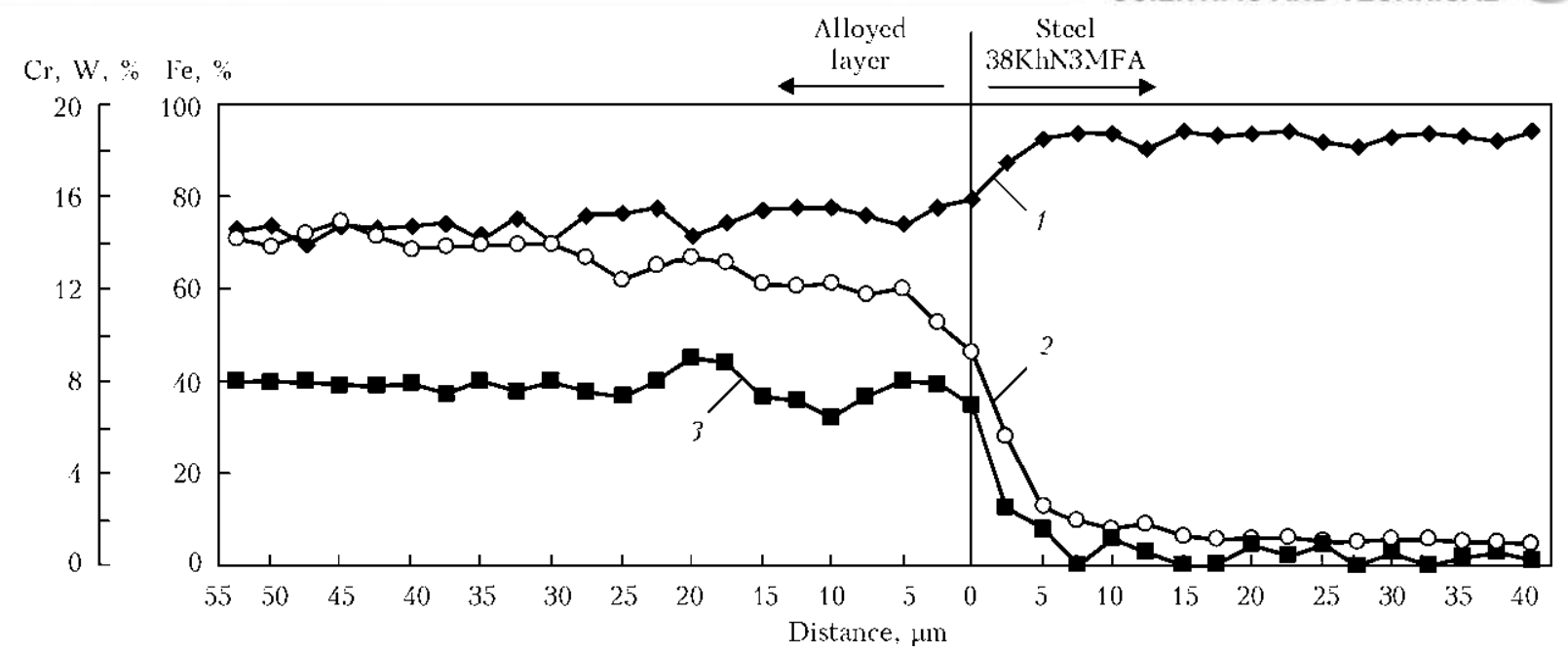

Figure 4. Concentration variations of iron (1), chromium (2) and tungsten (3) from outer surface of alloyed layer to base metal 38KhN3MFA after laser alloying at $P=3.5 \mathrm{~kW}$ and $v=30 \mathrm{~m} / \mathrm{h}$

HAZ is observed from the side of $38 \mathrm{KhN} 3 \mathrm{MFA}$ base metal directly near the fusion line. The width of the latter rises from 1.30 to $1.65 \mathrm{~mm}$ with increase of microhardness in this zone at alloying speed rise from 24 to $45 \mathrm{~m} / \mathrm{h}$, respectively. It should be noted, in this case, that the structural mixture of sorbite and martensite is observed in the base metal, whereas HAZ metal has martensite structure for all considered cases of alloying speed. Besides, concentration variations in the treated surfaces were investigated and showed that the most uniform saturation of the surface layer by alloying elements is noted with $v=$ $=30 \mathrm{~m} / \mathrm{h}$ and $P=3.5 \mathrm{~kW}$. In this case, concentration of elements makes, wt.\%: 70-75 Fe, 12$14 \mathrm{Cr}, 7-8 \mathrm{~W}$, without rapid gradient of concentration variations in a transfer zone (extension of which does not exceed $25 \mu \mathrm{m}$ ) from the fusion line in a direction of outer surface of alloyed layer (Figure 4).

Investigations of nature of inclusions in the treated surfaces were carried in addition to the investigations of concentration variations. It is shown that coarse inclusions (Figure 5) in the amount of up to $1 \%$ and $25 \mu \mathrm{m}$ size are observed in the case of laser alloying of surface layer at

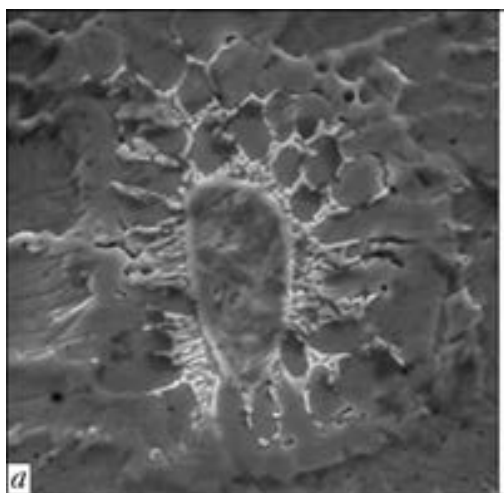

all alloying speeds. These inclusions differ by high content of tungsten (up to 95-97\%), and, obviously, being the $\mathrm{WC}-\mathrm{W}_{2} \mathrm{C}$ particles not dissolved during the alloying process.

The next stage of work was directed on investigation of presence and nature of cracks, zones of their distribution in the surface layers at $P=$ $=3.5 \mathrm{~kW}$. It was determined, as a result, that their maximum size (length up to $500 \mu \mathrm{m}$ ) and amount (up to $10 \%$ ) is observed in the case of $v=45 \mathrm{~m} / \mathrm{h}$, whereas length of crack propagation somewhat reduces and makes $50-450 \mu \mathrm{m}$ at their amount up to $2 \%$ (Figure $6, a$ ) with $24 \mathrm{~m} / \mathrm{h}$ minimum speed. It should be noted that content of chromium rises up to $20-26 \%$ in areas with microcracks, tungsten concentration at that makes around $2-5 \%$. Increase of chromium content (Figure $6, b$ ) is sufficiently well observed at a map of concentration distribution of chemical elements in a central zone of the alloyed layer in the presence of crack. However, the microcracks are virtually absent under conditions of average speeds $(v=30 \mathrm{~m} / \mathrm{h})$ that indicates the optimum structural state of the alloyed layer from point of view of crack resistance.

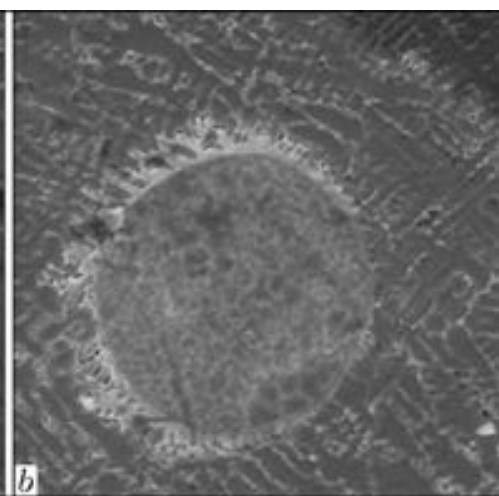

Figure 5. Microstructure of surface layer with $\mathrm{WC}-\mathrm{W}_{2} \mathrm{C}$ inclusions in laser alloying $(a-\times 3100 ; b-\times 1200)$ 


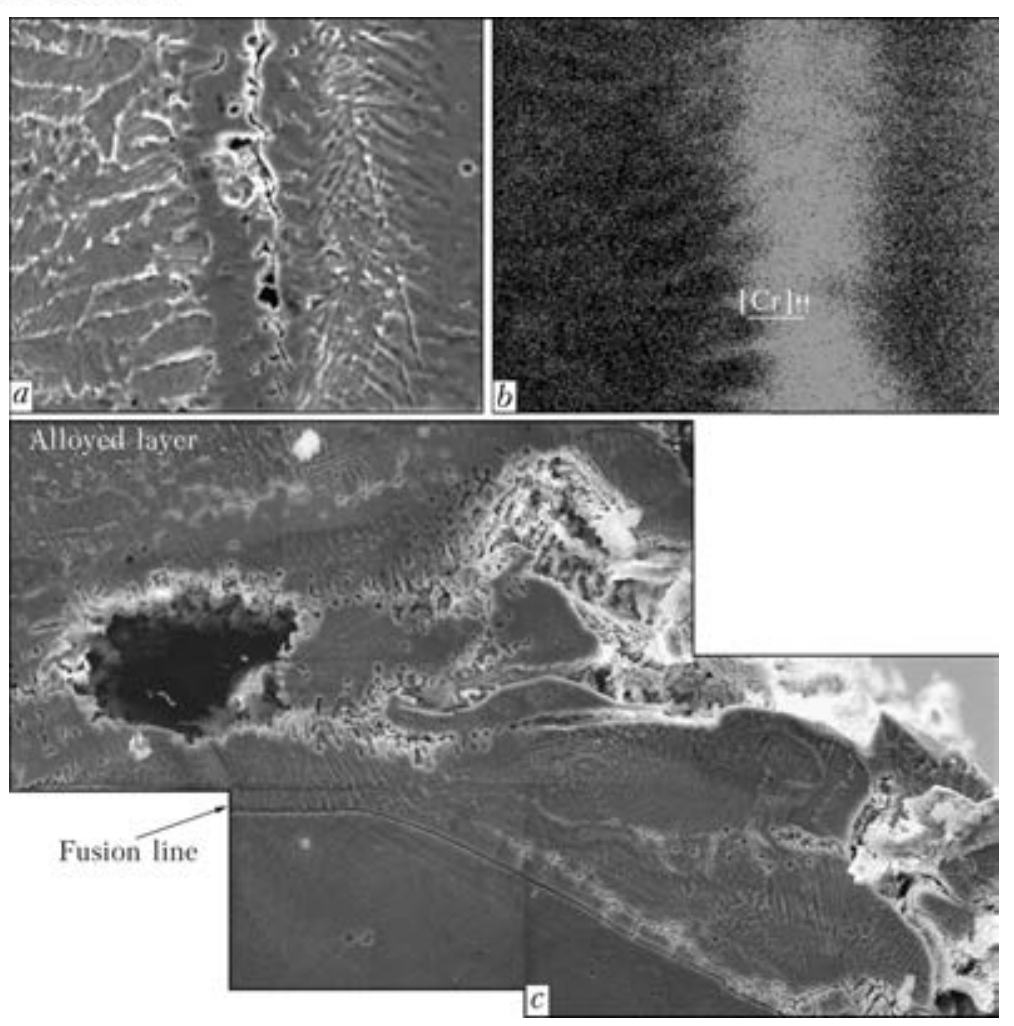

Figure 6. Microstructure of alloyed layer with microcrack in central zone $(a-\times 1500)$, distribution of chromium along given crack $(b-\times 1500)$, and microstructure of alloyed layer with microcrack in area of fusion line $(c-\times 1200)$ in the case of application of laser treatment method

Increase of irradiation power to $4.4 \mathrm{~kW}$ promotes reduction of thickness of the alloyed layer from 2.70 to $1.50 \mathrm{~mm}$ with rise of treatment speed from 24 to $42 \mathrm{~m} / \mathrm{h}$. Metal of the alloyed layer has defined crystalline structure (as in the case of alloying at $P=3.5 \mathrm{~kW}$ ), having large extension (elongation) at average shape coefficient $\kappa=10$ for all cases of treatment speeds. This is approximately 2 times higher in comparison with the structural variations observed in alloying using $3.5 \mathrm{~kW}$ power.

Reduction of hardness of the microalloyed layer on average to $26 \%$ is also observed depending on increase of alloying speed at $P=4.4 \mathrm{~kW}$. At that, for all cases of applied alloying speeds, the microhardness gradient $\Delta H V$ in the fusion line (namely, $\Delta H V$ between alloyed layer and base metal) reduces with increase of speed of laser alloying from 24 to $36 \mathrm{~m} / \mathrm{h}$. However, rapid rise of the microhardness gradient is observed in the case of maximum speed $42 \mathrm{~m} / \mathrm{h}$.

Investigation of concentration variations along the transfer zone, the size of which reduces from 60 to $40 \mu \mathrm{m}$ for $P=4.4 \mathrm{~kW}$ (at speed changing from 24 to $42 \mathrm{~m} / \mathrm{h}$ ), showed insignificant variations of iron concentration in the alloyed layer $\rightarrow$ fusion zone $\rightarrow$ base metal transfer. Distribution of chromium concentration varies from 8 to $13 \%$ in the alloyed layer with rise of speed, with gradual reduction, approximately, to $8 \%$ in the transfer zone in approaching to the fusion line. Tungsten distribution also changes from 2 to $5 \%$ in the alloyed layer in the case of rise of laser alloying speed, and its concentration in the transfer zone gradually reduces, approximately, 2 times at transfer to the fusion line.

As for the presence of cracks and factors, related with crack formation, then the investigations determined presence of microcracks (in all investigated areas), length of which reduce from 500 to $40 \mu \mathrm{m}$ with increase of the treatment speed (see Figure 6) in all specimens, obtained with $P=4.4 \mathrm{~kW}$. At that, the zone of crack formation exhibits a rise of chromium concentration from 17 to $26 \%$ with increase of alloying speed, and content of tungsten remains at the level of 1.0$4.5 \%$ in all modes.

Laser-microplasma alloying. The following was determined in relation to structural-phase and concentration variations, and conditions of crack formation in the surfaces of 38KhN3MFA steel, treated by combined laser-microplasma source using constant $P=3 \mathrm{~kW}$, but at different speed (from 30 to $45 \mathrm{~m} / \mathrm{h}$ ) in deposition of different number of paths.

Thickness of the alloyed layers, obtained by method of laser-microplasma alloying, reduces from 1.75 to $1.58 \mathrm{~mm}$ with rise of alloying speed. Metal of alloyed surface layer, similar to laser 


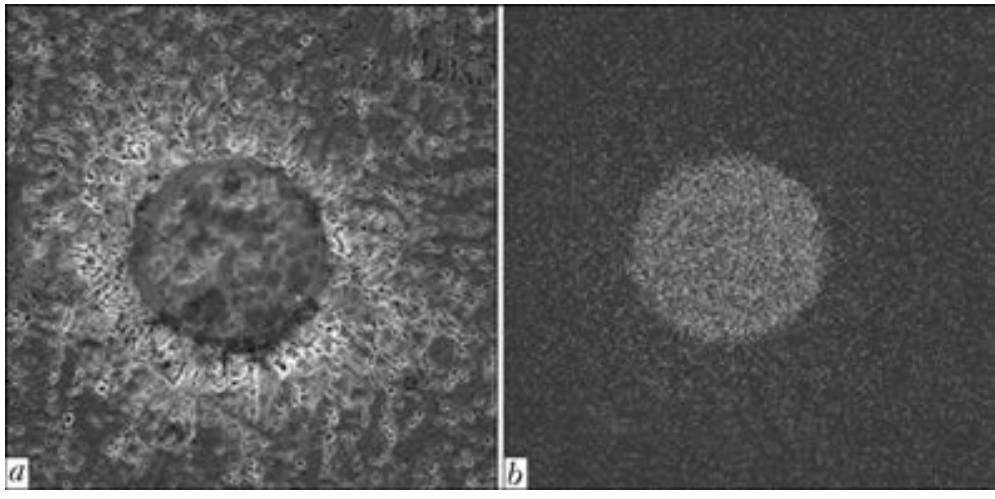

Figure 7. Microstructure $(\times 1010)$ of surface layer with $\mathrm{WC}-\mathrm{W}_{2} \mathrm{C}$ inclusions in laser-microplasma alloying: $a-$ appearance of inclusions; $b-$ maps of tungsten distribution in these inclusions

treatment, has defined crystalline structure, but differ by more equiaxed and fine grain crystalline particles (see Figure $3, b$ ) and coefficient of their shape rises from 4 at $v=30 \mathrm{~m} / \mathrm{h}$ to 8 at $45 \mathrm{~m} / \mathrm{h}$.

It should be noted that width of HAZ area, forming in the fusion line from $38 \mathrm{KhN} 3 \mathrm{MFA}$ steel side, reduces from 1.65 to $1.25 \mathrm{~mm}$ with increase of alloying speed in contrast to laser treatment, where this area rises on the contrary. HAZ metal microstructure, as in laser treatment, is mainly martensite, but characterizes by $20-30 \%$ reduction of microhardness under conditions of rise of alloying speed and deposition of several overlap paths.

Investigations of concentration variations showed insignificant change on iron in all studied areas (from outer surface to base metal). At that, distribution of chromium in the alloyed layer changes from 6 to $18 \%$ depending on increase of alloying speed and number of deposited paths, and tungsten distribution in the alloyed layer varies from $2-3$ to $8 \%$, respectively.

Alloyed layer, obtained by laser-microplasma alloying method, at all alloying speeds (as well as in laser alloying) demonstrates presence of inclusions, the volume fraction of which rises from 1 to $10 \%$ with increase of alloying speed from 30 to $45 \mathrm{~m} / \mathrm{h}$, respectively. These inclusions

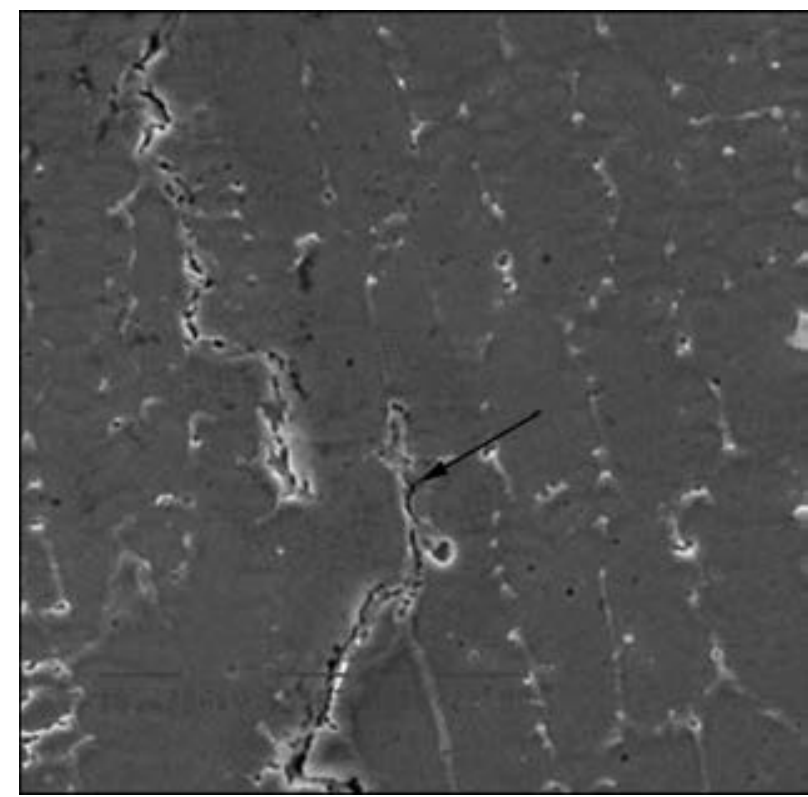

Figure 8. Microstructure $(\times 1550)$ of surface layer with microcrack after laser-microplasma alloying

have $50-230 \mu \mathrm{m}$ size and consist mainly of $\mathrm{WC}-$ $\mathrm{W}_{2} \mathrm{C}$ with tungsten content on average $97 \%$ (Figure 7).

The investigation also determined presence of microcracks (volume fraction $V_{\text {cr }}$ from 3 to $30 \%$ ) under conditions of laser-microplasma alloying. However, in contract to modes of laser alloying,

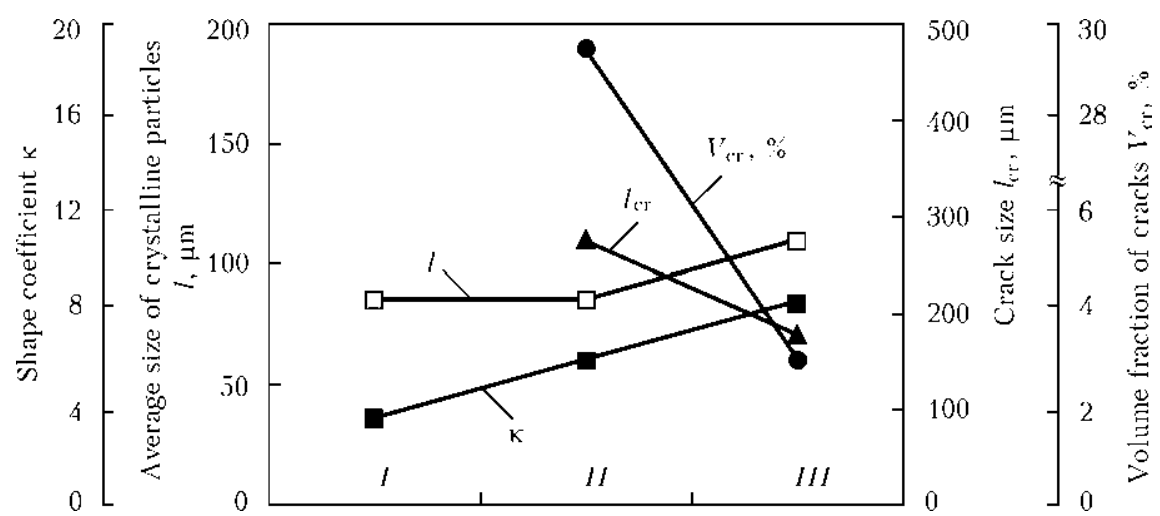

Figure 9. Comparative diagram of structural parameters and microcracks in alloyed layer after laser-microplasma treatment: $I-P=3 \mathrm{~kW}, v=30 \mathrm{~m} / \mathrm{h}$, deposition of 1 path; $I I-P=3 \mathrm{~kW}, v=30 \mathrm{~m} / \mathrm{h}$, deposition of 4 paths; $I I I-P=$ $=3 \mathrm{~kW}, v=45 \mathrm{~m} / \mathrm{h}$, deposition of 3 paths 
such defects are observed only in the alloyed layer along crystalline particle boundaries (Figure 8), and they are virtually absent in the zone of fusion line, that indicate good cohesion of the alloyed layer with $38 \mathrm{KhN} 3 \mathrm{MFA}$ steel. Increase of chromium content to $12-20 \%$ is registered in the areas of crack formation. It should be specifically outlined that no microcracks are present $\left(\mathrm{Fi}^{-}\right.$ gure 9) in the case of laser-microplasma alloying with $v=30 \mathrm{~m} / \mathrm{h}$ (one path).

Thus, it was determined at present stage of investigation that the most optimum structural parameters of the alloyed layer are formed using $P=3.5 \mathrm{~kW}$, and $v=30 \mathrm{~m} / \mathrm{h}$ mode for laser alloying, and $P=3 \mathrm{~kW}, v=30 \mathrm{~m} / \mathrm{h}$ for lasermicroplasma alloying (deposition of one path).

\section{Conclusions}

1. Susceptibility to crack formation of specimens from 38KhN3MFA steel in laser and laser-microplasma alloying is caused, first of all, by structural (size of crystalline particles, coefficient of their shape) and concentration variations, related with redistribution of elements, in particular, chromium, that results in formation of sharp grain boundary concentration gradients.
2. Absence of microcracks in the fusion zone during laser-microplasma method allows making a conclusion about its perspective for parts manufactured from 38KhN3MFA steel.

3. It was determined, at present stage of investigation, that the most optimum structural parameters of the alloyed layer are formed using $P=3.5 \mathrm{~kW}$ and $v=30 \mathrm{~m} / \mathrm{h}$ mode for laser alloying, and $P=3 \mathrm{~kW}, v=30 \mathrm{~m} / \mathrm{h}$ for lasermicroplasma alloying (one path).

1. Isaev, G.P. (2002) Laser-ion alloying of metals and alloys. Vestnik KamchatGTU, 1, 160-164.

2. Lakhtin, Yu.M., Leontieva, V.P. (1980) Materials science: Manual for institutions of higher education. Moscow: Mashinostroenie.

3. Petrova, L.G. (2010) Practical application of models of chemical-heat treatment for development of surface strengthening technologies. Vestnik KharkovNADI, 51, 26-34.

4. Grigoriants, A.G. (1989) Principles of laser treatment of materials. Moscow: Mashinostroenie.

5. Grigoriants, A.G., Shiganov, I.N., Misyurov, A.I. (2006) Technological processes of laser treatment: Manual for institutions of higher education. Moscow: N.E. Bauman MGTU.

6. Grabin, V.F. (1982) Metals science of fusion welding. Kiev: Naukova Dumka.

Received 30.09.2013 


\title{
PECULIARITIES OF STRUCTURE OF COATINGS OF Fe-Cr-Al SYSTEM FLUX-CORED WIRE PRODUCED UNDER CONDITIONS OF SUPERSONIC ELECTRIC ARC METALLIZATION
}

\author{
V.N. KORZHIK, A.L. BORISOVA, G.N. GORDAN, N.P. LYUTIK, A.A. CHAJKA and T.V. KAJDA \\ E.O. Paton Electric Welding Institute, NASU
}

11 Bozhenko Str., 03680, Kiev, Ukraine. E-mail: office@paton.kiev.ua

\begin{abstract}
To increase the efficiency of application of method of supersonic electric arc metallization (EAM) the investigations of structure and phase composition of coatings of flux-cored wire of the system $\mathrm{Fe}-\mathrm{Cr}-\mathrm{Al}$ were carried out in the frames of this work. Presented are the results of investigations of coatings produced by EAM method using the conventional and modified installation EM-14 and also installation PLAZER 15-SA for supersonic electric arc spraying. It is shown that use of supersonic gas jets at EAM allows significant improvement of coating quality, i.e. provides higher level of homogeneity and fine dispersion of structure (the thickness of lamellas is decreased from 10-30 to 5-10 $\mu \mathrm{m}$ ), decreases porosity by 3-5 times, decreases oxides content by $2-3$ times, $30-50 \%$ increases the hardness. The formation of solid solution of chromium and aluminium in iron with increased content of chromium at supersonic EAM is a precondition for ensuring the heat resistance of developed coatings of up to $1350{ }^{\circ} \mathrm{C}$, which allows considerably expanding the scales of application of this method in deposition of protective coatings. 10 Ref., 3 Tables, 6 Figures.
\end{abstract}

$\boldsymbol{K} \boldsymbol{e} \boldsymbol{y} \boldsymbol{w} \boldsymbol{O} \boldsymbol{r} \boldsymbol{s}:$ electric arc metallization, supersonic method, coating, microstructure, phase composition, microhardness

Gas thermal methods of spraying (GTS), first of all gas-flame, plasma, detonation and electric arc metallization (EAM), belong to the basic methods of deposition of protective and restoration coatings, providing the highest economy of metal under the conditions of mass production. Among the mentioned methods the EAM is the simplest, the most efficient and the cheapest one. Thus, according to the existing technical and economic evaluation, the coatings produced using EAM method are 3-10 times cheaper than those produced using other gas thermal methods, like plasma, detonation spraying, etc. [1].

The assortment of wire materials for GTS, including wires of ferrous and non-ferrous metals of solid section, restricted the field of EAM application. Application of flux-cored wires for EAM allowed considerable expanding of scales of application for the given EAM method due to formation of structure with the new physical and chemical properties providing their improved resistance to wear and corrosion. As, for example, is followed from works [2, 3], the use of fluxcored wire systems $\mathrm{Fe}-\mathrm{Cr}-\mathrm{C}$ and $\mathrm{Fe}-\mathrm{Cr}-\mathrm{Al}$ allowed controlling the chemical and phase compositions of coatings within the wide ranges and, consequently, their operation properties.
The authors of these works established that during arc metallization the matrix phase of coating is a solid solution of chromium or chromium with aluminium in $\alpha$ - or $\gamma$-Fe. In the coatings of $\mathrm{Fe}-\mathrm{Cr}$ the $\gamma$-phase prevails, and $\alpha$-phase - in the coating of $\mathrm{Fe}-\mathrm{Cr}-\mathrm{Al}$ system.

The field of application of GTS methods is restricted not always by insufficient strength of bond of coating with the base, and also low mechanical strength of the coating, the reason of which is insufficient energy input to the zone of formation of joining of particles with the base and between each other, that at a short period of hard-phase interaction process proceeding $\left(10^{-3}-10^{-4} \mathrm{~s}\right)$, which controls the formation of forces of adhesion of coating with the base [4], a number of atoms, participating in it, is restricted. At the same time, the realization of GTS process in the air predetermines the formation of oxide films on the sprayed particles and surface of forming coating, which leads to considerable increase of energy for activation of the process of interaction and to embrittlement of sprayed material. In this connection at the present time the modernization of GTS methods is performed due to application of supersonic gas jets (of speeds up to 2-3 M) with increase of kinetic energy of particles being sprayed [5].

On the basis of application of supersonic jets of combustion products of gaseous and liquid fuel 
Table 1. Technological conditions of spraying the coatings using EAM method with flux-cored wire of $1.8 \mathrm{~mm}$ diameter of system $\mathrm{Fe}-\mathrm{Cr}-\mathrm{Al}$

\begin{tabular}{|c|c|c|c|c|c|c|}
\hline Type of installation & Voltage, V & Current, A & $\begin{array}{c}\text { Air } \\
\text { consumption, } \\
\mathrm{m}^{3} / \mathrm{h}\end{array}$ & $\begin{array}{c}\text { Propane } \\
\text { consumption, } \\
\mathrm{m}^{3} / \mathrm{h}\end{array}$ & $\begin{array}{c}\text { Air pressure, } \\
\mathrm{MPa}\end{array}$ & $\begin{array}{c}\text { Spraying } \\
\text { distance, mm }\end{array}$ \\
\hline \multicolumn{7}{|c|}{ Conventional electric arc spraying } \\
\hline Basic installation EM-14 & $32-34$ & $200-250$ & $120-130$ & - & $0.6-0.7$ & $150-180$ \\
\hline \multicolumn{7}{|c|}{ Modified electric arc spraying } \\
\hline Modified installation EM-14 & $32-34$ & $200-250$ & $120-130$ & - & $0.6-0.7$ & $150-180$ \\
\hline \multicolumn{7}{|c|}{ Supersonic electric arc spraying } \\
\hline Installation PLAZER15-SA & $34-36$ & $160-180$ & 90 & 4.0 & 0.6 & $70-130$ \\
\hline
\end{tabular}

the method of high-speed gas-plasma spraying (HVOF) with design of specialized equipment for its realization was developed [6]. Nowadays HVOF technology finds ever wider practical application due to possibility of producing coatings with high values of density and strength of their adhesion with the base.

The other trend in development of supersonic GTS technologies realized within the joint works of the E.O. Paton Electric Welding Institute and the Gas Institute of the NASU is connected with the development and application of plasmatrons using the combustion products of mixture of air with gas fuel as a working plasma gas [7]. The investigation of properties of the coatings produced in such a way showed the possibility of increasing the strength of adhesion of coatings (up to $150 \mathrm{MPa}$ ), decreasing their porosity and level of oxidation [7].

In the course of development of this trend at the PWI together with the Scientific and Technical Centre PLASER Ltd. and VISP Ltd. the technology was developed and the installation PLAZER15-SA for supersonic electric arc spraying was created $[8,9]$. The technology of supersonic EAM overcomes the basic disadvantages of the electric arc spraying method, connected with the low quality of coatings. The installation provides formation of a supersonic gas jet. The supersonic flow of combustion products of propane-

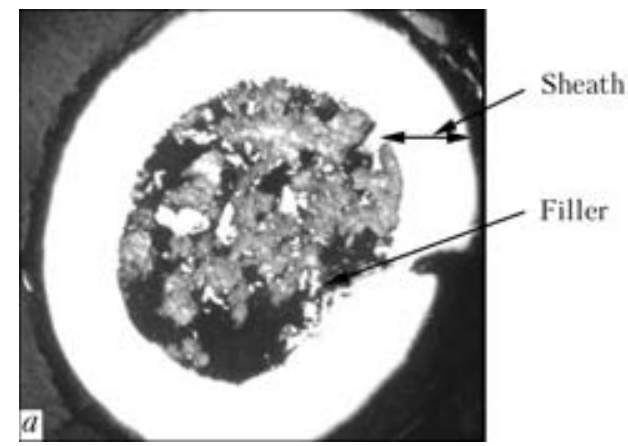

air mixture, directed to the arc zone, disperses the melt and transports the sprayed metal to the base. Using the installation PLAZER 15-SA, the size of molten particles remains by $90 \%$ in the range of $30-80 \mu \mathrm{m}$, which are transformed to the discs of $5-10 \mu \mathrm{m}$ thickness during deformation on the surface. The jet of combustion products almost does not contain oxygen and protects molten metal from oxidation in the arc zone. In the process of deposition of coating the part is heated for not more than up to $150{ }^{\circ} \mathrm{C}$. This guarantees the absence of the part deformation.

The aim of this work is the investigation of peculiarities of structure-phase state of coatings of flux-cored wire of the system $\mathrm{Fe}-\mathrm{Cr}-\mathrm{Al}$ produced using supersonic EAM method. The comparative investigations of coating of flux-cored wire produced using conventional basic installation EM-14, modified basic installation EM-14 with applying secondary air flow and adjustable angle of opening the particles flow and installation PLAZER15-SA for supersonic EAM.

Methods of investigations and initial materials. The investigations of structure of coatings were carried out using methods of metallography (microscope «Neophot-32»), X-ray spectral microanalysis (microanalyser CAMEBAX), X-ray diffraction phase analysis (diffractometer DRON-UM1, monochromatic $\mathrm{Cu} K_{\alpha}$-radiation). The porosity of coatings was determined in the

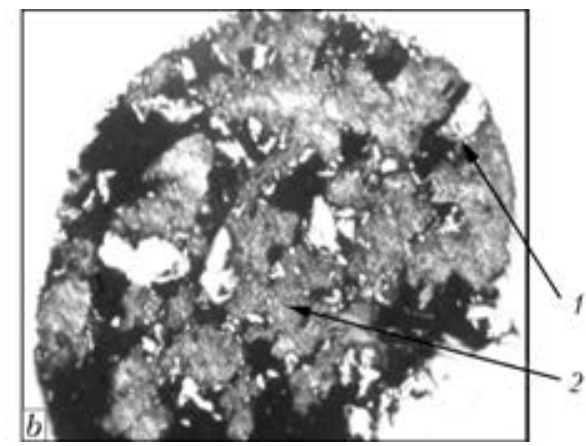

Figure 1. Microstructure $(\times 50)$ of cross section of wire $(a)$, microstructure $(\times 100)$ of filler of $16.6 \mathrm{Fe}, 82.8 \mathrm{Cr}, 0.36 \mathrm{Al}$, $0.2 \mathrm{Mn}(1)$ and $0.36 \mathrm{Fe}, 0.2 \mathrm{Cr}, 99.67 \mathrm{Al}, 0.07 \mathrm{Mn}$ (2) composition 


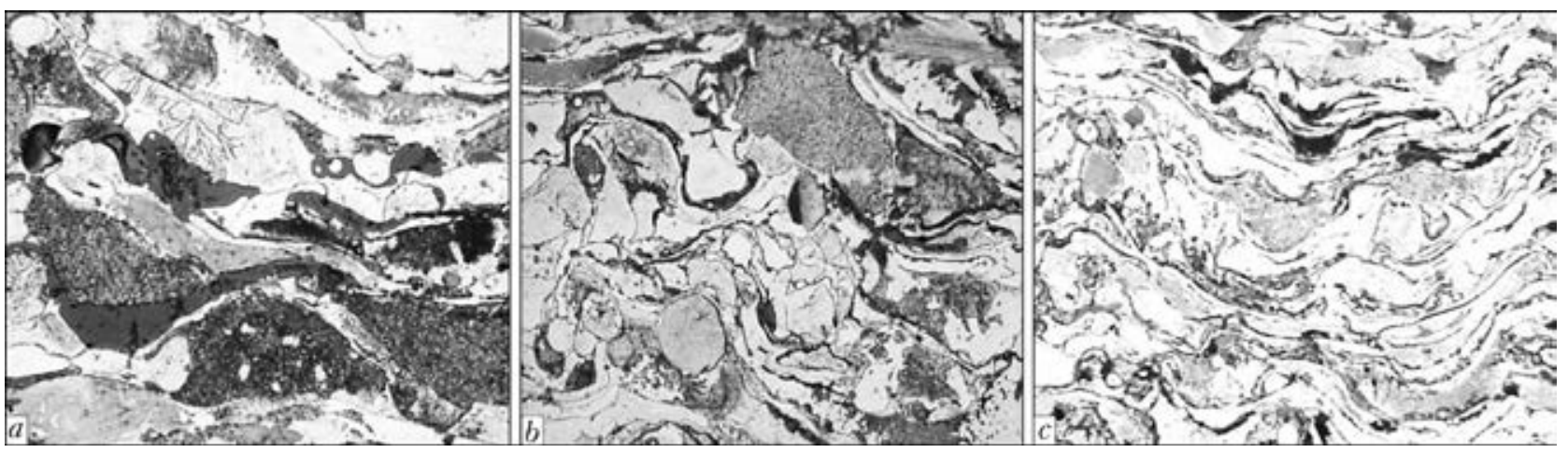

Figure 2. Microstructure $(\times 400)$ of coatings of the $\mathrm{Fe}-\mathrm{Cr}-\mathrm{Al}$ system flux-cored wire produced using different EAM methods: $a$ - conventional; $b-$ modified; $c-$ supersonic spraying

device OMNIMET, microhardness of specimens was measured in the LECO microhardness meter at the indenter loading of $0.25 \mathrm{~N}$.

As a material for spraying the flux-cored wire of the system $\mathrm{Fe}-\mathrm{Cr}-\mathrm{Al}$ was applied. The conditions of coatings spraying are given in Table 1.

Results of work. Investigated was the chemical composition and microstrucutre of initial flux-cored wire and coatings, produced using EAM methods with subsonic and supersonic jets. The flux-cored wire of the system $\mathrm{Fe}-\mathrm{Cr}-\mathrm{Al}$ is composed of a sheath (08kp steel strip) and filler (Figure 1, $a$ ). The composition of a sheath of the flux-cored wire is, wt.\%: $99.2 \mathrm{Fe} ; 0.45 \mathrm{Cr} ; 0.2 \mathrm{Al}$; $0.2 \mathrm{Mn}$. Filler of the wire is composed of mixture of powders $\mathrm{FeCr}$ and $\mathrm{Al}$ with the size of particles of up to $150 \mu \mathrm{m}$. Microstrucutre and composition of filler are presented in Figure 1, $b$.

The analysis of results of metallographic investigations of coatings showed that microstructure at subsonic speeds of air outflow is heterogeneous, coarse-grain, with great number of pores and oxide inclusions. Material of coating is overheated and oxidized, oxide interlayers contain 29-32\% of oxygen, mass fraction of oxygen in lamellas reaches $2.5 \%$ (Figure 2, $a$ ). The particles of spherical shape are also observed, which due

Table 2. Phase composition of coatings produced using different methods of spraying using flux-cored wire of $\mathrm{Fe}-\mathrm{Cr}-\mathrm{Al}$ system

\begin{tabular}{|c|c|c|}
\hline Spraying method & Phase $(a, \mathrm{~nm})$ & $\begin{array}{c}\text { Content, } \\
\text { wt.\% }\end{array}$ \\
\hline \multirow[t]{3}{*}{ Conventional } & S.s. of $\mathrm{Cr}$ and $\mathrm{Al}$ in $\alpha-\mathrm{Fe}(0.2879)$ & 53.36 \\
\hline & S.s. of $\mathrm{Cr}$ and $\mathrm{Al}$ in $\gamma$-Fe $(0.3627)$ & 23.70 \\
\hline & $\mathrm{Al}_{2} \mathrm{O}_{3}(0.7916)$ & 22.93 \\
\hline \multirow{3}{*}{$\begin{array}{l}\text { Conventional } \\
\text { modified }\end{array}$} & S.s. of $\mathrm{Cr}$ and $\mathrm{Al}$ in $\alpha-\mathrm{Fe}(0.2875)$ & 57.08 \\
\hline & S.s. of $\mathrm{Cr}$ and $\mathrm{Al}$ in $\gamma_{1}-\mathrm{Fe}(0.3677)$ & 8.58 \\
\hline & S.s. of $\mathrm{Cr}$ and $\mathrm{Al}$ in $\gamma_{2}-\mathrm{Fe}(0.36305)$ & 34.34 \\
\hline \multirow[t]{3}{*}{ Supersonic } & S.s. of $\mathrm{Cr}$ and $\mathrm{Al}$ in $\alpha-\mathrm{Fe}(0.2870)$ & 22.39 \\
\hline & S.s. of $\mathrm{Cr}$ and $\mathrm{Al}$ in $\gamma_{1}-\mathrm{Fe}(0.3677)$ & 28.05 \\
\hline & S.s. of $\mathrm{Cr}$ and $\mathrm{Al}$ in $\gamma_{2}-\mathrm{Fe}(0.3633)$ & 49.56 \\
\hline
\end{tabular}

to a low speed of flying managed to cool down before their collision with the surface being sprayed (Figure 3 ).

The coating, produced using the modified basic installation applying the additional air flow and adjustable angle of opening the particles flow, is less oxidized. In the lamellas and oxide interlayers the mass fraction of oxygen amounts, respectively, to $1.6-1.8$ and $29-30 \%$. The thickness of lamellas $\delta$ for these coatings is the same as under the conventional subsonic conditions and equal to $10-30 \mu \mathrm{m}$ (Figure 2, b), porosity of coatings amounts to $2-3 \%$.

In transition to supersonic air-gas EAM method, with increase in the rate of air flow, the speed of flying particles increases and microstructure of the produced coating is subjected to considerable changes. Combination of small size of sprayed particles with their high speeds at the moment of collision with the base surface leads to high speeds of their material cooling. In general, the particles have lamella-like shape and are subjected to significant deformations. The inclusions of globular particles are not observed. Thin

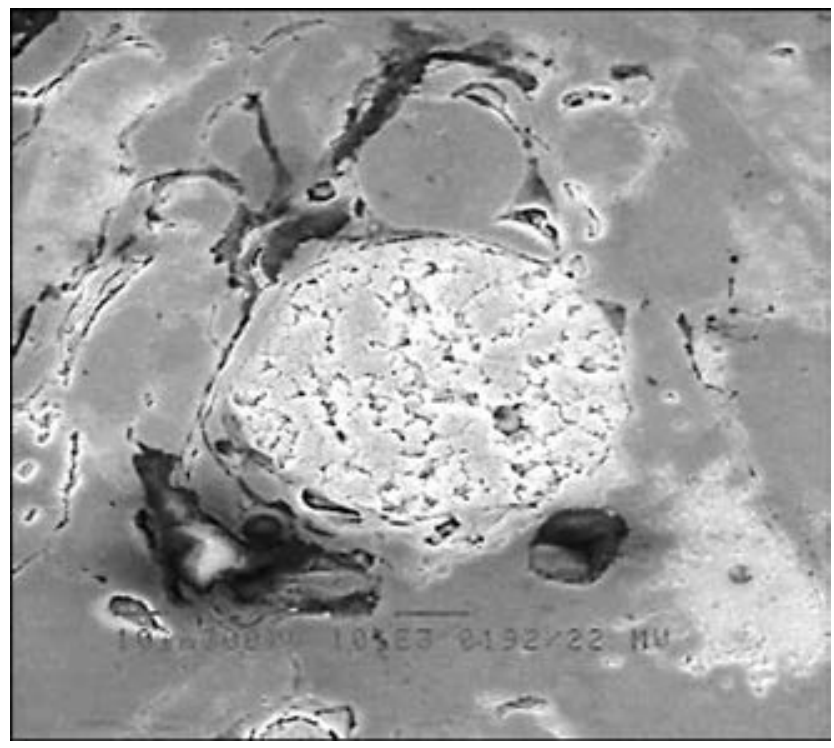

Figure 3. Appearance of single particle in the $\mathrm{Fe}-\mathrm{Cr}-\mathrm{Al}-$ system coating in EAM $(\times 1000)$ 

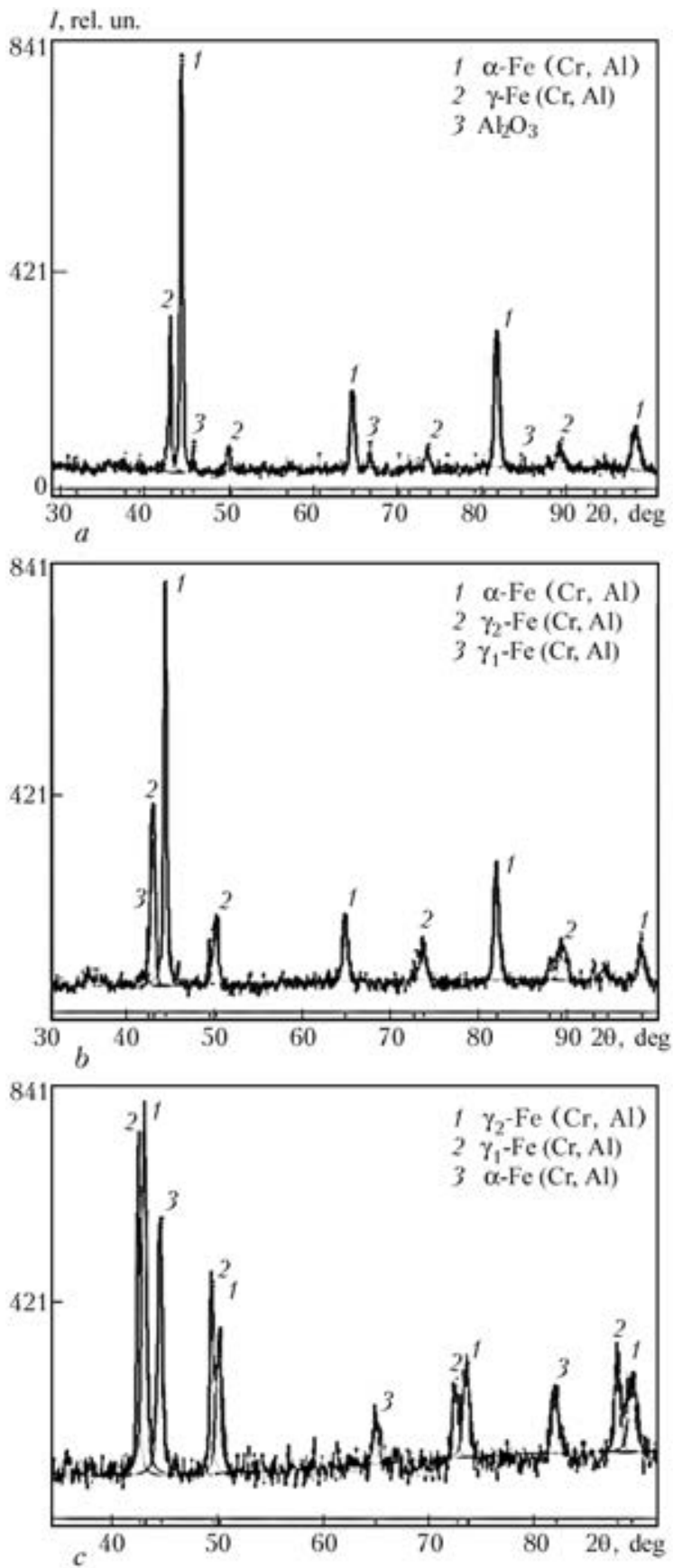

Figure 4. Diffractograms of the $\mathrm{Fe}-\mathrm{Cr}-\mathrm{Al}$ coatings produced using different EAM methods: $a-$ conventional; $b-$ modified; $c$ - supersonic spraying

oxide interlayers are noted. Across the whole thickness the coatings have homogeneous thinlamellar structure, which evidences of the process stability. In the coatings deposited at supersonic air-gas spraying, $\delta=5-10 \mu \mathrm{m}$ (Figure $2, c$ ). Porosity of the structure is decreased and amounts to $0.4 \%$.

It follows from the analysis of results of X-ray spectral microanalysis and diffractograms of the coatings (Table 2, Figures 4 and 5) that all the investigated coatings produced using methods of conventional subsonic EAM, modified and supersonic EAM contain solid solution (S.s.) of alu-
Table 3. Composition of the $\mathrm{Fe}-\mathrm{Cr}-\mathrm{Al}$ system coating in different EAM methods

\begin{tabular}{|c|c|c|c|c|}
\hline \multirow{2}{*}{ Coating area } & \multicolumn{4}{|c|}{ Content of elements in different coating areas, wt.\% } \\
\hline & $\mathrm{Al}$ & $\mathrm{Cr}$ & $\mathrm{Fe}$ & $\mathrm{O}$ \\
\hline \multicolumn{5}{|c|}{ Subsonic conventional spraying } \\
\hline $\begin{array}{c}\text { Grey } \\
\text { lamellas }\end{array}$ & $5.0-5.2$ & $14.0-15.0$ & 78 & $1.9-2.5$ \\
\hline $\begin{array}{c}\text { White } \\
\text { lamellas }\end{array}$ & $3.5-4.0$ & $16.8-17.1$ & 80 & 0 \\
\hline $\begin{array}{c}\text { Oxide } \\
\text { interlayers }\end{array}$ & $35.0-39.0$ & $6.0-7.0$ & 30 & $29.0-32.0$ \\
\hline \multicolumn{5}{|c|}{ Subsonic modified spraying } \\
\hline $\begin{array}{c}\text { Grey } \\
\text { lamellas }\end{array}$ & $6.0-6.2$ & $15.0-15.4$ & $75-76$ & $1.6-1.8$ \\
\hline $\begin{array}{c}\text { White } \\
\text { lamellas }\end{array}$ & 5.9 & $13.0-14.5$ & 80 & 0 \\
\hline $\begin{array}{c}\text { Oxide } \\
\text { interlayers }\end{array}$ & $37.0-39.0$ & $5.0-6.0$ & $26-27$ & $29.0-30.0$ \\
\hline \multicolumn{5}{|c|}{ Supersonic spraying } \\
\hline $\begin{array}{c}\text { Grey } \\
\text { lamellas }\end{array}$ & $4.8-5.6$ & $16.9-20.5$ & $75-76$ & $1.2-1.3$ \\
\hline $\begin{array}{c}\text { White } \\
\text { lamellas }\end{array}$ & $6.0-6.2$ & $20.0-20.5$ & $75-73$ & $0-0.4$ \\
\hline $\begin{array}{c}\text { Oxide } \\
\text { interlayers }\end{array}$ & $18.0-23.0$ & $10.6-14.0$ & $50-55$ & $11.5-17.0$ \\
\hline
\end{tabular}

minium and chromium in $\alpha-\mathrm{Fe}$ (BCC lattice with atomic radius $a=0.2879 \mathrm{~nm}$ ), and solid solutions of aluminium and chromium in $\gamma$-Fe with FCC lattice and different content of these elements. According to the data of X-ray spectral microanalysis at conventional arc and modified metallization a solid solution of chromium with aluminium in $\alpha-\mathrm{Fe}$ is prevailed, while in case of supersonic EAM the $\gamma$-phase is the main phase in the coatings. At supersonic and modified EAM the phase $\gamma$-Fe component with changed parameters exists in two modifications, namely: $\gamma_{1}-\mathrm{Fe}(\mathrm{Cr}, \mathrm{Al})$ with $a=0.3677 \mathrm{~nm}$, and $\gamma_{2}-\mathrm{Fe}(\mathrm{Cr}, \mathrm{Al})$ with $a=$ $=0.3633 \mathrm{~nm}$ (Figure 4, b,c).

The difference in values of parameters of lattice of $\gamma_{1}$-Fe and $\gamma_{2}$-Fe evidences of different content of alloying elements. The distribution of alloying elements was investigated on the sections, approximately in the central part of coatings, in the depth, perpendicularly to the interface of coatings with the base. The content of elements in the coating is given in Table 3 and Figure 5. It was established that maximum concentration of chromium in the Fe-based solid solution in lamellas of coatings, produced at conventional and modified spraying, amounts to $16.8-17.1$ and 15.0-15.4 wt.\% respectively, under the same conditions the content of aluminium amounts ap- 

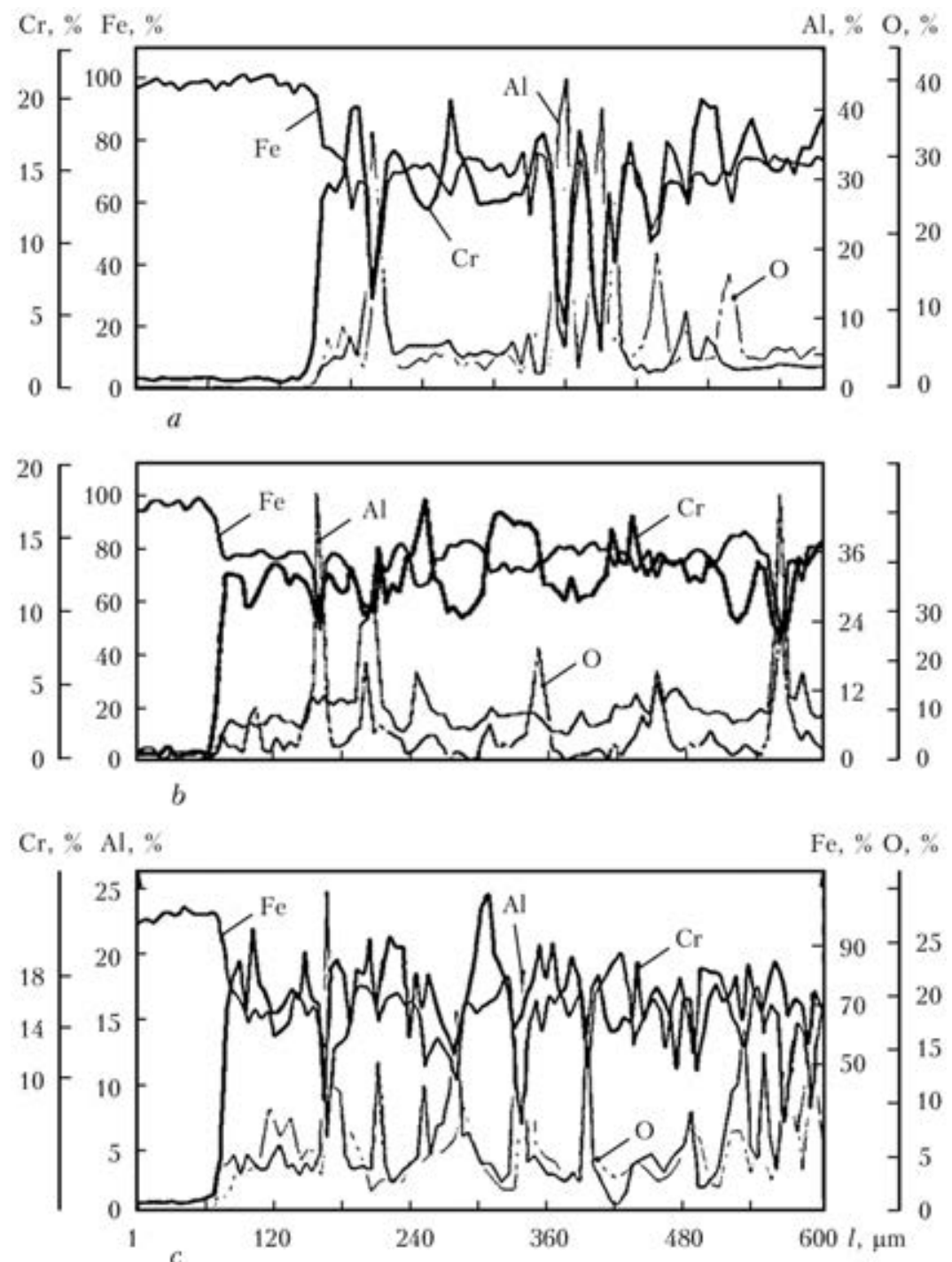

Figure 5. Distribution of alloying elements across the thickness of coatings produced using different EAM methods: $a-$ conventional; $b-$ modified; $c-$ supersonic

proximately from 4.0 to $6.2 \%$. Moreover, in the process of spraying the aluminium interacts with oxygen, the inclusions are formed on the base of $\mathrm{Al}_{2} \mathrm{O}_{3}$ containing 35-39 wt.\% $\mathrm{Al}$ and 2932 wt.\% O.

While using supersonic jets the turbulent mode of jets flowing out transfers to laminar one, thus decreasing the air entry to the mixture and simultaneously increasing the rate of particles due to increase in speed of gas jet.

During supersonic spraying the amount of chromium and aluminium solved in iron increases, maximum concentration of chromium in lamellas reaches 20.0-20.5 wt.\%. A solid solution of such concentration is characterized by a high resistance to oxidation by air oxygen. The level of oxidation of sprayed coating is considerably decreased. In lamellas the content of oxygen is about $1 \%$.

If to compare the obtained results of X-ray diffraction phase analysis and X-ray spectral mi-

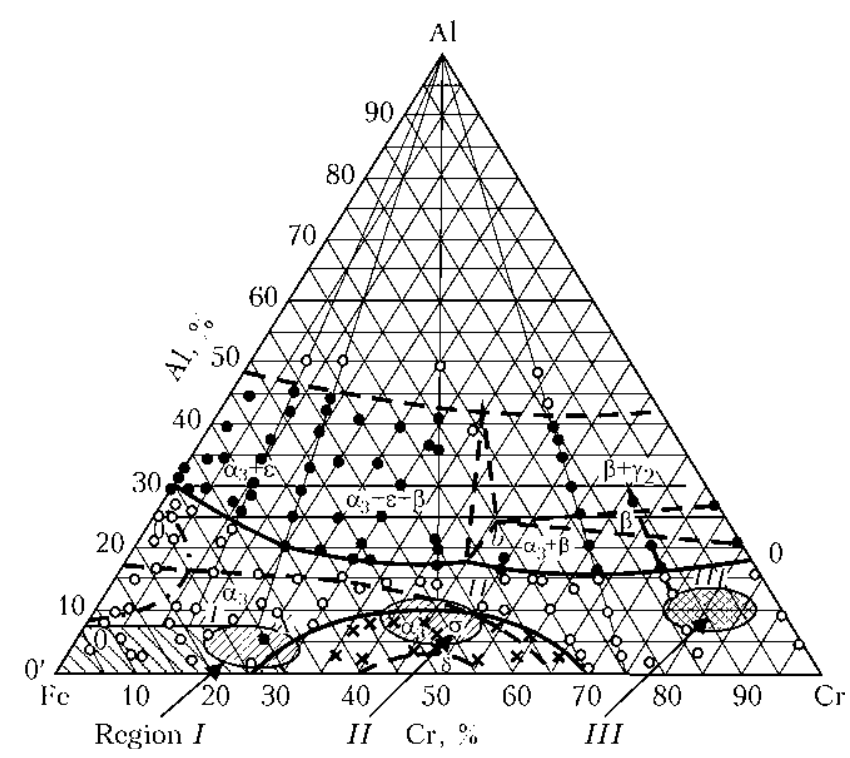

Figure 6. Diagram of $\mathrm{Fe}-\mathrm{Cr}-\mathrm{Al}$ phase equilibrium (for designations see the text) 
croanalysis of the coating, produced at supersonic EAM, with the region of ternary diagram $\mathrm{Fe}^{-}$ $\mathrm{Cr}-\mathrm{Al}$ (Figure 6) by the chemical composition corresponding to the composition of investigated coating, then the coating gets to the designated high-temperature region $I$, which provides heat resistance up to the temperature of $1350{ }^{\circ} \mathrm{C}$ [10].

Thus, at the increased content of up to $20.5 \% \mathrm{Cr}$ and $6.2 \% \mathrm{Al}$ in the Fe solid solution, the heat resistance of coatings produced in supersonic EAM up to $1350{ }^{\circ} \mathrm{C}$ is provided.

Comparison of values of microhardness of coatings of flux-cored wire, sprayed using different methods, shows that microhardness of coating produced in conventional EAM is changed in the limits from 1930 to $4200 \mathrm{MPa}$, microhardness of coating produced using modified installation is changed from 2540 to $5100 \mathrm{MPa}$. Maximum microhardness belongs to the supersonic coatings where the range of values is in the limits of 3900$6100 \mathrm{MPa}$, which can be connected with the increase of chromium content in the Fe-based solid solution.

\section{Conclusions}

As a result of carried out investigations it was found that the process of electric arc air-gas supersonic metallization as compared to the conventional GTS methods allows producing coatings with more homogeneous and fine-grain structure. The thickness of lamellas is 2-3 times decreased due to a small period of contact of molten particles with atmosphere and their high speed, the oxidation of material being sprayed is $2-3$ times decreased, and the porosity is $3-5$ times decreased. Microhardness of coating produced in supersonic EAM exceeds microhardness of sub- sonic coatings approximately by $30-50 \%$. Using $\mathrm{X}$-ray spectral microanalysis and X-ray diffraction phase analysis it was established that strengthening of coatings is provided by formation of oversaturated solid solution of iron with increased content of chromium of up to $20.5 \mathrm{wt} . \%$ and aluminium of up to $6.2 \mathrm{wt} . \%$. The flux-cored wire of the system $\mathrm{Fe}-\mathrm{Cr}-\mathrm{Al}$ allows producing the structure with content of austenite of up to 80 wt.\% in the coatings.

1. Boronenkov, V.N., Korobov, Yu.S. (2012) Bases of arc metallizing. Physical-chemical principles. Ekaterinburg: UralGU.

2. Pokhmursky, V.I., Student, M.M., Dovgunyk, V.M. et al. (2003) Structure and tribotechnical characteristics of coatings produced by electric arc metallizing using flux-cored wires. The Paton Welding J., 8, 12-16.

3. Borisova, A.L., Kajda, T.V., Mits, I.V. (1995) Structure and properties of coatings on ferrochrome and ferrochromealuminium base, produced by electric arc metallizing using flux-cored wires. Avtomatich. Svarka, 6, 3-6.

4. Kudinov, V.V. (1977) Plasma coatings. Moscow: Nauka.

5. Borisov, Yu.S., Petrov, S.V. (1995) Application of supersonic jets in thermal spraying technology. Avtomatich. Svarka, 1, 41-44.

6. Frolov, V.A., Poklad, V.A., Ryabenko, B.V. et al. (2006) Technological peculiarities of methods of supersonic thermal spraying (Review). Svarochn. Proizvodstvo, 11, 38-47.

7. Petrov, S.V., Karp, I.N. (1993) Plasma air-gas spraying. Kiev: Naukova Dumka.

8. Korzhik, V.N., Krivtsun, I.V., Petrov, S.V. et al. (2009) New technology «Plazer» for renovation of railway parts. Remont, Vosstanovlenie, Modernizatsiya, 1, 20-22

9. Petrov, S.V., Korzhik, V.N. (2011) Plazer15-SA installation for electric arc supersonic spraying. Svarshchik, 1, 117-121.

10. Hudremont, E. (1966) Special steels. Moscow: Metallurgiya.

Received 04.07.2013 


\title{
ELECTRON BEAM WELDING OF LARGE-SIZE THICK-WALL STRUCTURES OF MAGNESIUM ALLOYS
}

\author{
V.M. NESTERENKOV and A.A. BONDAREV \\ E.O. Paton Electric Welding Institute, NASU \\ 11 Bozhenko Str., 03680, Kiev, Ukraine. E-mail: office@paton.kiev.ua
}

\begin{abstract}
In the nearest future in erection of space platforms and other large-size thick-wall structures the application of light magnesium alloys will be challenging. Therefore, the investigations on their updating and evaluation of a feasibility of producing the quality welded joints are urgent. In this work the results of experimental investigation of weldability of magnesium MA2 alloy of $100 \mathrm{~mm}$ thickness by electron beam and optimizing the technology of manufacture of large-size structures of this alloy are described. The variants of preparation and treatment of surface of edges to be welded and areas of base metal adjacent to it before welding are offered. From the results of penetration of metal across the whole thickness of the plate and metallographic investigations of peculiarities of weld formation, the optimal conditions of welding by accelerating voltage, beam current, focusing current, scanning parameters, deepening of focal spot and spatial butt position were established. The technical documentation was worked out and ready-metal assembly-welding stand was manufactured to perform assembly for EBW of billets of plates of $3000 \times 3000 \times 100 \mathrm{~mm}$ size. To prevent defects in external formation of joints, it was offered to use cover plates on the face side of a butt and backings on the side of a weld root, which are arranged along the whole length of a butt and manufactured of the same alloy. They should be fastened to the product to be welded on the tacks made by argon arc welding just after assembly on the stand. Considering the results of carried out investigations the plate structure of $3000 \times 3000 \times 100 \mathrm{~mm}$ size was manufactured of magnesium MA2 alloy using EBW. 5 Ref., 3 Tables, 6 Figures.
\end{abstract}

$\boldsymbol{K} \boldsymbol{e} \boldsymbol{y} \boldsymbol{w} \boldsymbol{o} \boldsymbol{r} \boldsymbol{s}:$ electron beam welding, magnesium alloys, large thicknesses, large-size structures, cathodes of welding guns, optimal welding parameters, coefficient of strength of joints, ultrasonic testing

At the present time among the variety of metal structural materials the light nonferrous metals, including also magnesium alloys, are widely applied. The main fields of their application are aircraft and rocket construction and also space vehicles building, where reduction in weight characteristics of the products has a great significance $[1,2]$.

The development of reliable methods for producing permanent welded joints will promote the wider application of magnesium alloys in manufacture of structures of large sizes. The solution of this problem concerns both the sphere of modernization of metallurgy of production of magnesium alloys of different alloying systems themselves and also investigations in the direction of development of technology of their welding using different methods. In the present work the results of investigations on evaluation of principal feasibility of application of magnesium alloy MA2 as applied to the production of large-size thickwall structures for the future space platforms are given.

(c) V.M. NESTERENKOV and A.A. BONDAREV, 2014
The first experiments on optimizing the technology of EBW of MA2 alloy showed the presence of great vapor-gas flow from weld pool. When that flow gets to the cathode spacing, it leads to increasing the pressure and occurrence of electric breakdowns in the gun. Therefore, it is necessary to increase either power of system for pumping out of cathode unit of the gun, which is not always possible to be realized at the operating machines, or working distance between the gun and the workpiece. In our experiments the working distance was set equal to $320 \mathrm{~mm}$.

Negative influence of vapor-gas flow affects also the condition of cathode surface. Aluminium and its oxides getting to the surface of lanthanum-boride cathodes form eutectics, which decrease the emission of electrons. The current beam is changed, which violates the geometry of penetrations. Especially this is observed in producing long welds, characteristic of the joints of billets of space platforms.

Under this reason the metal cathodes with the working temperature of $2800{ }^{\circ} \mathrm{C}$ find ever wider application during recent time, due to which the evaporation of metal particles from the surface of cathodes and prevention of cathodes metallization occur. The main difficulties in use of hightemperature metal cathodes are connected with high power of cathode heating and life of insu- 


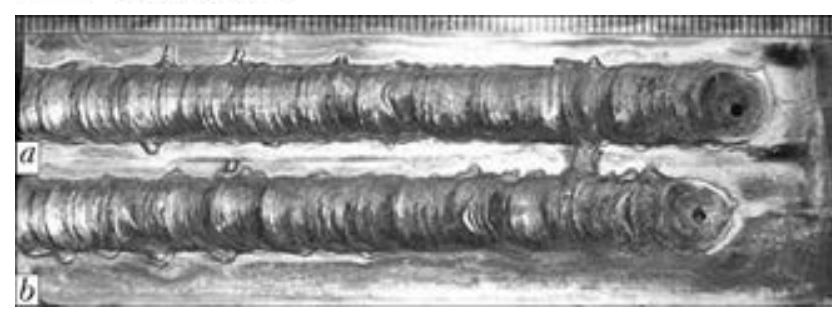

Figure 1. Formation of upper beads of welds in EBW of magnesium MA2 alloy (for $a$ and $b$ see the text)

lators and all the elements of cathode unit at high temperatures.

To decrease the power of heating the cathodes, a new design of fastening the tungsten electrode, manufactured using laser beam, was designed at the E.O. Paton Electric Welding Institute [3]. New design of tungsten cathodes of $3 \mathrm{~mm}$ diameter allows generating electron beam of $500 \mathrm{~mA}$ current at $70 \mathrm{~W}$ preheat power. Using tungsten cathodes of $4.2 \mathrm{~mm}$ diameter the beam current of $1000 \mathrm{~mA}$ is achieved at heating power of $100 \mathrm{~W}$. These cathodes, used by us in the investigations, showed high stability of formation of long welds at EBW of magnesium alloys of large thickness.

The stability of formation of welded joints on magnesium alloys is provided also by the stability of operation of the whole power complex of the machine. Even negligible non-uniformity in movement of alloy MA2 billets being welded has a negative influence on welds shape.

At instability of welding speed of more than $5 \%$, on the upper bead of welds the appearance of overlaps is clearly seen (Figure 1, $a$ ), and in the root the increasing in amplitude of variation in penetration depth can be observed. At instability of welding speed of less than $3 \%$ the nonuniformity of welds formation is reduced ( $\mathrm{Fi}-$ gure $1, b)$.

The necessary parameters of the system for moving the gun and the product were achieved

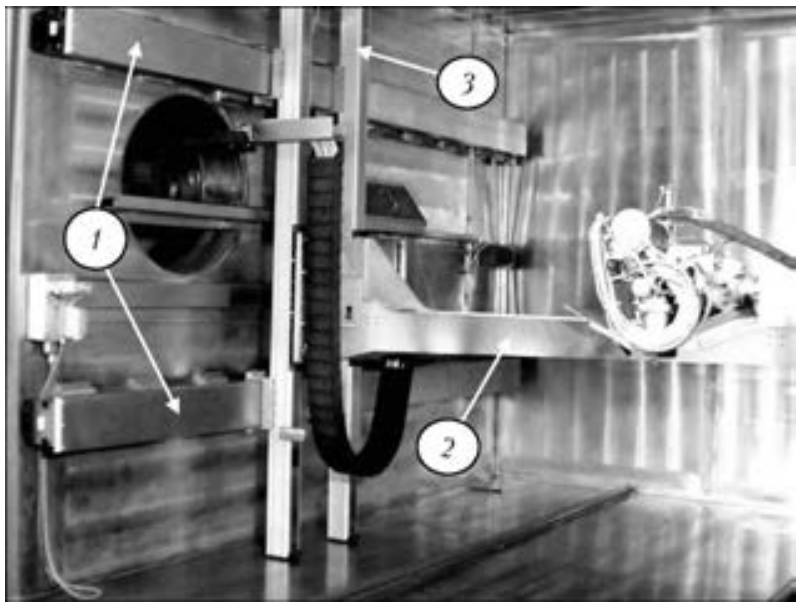

Figure 2. Mechanism of gun movement along the coordinates $X-X(1), Y-Y(2)$ and $Z-Z$ (3) using the machine for EBW equipped with linear modules MKK35 («Rexroth», Germany). Figure 2 shows the mechanism for movement of gun of machine UL 219, which was used in mastering the technology of MA2 alloy welding. It provided the sufficient accuracy of movement $(0.08 \mathrm{~mm})$ and met the requirements to instability of welding speed.

The mechanism has three levels of freedom along the axes $X-X, Y-Y$ and $Z-Z$. The movement of EB gun along the chamber in axis $X-X$ is performed by wheel-out of tables of linear modules MKK35-165 of $3800 \mathrm{~mm}$ length, which are equipped with a drive composed of two ball-andscrew gears with the pitch of $5 \mathrm{~mm}$, two gear belt transmissions with gear ratios $i=2$ and electric motor of $5 \mathrm{~N} \cdot \mathrm{m}$ torque.

At the tables of linear modules MKK35-165 two linear modules MKK25-110 of $2830 \mathrm{~mm}$ length are installed equipped with a drive, which is composed of one ball-and-screw gear with pitch of $5 \mathrm{~mm}$, one gear belt transmission with gear ratio $i=3.6$ and electric motor of $5 \mathrm{~N} \cdot \mathrm{m}$ torque. These modules allow the EB gun to move along the axis $Z-Z$.

In turn, a beam with linear modules MKK15-60 of $2200 \mathrm{~mm}$ length was mounted at the tables of linear modules MKK25-110 of $2830 \mathrm{~mm}$ length and equipped with a drive composed of one ball gear of $5 \mathrm{~mm}$ pitch, one gear belt transmission with gear ratio $i=3$ and electric motor with $0.83 \mathrm{~N} \cdot \mathrm{m}$ torque. These modules allow moving the gun along the axis $Y-Y$.

The speed of movement of EB gun along the axes $X-X, Y-Y$ and $Z-Z$ is preset in the limits of $6-120 \mathrm{~m} / \mathrm{h}(1.66-33.30 \mathrm{~mm} / \mathrm{s})$.

To provide control and accurate positioning, all the electric motors are equipped with sensors of angle movements. The signals from sensors are used to control EBW parameters using computer system on the base of high-precise CNC and PLC. Visual method of design of EBW programs is used [4]. Additionally to the applied traditional computational complex combining CNC and PLC in its composition, the machine UL 209 uses higher level of interface of operator for visual design of working programs and control of welding process, and also additional computer, which, independently of other processor units, solves the problems of butt identification according to the RASTR image of workpiece surface, obtained from the monitoring device, were introduced. Together with the main computer it provides performance of functions of automatic training, correcting and seam tracking. Visually designed program of welding during its launching for automatic performance, without participation of the 


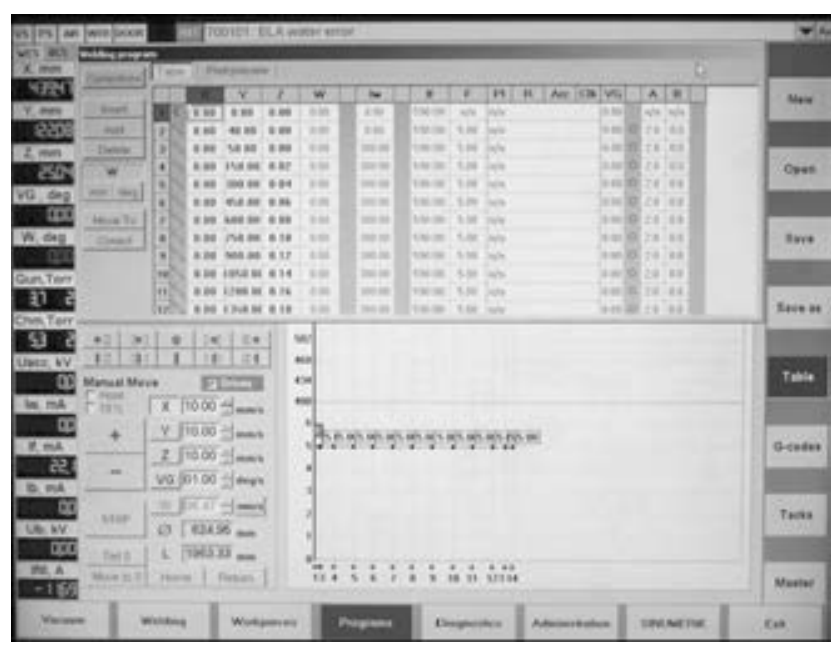

Figure 3. Example of visual programming of parameters of welding the butt joint of magnesium MA2 alloy

operator, is converted to the succession of $\mathrm{G}^{-}$ codes, executed by CNC. The example of such program, used for EBW of butts of magnesium MA2 alloy of $1500 \mathrm{~mm}$ length, is given in $\mathrm{Fi}$ gure 3 .

Mastering of technology of EBW of thick-wall magnesium alloy workpieces was performed in two stages. At the first one the experiments were carried out on optimizing welding mode parameters for stable formation of joints at complete absence of any defects of welds. On these butt joints the strength characteristics on specimens, cut out in different directions across the thickness of butts, were determined [5]. At the second stage the welding-assembly stands were designed and manufactured, their tests were made, and then welding was performed with their use and largesize structures for pilot production were manufactured.

Figure 4 shows the sketch of plate of space platform of magnesium MA2 alloy, which is welded of four billets of $1500 \times 1500 \mathrm{~mm}$ size and $105 \mathrm{~mm}$ thick. At the same sketch four holes of

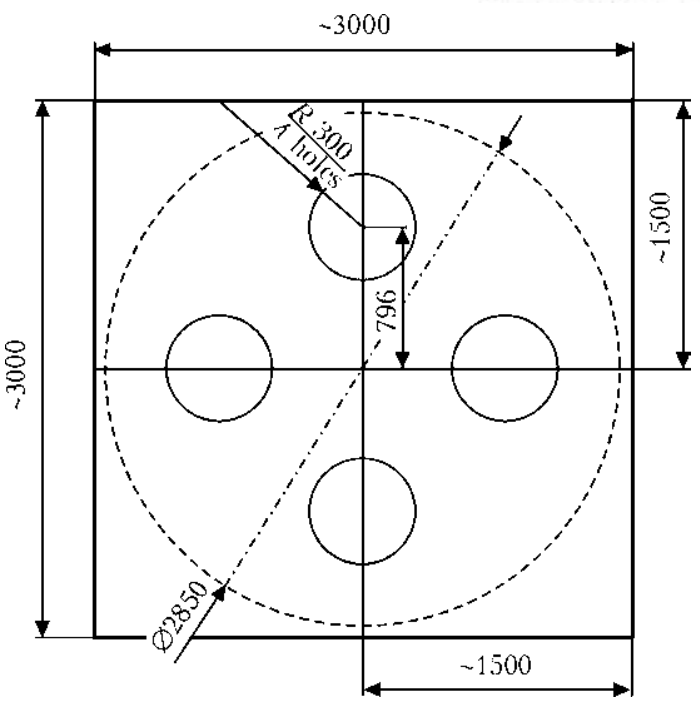

Figure 4. Sketch of design of the plate of magnesium MA2 alloy (chain line - diameter of plate cut out after welding)

$600 \mathrm{~mm}$ diameter are shown, which are cut out after welding.

In Tables 1 and 2 the chemical composition and mechanical properties of initial billets of 100 and $105 \mathrm{~mm}$ thickness are given, which were subjected to welding, and after optimization of parameters of welding conditions they were used for mechanical tests.

During evaluation of the influence of welding condition parameters on quality of welds formation the penetration was performed on base metal and then the macrosections were made, and presence or absence of defects in welds and HAZ were determined.

The stable quality of joints formation is achieved in producing horizontal welds in vertical plane using horizontal beam at the beam power of $16 \mathrm{~kW}$ and welding speed of $5 \mathrm{~mm} / \mathrm{s}$.

Figure 5, $a$ shows macrosection of cross section of produced welds in EBW using horizontal beam. All welded joints are characterized by the presence of undercuts on the side of beam entry

Table 1. Chemical composition of semi-products (plate) of different batches of magnesium MA2 alloy, wt.\%

\begin{tabular}{||c|c|c|c|c|c|c|c|c||}
\hline \hline № & $\begin{array}{c}\text { Plate } \\
\text { thickness, } \\
\mathrm{mm}\end{array}$ & $\mathrm{Al}$ & $\mathrm{Zn}$ & $\mathrm{Mn}$ & $\mathrm{Fe}$ & $\mathrm{Si}$ & $\mathrm{Cu}$ & $\mathrm{Ni}$ \\
\hline 1 & 105 & $3.35-3.57$ & $0.47-0.51$ & $0.34-0.42$ & $0.0048-0.0042$ & $0.0023-0.0420$ & $0.0010-0.0033$ & $0.0003-0.00052$ \\
\hline 2 & 100 & $3.5-3.8$ & $0.60-0.68$ & $0.1-0.2$ & $0.020-0.022$ & $0.14-0.18$ & 0 & 0 \\
\hline
\end{tabular}

Table 2. Mechanical properties of base metal of MA2 alloy semi-products at the tests of specimens cut out in different directions along the plate section

\begin{tabular}{||c|c|c|c|c|c|c|c|c|c|c||}
\hline \hline \multirow{2}{*}{$№$} & $\begin{array}{c}\text { Plate } \\
\text { thickness, } \\
\mathrm{mm}\end{array}$ & \multicolumn{4}{|c|}{$\sigma_{\mathrm{t}}, \mathrm{MPa}$} & \multicolumn{3}{|c|}{$\sigma_{0.2}, \mathrm{MPa}$} & \multicolumn{3}{c||}{$\delta, \%$} \\
\hline 1 & 105 & $255-260$ & $249-261$ & $246-269$ & $186-197$ & $190-192$ & $74.3-82.0$ & $14-16$ & $9.1-17.0$ & $11-13$ \\
\hline 2 & 100 & $237.2-250.8$ & $227.2-248.1$ & $270.9-277.5$ & $133.9-144.6$ & $131.1-139.8$ & $60.7-61.3$ & $9.4-21.0$ & $9.2-19.2$ & $18.2-18.3$ \\
\hline
\end{tabular}




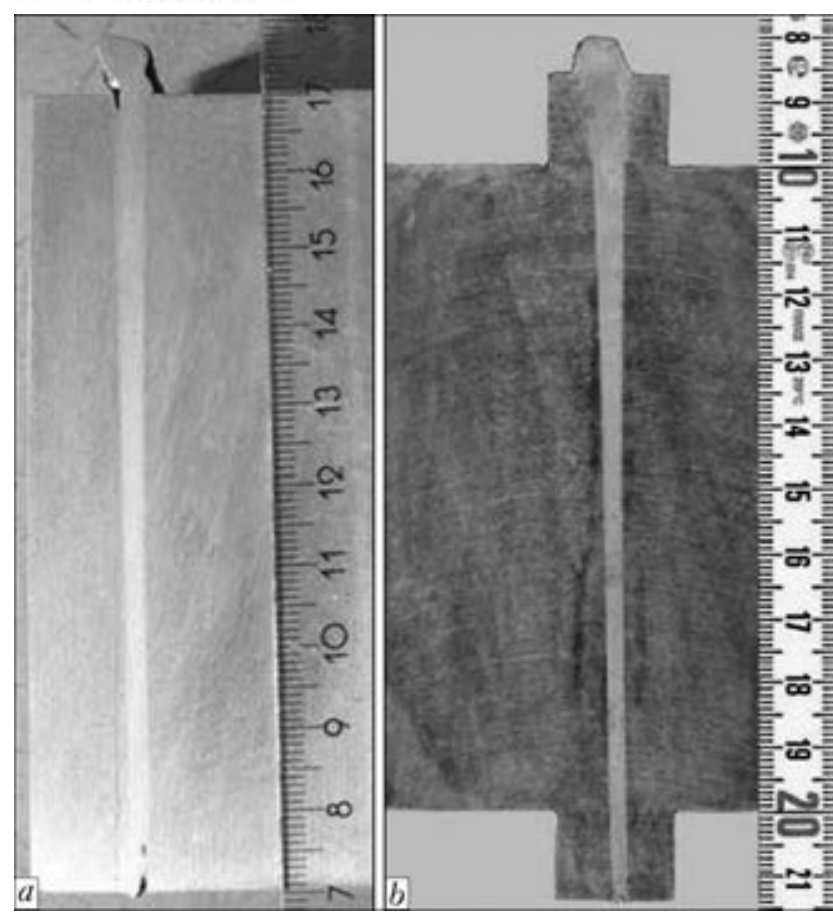

Figure 5. Transverse sections of welded joints of magnesium MA2 alloy (for $a$ and $b$ see the text)

and cover plates, which are installed at the top and in the butt root (Figure 5, b) and fastened before argon arc welding. The thickness of cover and backing plates was $15 \mathrm{~mm}$. Considering the increase in total penetration depth the welding current was also increased to $380 \mathrm{~mA}$. Welding speed, current of focusing lens $I_{\mathrm{f}}=590 \mathrm{~mA}$, accelerating voltage $U_{\text {acc }}=60 \mathrm{kV}$ and technological beam scanning around the circumference of $2 \mathrm{~mm}$ diameter remained unchanged.

In all the cases the surface of edges to be welded and also surfaces of plates adjacent to the butt were scraped to the depth of $0.1-0.2 \mathrm{~mm}$. In welding of billets of $1500 \times 1500 \times 100 \mathrm{~mm}$ size the butt tacks were made under condition: $I_{\mathrm{b}}=100 \mathrm{~mA}, I_{\mathrm{f}}=620 \mathrm{~mA}, v_{\mathrm{w}}=5 \mathrm{~mm} / \mathrm{s}$, oscillations of the beam around the circle of $2 \mathrm{~mm}$ diameter. At the butt of $1500 \mathrm{~mm}$ length 5 tacks of $120 \mathrm{~mm}$ length with the pitch between the tacks of $150 \mathrm{~mm}$ were performed. Before making tacks the butt was degassed by defocused electron

Table 3. Strength characteristics of welded joints of MA2 alloy

\begin{tabular}{||c|c|c|c|c|c||}
\hline \hline № & $\begin{array}{c}\text { Place of } \\
\text { specimens } \\
\text { cut-out }\end{array}$ & $\sigma_{\mathrm{t}}, \mathrm{MPa}$ & $\sigma_{0.2}, \mathrm{MPa}$ & $\delta, \%$ & $\begin{array}{c}\text { Strength } \\
\text { coeffi- } \\
\text { cient }\end{array}$ \\
\hline 1 & $\begin{array}{c}\text { Along the } \\
\text { rolling }\end{array}$ & $\frac{231.2-240.5}{235.2}$ & $\frac{132.9-141.0}{136.6}$ & 14.5 & 0.97 \\
\hline 2 & $\begin{array}{c}\text { Across the } \\
\text { rolling }\end{array}$ & $\frac{229.7-283.8}{232.0}$ & $\frac{131.6-138.9}{135.8}$ & 16.2 & 0.96 \\
\hline 3 & $\begin{array}{c}\text { Across the } \\
\text { thickness of } \\
\text { plate }\end{array}$ & $\frac{258.2-260.4}{259.3}$ & $\frac{72.4-81.7}{76.9}$ & 11.5 & 0.94 \\
\hline
\end{tabular}

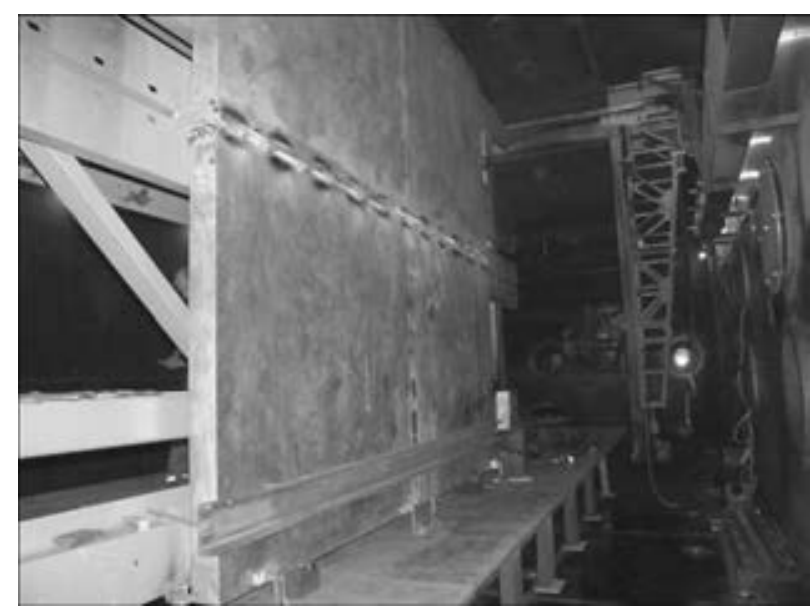

Figure 6. General view of platform of MA2 alloy before making the last weld of $3000 \mathrm{~mm}$ length

beam of small power. The tacks were made in the staggered order starting from the middle of butt length. Then, mechanical cleaning of their surface, installing and fixation of cover plate atop the butt and backing plate on the side of a root were performed. On the both sides of a butt the run-in and run-out tabs were mounted and fastened. In such a condition the butts of $1500 \mathrm{~mm}$ length were welded.

After completion of welding, the plates of $3000 \times 1500 \times 105 \mathrm{~mm}$ size were removed from welding stand, and cover plates were cut off from the face side of the plates, as well as root and run-in and run-out tabs at the beginning and end of welds were cut out using angular grinding machine.

EBW of the last butt of $3000 \mathrm{~mm}$ length was performed on the special assembly-welding stand. The tacks of a butt were fastened by electron beam on both sides with turnover of the workpiece beyond the vacuum chamber. The further cleaning of tacks and fastening of cover plates and run-out tabs were carried out according to the above-mentioned technology. The general view of the platform equipped and installed in the vacuum chamber is given in Figure 6 .

After welding, the table assembled according to the scheme like that is wheeled out from the chamber, welded product is transported using crane to the area of ultrasonic testing and measurements of residual deformation.

Simultaneously with the as-prepared and asassembled plate on the stand, the specimens-witnesses, necessary for the further manufacture of sections, intended for metallographic investigations, defining of distribution of hardness in the weld metal and HAZ and also for investigations of mechanical properties were loaded to the vacuum chamber. 
Round specimens for determination of ultimate rupture resistance were manufactured of different areas both across the thickness of a butt, as well as in different directions of rolling of plates at their metallurgical production. The test results of specimens are given in Table 3 . Having compared these data with the characteristics of the base metal, given in Table 2, one can make the conclusion that the coefficient of strength of joints in all the cases exceeds the value 0.9 , which had to be provided according to the technical assignment.

The quality control of welds after removing the plates from the assembly-welding stand was performed applying ultrasonic flaw detector UD2-70. The plate was arranged in this case on the lodgement in horizontal position in the way that the weld was in gravity position. The scanning was performed on the both sides of the weld. The ultrasonic testing of quality of butt welded joints with thickness of edges of $100 \mathrm{~mm}$ did not detect any defects along the total length of welds of $6000 \mathrm{~mm}$.

The evaluation of level of deformation of a plate according to the scheme of measurements of deflections showed that after producing of final weld the deformation of plate is varied within the limits of $\pm 1.5 \mathrm{~mm}$.

\section{Conclusions}

1. Principal feasibility of application of EBW in manufacture of thick-wall welded structures of magnesium alloys is shown.

2. Optimal parameters of conditions and basic technological requirements in EBW of billets of magnesium MA2 alloy with the thickness of edges of $100 \mathrm{~mm}$ were established.

3 . The technology of manufacture of large-size products of $3000 \times 3000 \times 100 \mathrm{~mm}$ of magnesium MA2 alloy was developed and passed pilot-industrial testing.

1. (1978) Magnesium alloys: Refer. Book. Vol. 1: Metals science of magnesium and its alloys; Vol. 2: Technology of production and properties of castings and deformed semi-products. Moscow: Metallurgiya.

2. Olshansky, N.A., Khokhlovsky, A.S. (1985) Properties of EB-welded joints of aluminium and magnesium alloys of large thickness. In: Actual problems of welding of nonferrous metals. Kiev: Naukova Dumka.

3. Nazarenko, O.K., Matvejchuk, V.A. (2012) Influence of violations of welding gun axial symmetry on focal spot position. The Paton Welding J., 7, 38-41.

4. Paton, B.E., Nazarenko, O.K., Nesterenkov, V.M. et al. (2004) Computer control of electron beam welding with multi-coordinate displacements of the gun and workpiece. Ibid., 5, 2-5.

5. Bondarev, A.A., Nesterenkov, V.M. (2013) Study of weldability of MA2 magnesium alloy by electron beam in vacuum. Kompres. Mashinostroenie, 2, 21-28.

Received 10.11.2013 


\title{
STRUCTURE AND PROPERTIES OF WELDED JOINTS OF 15Kh1M1FL STEEL AT REPAIR OF CASTING DEFECTS BY TRANSVERSE HILL METHOD
}

\author{
N.G. EFIMENKO ${ }^{1}$, O.Yu. ATOZHENKO ${ }^{1}$, A.V. VAVILOV ${ }^{2}$, A.G. KANTOR ${ }^{2}$ and E.I. UDALOVA ${ }^{2}$ \\ ${ }^{1}$ NTU «Kharkov Polytechnic Institute» \\ 21 Frunze Str., 61002, Kharkov, Ukraine. E-mail: svarka126@ukr.net \\ ${ }^{2}$ OJSC «Turboatom» \\ 199 Moskovsky Ave., 61037, Kharkov, Ukraine.
}

\begin{abstract}
Welding up casting defects in power equipment components from thermally stable steels involves the risk of brittle fracture as a result of increased volumetric stress state. Studying the influence of technological measures for controlling the thermodeformational welding cycle in order to obtain a favourable structure and properties in welded joints, is of interest. In this work the influence of transverse «hill» welding without preheating or heat treatment on mechanical properties and structure of various zones of welded joints from 15Kh1M1FL steel was studied, and these values were compared with the properties of welded joints after welding with preheating by the standard technology. It is established that after transverse «hill» welding upper granular bainite structure forms in the high-temperature zone of HAZ metal and in the weld metal, which is characterized by an optimum set of mechanical properties, namely a combination of high strength with high enough impact toughness values. It is shown that cold cracking resistance after transverse «hill» welding without preheating is higher than after welding by the standard technology. 12 Ref., 6 Figures.
\end{abstract}

$\boldsymbol{K} \boldsymbol{e} \boldsymbol{y} \boldsymbol{w} \boldsymbol{o r d} \boldsymbol{s}:$ steel, welding, preheating, heat treatment, granular bainite, subgranular structure, properties

In welding up casting defects in large-sized thickwalled structures of power equipment from lowalloyed thermally stable steels the main risk is quenching structure formation in the high-temperature zone of HAZ metal, that does not eliminate cold cracking. Specific difficulties arise in repair of defects in massive structures from 15Kh1M1FL steel (for instance, turbine casing of about $100 \mathrm{t}$ weight).

At solidification the deposit metal stays within rigid contours formed at defect cutting-out, that impairs the conditions for its plastic flow. The situation is further complicated when the volume of cut-out areas for welding-up reaches $1000 \mathrm{~cm}^{3}$ and more. Lowering of deformational ability of solidified metal leads to increase of volumetric stress state and creates the conditions for brittle fracture of structures in service. To lower the stressed state of metal in the area of defect welding-up, in keeping with the normative documents, it is necessary to ensure performance of additional technological operations (local preheating and concurrent heating and postweld high tempering).

On the other hand, a number of studies [1-4] give investigation results confirming the imprac- ticality and even risk of conducting high preheating in welding of hardening steels. At present technological solutions for welding large-sized structures from hardening steels without preheating or heat treatment, ensuring technological strength, have been studied and are recommended.

Analysis of currently available welding processes showed that the most acceptable one for repair welding of hardening steels without preheating is the transverse «hill» welding (THW) $[4,5]$, which ensures self-preheating and self-heat treatment from welding heat. The method is based on controlling the heat input by deposited metal layers filling the groove that, in its turn, allows influencing the thermodeformational cycle through periodical heat impact and formation of a certain type of structures. Work [4] specifies the technology of repair of large-sized massive structures by THW from readily weldable steels without preheating or heat treatment. This method is not well enough studied in the case of thermally stable hardening steels.

This work is devoted to substantiation of THW applicability in repair of defects without preheating of massive structures from 15Kh1M1FL steel. 
Material and experimental procedure. Structure and property studies were performed on cast billets from $15 \mathrm{Kh} 1 \mathrm{M} 1 \mathrm{FL}$ steel of $120 \mathrm{~mm}$ diameter and $300 \mathrm{~mm}$ length, heat-treated in standard technology mode (normalizing at $970-1000{ }^{\circ} \mathrm{C}$, tempering at $720-750{ }^{\circ} \mathrm{C}$ ). In the billet middle part longitudinal recesses of $60 \mathrm{~mm}$ depth, $50 \mathrm{~mm}$ width and $270 \mathrm{~mm}$ length were mechanically cut out for welding-up. Welding-up was performed by electric-arc process with $4 \mathrm{~mm}$ electrodes of E-09Kh1M1F type of TML-ZU grade in the following mode: $I_{\mathrm{w}}=160-170 \mathrm{~A}, U_{\mathrm{a}}=26 \mathrm{~V}$. Here one batch of the billets was welded according to standard technology - by step-back welding (SBW) with preheating up to $200-250{ }^{\circ} \mathrm{C}$, the other batch was $\mathrm{TH}$-welded without preheating by layer-by-layer filling of the groove.

In THW-up recesses angle of billet inclination relative to the horizontal plane in the range of 25-30 was ensured [6]. HAZ metal temperature was measured with thermocouples, which were caulked-in in different points of the welded joint at 1, 2, 3, 4 and $7 \mathrm{~mm}$ distance from the groove edge. The readings were recorded in EPP-09M3 instrument. It is established that the width of metal interlayer heated above $850{ }^{\circ} \mathrm{C}$ is in the range of $1 \mathrm{~mm}$. At $2-3 \mathrm{~mm}$ distance from the fusion line, heating temperature reached $630-660{ }^{\circ} \mathrm{C}$.

After welding part of the billets were tempered together with the casing parts at 720 $750{ }^{\circ} \mathrm{C}$ with $3 \mathrm{~h}$ soaking.

Macroanalysis and hardness measurement were performed on $13-14 \mathrm{~mm}$ thick templates cut out in the transverse direction relative to weld axis. $H V 5$ hardness was measured on three levels by weld height $(10,25$ and $40 \mathrm{~mm})$. After that samples were cut out of the templates to determine mechanical properties in different joint zones. Impact toughness was determined on standard samples with notches in the base metal, in the HAZ high-temperature zone and in the weld metal at the following temperatures: $K C U$ - from -20 up to $350{ }^{\circ} \mathrm{C}, K C V$ - from -60 up to $100{ }^{\circ} \mathrm{C}$.

Microstructure was studied by the method of optical and electron microscopy. In order to detect grain boundaries in the HAZ and deposited metal, microsection etching was performed in oversaturated water solution of picric acid with SA addition. Grain size was determined by method of random secants.

Investigation results. Macroanalysis showed that HAZ width was equal to $2.5-3.8 \mathrm{~mm}$, no macrodefects were found, and weld metal was highly sound.
Nature of hardness variation by zones on all the levels is practically the same. Figure 1 shows the graphs of its average value variation on one level of $25 \mathrm{~mm}$. It is established that after application of both welding techniques without tempering hardness of weld metal and high-temperature zone of HAZ metal is higher than that of the base metal.

So, in the joint made by SBW with preheating, the highest hardness $(H V 370)$ is noted in weld metal near the fusion line (Figure 1, a). After THW hardness of all the zones is lower by approximately $H V 50$.

Comparison of obtained hardness values with hardness data and their respective structural diagrams of anisothermal decomposition of austenite in $15 \mathrm{Kh} 1 \mathrm{MFL}$ steel [6] shows that at cooling in higher hardness zones under the conditions of SBW with preheating first austenite transformation into lower bainite takes place, and then martensite forms with preservation of residual austenite (about $12 \%$ ). At THW without preheating upper bainite (up to $70 \%$ ) with martensite and residual austenite forms that is not contradictory to works $[7,8]$.
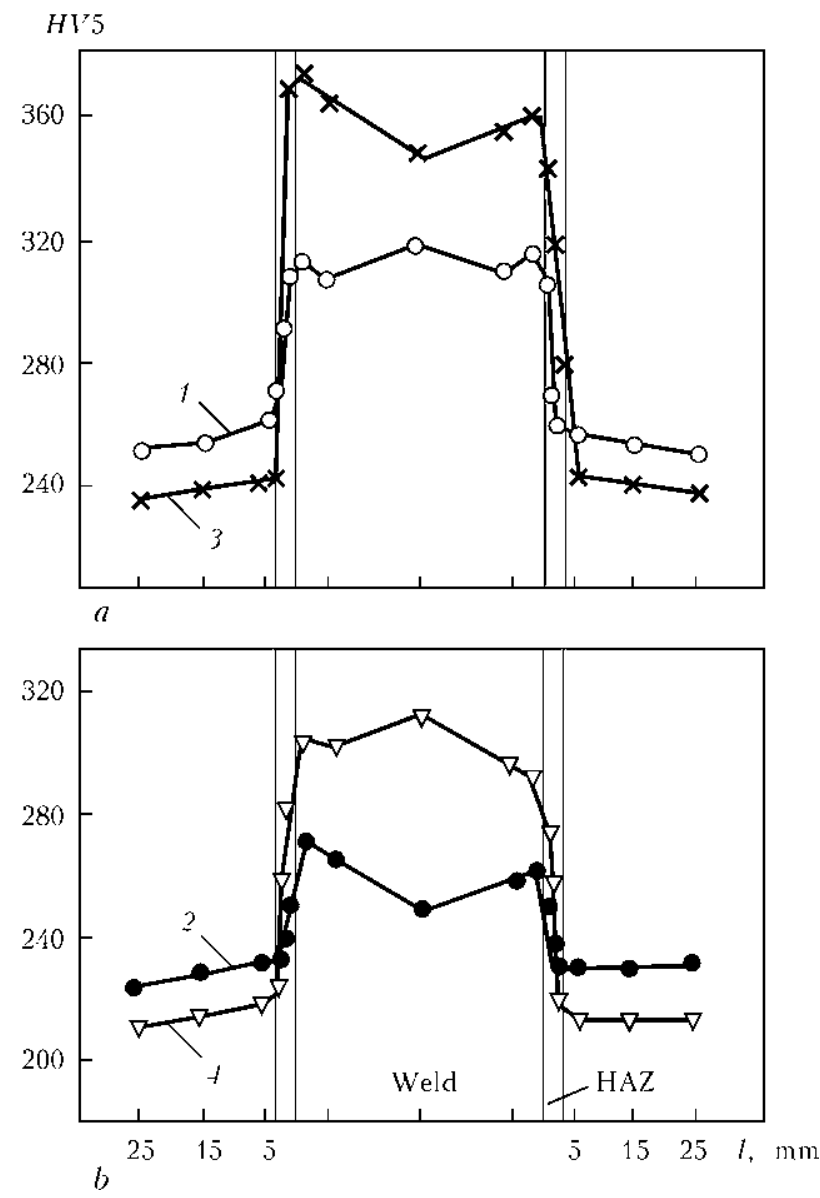

Figure 1. Variation of hardness in 15Kh1MFL steel welded joints: $a$ - without postweld heat treatment; $b-$ with postweld heat treatment; 1,2 - THW without preheating; 3, 4 - SBW with preheating 
$\sigma_{1}, \sigma_{0.2}, \mathrm{MPa}$

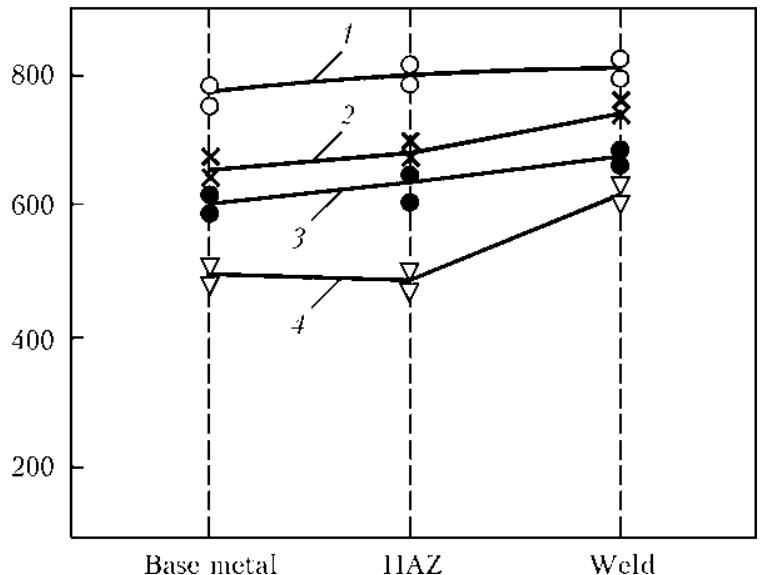

Figure 2. Change of strength properties of different zones in $15 \mathrm{Kh} 1 \mathrm{M} 1 \mathrm{FL}$ steel welded joints after THW: $1,3-\sigma_{\mathrm{t}}$ and $\sigma_{0.2}$ without postweld heat treatment; $2,4-\sigma_{\mathrm{t}}$ and $\sigma_{0.2}$ with high tempering after welding, respectively

Naturally, increase of self-preheating effect in THW promotes lowering of cooling rate, that leads to formation of upper bainite additionally prone to self-tempering, and lowers the risk of formation of structures leading to embrittlement of metal of this zone.

High tempering lowers the hardness of all zones of the welded joint (see Figure 1). However, it remains higher in the HAZ and in the weld metal near the fusion boundary (particularly after SBW). This is related to thermodeformational impact on grain morphology and structure in the HAZ and delayed decomposition of non-equilibrium structure. In the weld metal near the fusion line preservation of increased hardness after tempering can be also due to microchemical inhomogeneity, resulting from diffusion processes on the weld pool liquid metalbase metal boundary. Liquid metal volumes near the molten edge are more saturated with alloying elements, carbon and impurities, that delays solid

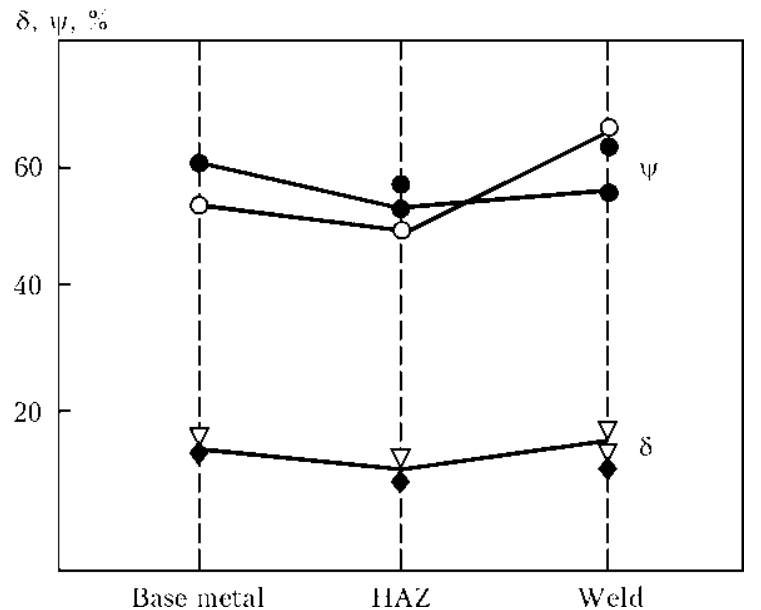

Figure 3. Variation of plastic properties in different zones of $15 \mathrm{Kh} 1 \mathrm{M} 1 \mathrm{FL}$ steel welded joints after THW without heat treatment (light symbols) and with high tempering (dark) solution decomposition and increases the number of precipitating carbide and intermetallic phases, thus increasing the hardness.

It is established that THW ensures high values of strength in all the zones (Figure 2) that satisfies the requirements of the norms for metal of thick-walled cast structures from $15 \mathrm{Kh} 1 \mathrm{M} 1 \mathrm{FL}$ steel. Level of $\sigma_{t}$ values is practically the same, despite hardness increase in the HAZ and weld metal; $\sigma_{0.2}$ level in the HAZ and weld metal rises somewhat, compared to base metal. After tempering $\sigma_{\mathrm{t}}$ and $\sigma_{0.2}$ values decrease in all the zones, but $\sigma_{0.2}$ in weld metal remains higher.

After THW relative elongation $\delta$ is practically the same (18-20\%) in all the zones, both in the case without tempering, and with postweld tempering (Figure 3). Reduction in area $\psi$ has high values for all the zones (more than $50 \%$ ), the highest $\psi$ values are found in weld metal after welding without tempering (68\%).

Results of impact toughness $\mathrm{KCU}$ testing showed that abrupt lowering of its values occurs in all the zones at $20^{\circ} \mathrm{C}$ (both without tempering, and with tempering after welding).

Comparative analysis of changes in mechanical properties, found in high-temperature zone of HAZ metal after both the welding methods (both with and without tempering), shows (Figure 4) that after THW without preheating strength
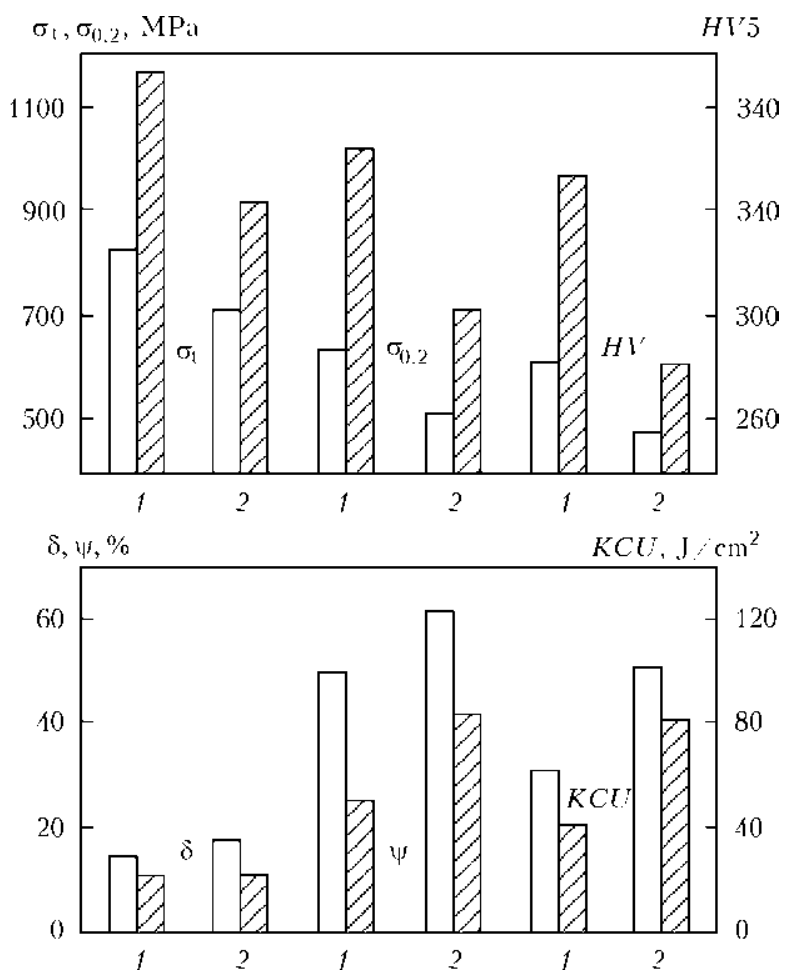

Figure 4. Mechanical properties of high-temperature zone of HAZ metal after welding of 15Kh1M1FL steel by different methods: light diagrams - THW without preheating; hatched - SBW with preheating up to $200{ }^{\circ} \mathrm{C} ; 1$ - without postweld heat treatment; 2 - with postweld high tempering 
properties are lower, and ductile characteristics and $K C U$ are higher than after SBW with preheating.

Brittle fracture susceptibility in high-temperature zone of HAZ metal was evaluated at determination of impact toughness of samples with a sharp notch $(K C V)$. It follows from Figure 5 that after THW $K C V$ values are higher at all testing temperatures. Here for both welding methods at testing from -60 up to $20{ }^{\circ} \mathrm{C} \mathrm{KCV}$ is higher in the case, if no postweld tempering was performed that is attributable to disperse phase precipitation and restructuring of dislocation structure of the grains, associated with the processes of recovery and polygonization. The same in both welding methods lowering of $\mathrm{KCV}$ at temperature below $-20{ }^{\circ} \mathrm{C}$ is noted that points to the fact that critical brittleness temperature does not depend on performance of additional technological operations (preheating and postweld tempering).

Microanalysis showed that in THW without preheating a structure consisting of upper granular bainite forms in the HAZ and weld metal (Figure 6,a). A weakly manifested transition to the structure of HAZ high-temperature zone is noted. At $1.5-2.0 \mathrm{~mm}$ distance from the boundary (Figure 6, b), HAZ metal microstructure consists of fine grains of hypoeutectoid ferrite and granular bainite. In the HAZ zone at about $3 \mathrm{~mm}$ distance from the fusion line (Figure $6, c$ ) incomplete phase recrystallization proceeded in the metal. Here coarse formations of excess ferrite did not undergo any phase recrystallization in welding. They, however, are fragmented into individual fine subgrains that is due to the processes of dynamic recrystallization and polygonization («in situ»). The above processes proceed under the conditions of plastic deformations and high heating temperatures, accompanying the entire thermal cycle of layer-by-layer filling of the groove in welding. The width of plastic deformation zone is 2 to 3 times greater than that of
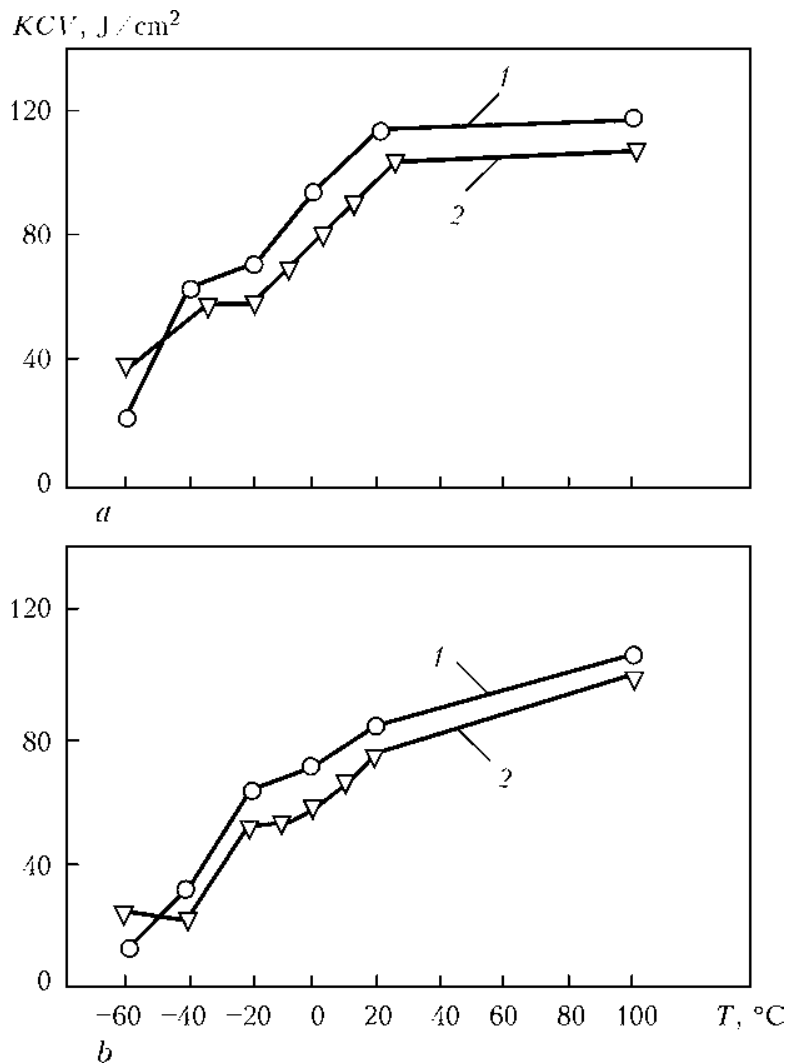

Figure 5. Influence of test temperature on $K C V$ impact toughness of metal in HAZ high-temperature zone after welding of $15 \mathrm{Kh} 1 \mathrm{M} 1 \mathrm{FL}$ steel by THW without preheating (1) and by SBW with preheating up to $200{ }^{\circ} \mathrm{C}$ (2): $a-$ without postweld heat treatment; $b$ - with postweld high tempering

the HAZ. Distribution of plastic deformation over the welded joint cross-section occurs nonuniformly.

In welded joints of thick-walled structures from low-alloyed steels plastic deformation can reach 4 to $5 \%$ and more $[1,9,10]$. Under such conditions polygonization and recrystallization occur simultaneously, competing with each other $[11,12]$, and thus creating a ramified network of sub-boundaries in the deformed grains. When studying the grain structure in welded joints made by THW, it was found that near the fusion zone some grains have serrated boundaries and

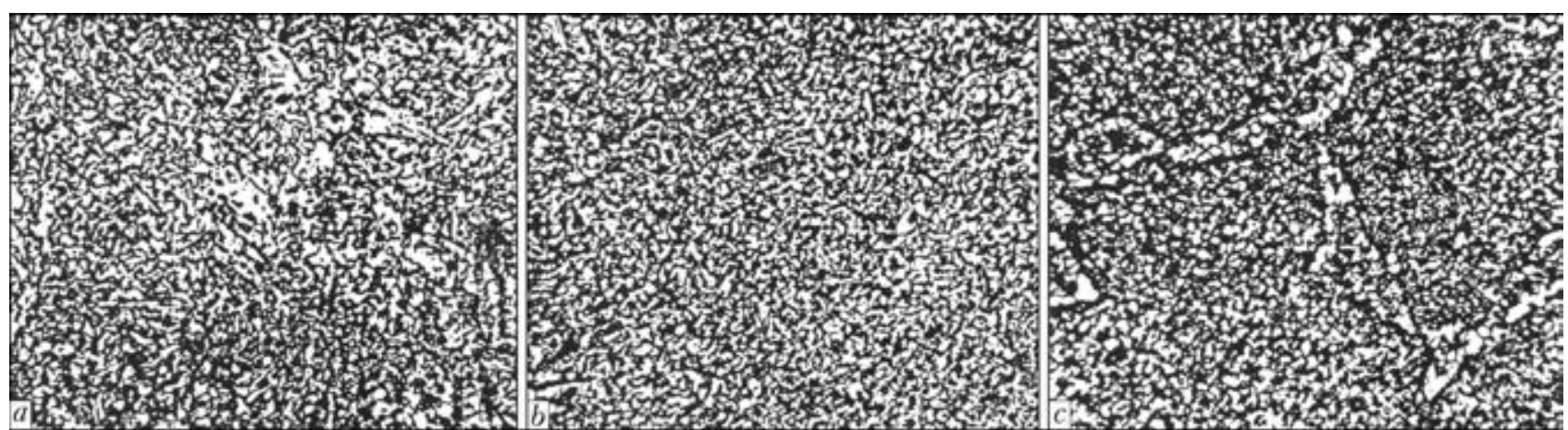

Figure 6. Microstructure $(\times 500)$ of $15 \mathrm{Kh} 1 \mathrm{M} 1 \mathrm{FL}$ steel welded joint made by THW without preheating and postweld heat treatment: $a$ - fusion zone; $b-\mathrm{HAZ}$ at approximately $2 \mathrm{~mm}$ distance from the fusion line; $c-$ same, about $3 \mathrm{~mm}$ 
deformed shape that results from plastic deformation, and in the HAZ high-temperature zone and in the weld the metal is fine-grained. So, in the HAZ $\overline{\mathrm{D}}_{\text {cond }} \approx 0.0192 \mathrm{~mm}$ (7-8 grain size number), and in weld metal $\overline{\mathrm{D}}_{\text {cond }} \approx 0.0186 \mathrm{~mm}$ (number 8-9). However, grain structure is heterogeneous, finer grains, corresponding approximately to number 13, are located along the boundaries of the main grains and inside them, that is a confirmation of the start of development of dynamic recrystallization processes. Fine-grained structure with a ramified network of subgrains ensures a high set of mechanical properties in the HAZ high-temperature zone and increases brittle fracture resistance.

\section{Conclusions}

1. In welded joints of $15 \mathrm{Kh} 1 \mathrm{M} 1 \mathrm{FL}$ steel made by THW and SBW, hardness is higher in the HAZ high-temperature zone and weld metal than in the base metal. Postweld tempering reduces the difference in hardness. However, a complete equalizing of its values does not occur, that is related to the processes of thermodeformational strengthening in the HAZ and weld and slowing down of non-equilibrium structure decomposition.

2. THW ensuring self-heating and self-heat treatment leads to formation of upper granular bainite structure in the HAZ and weld metal, which provides an optimum combination of mechanical properties and improves brittle fracture resistance.

3. $K C V$ impact toughness of HAZ high-temperature zone after both the welding methods is higher in welded joints not subjected to high tempering, in the test temperature range from -60 up to $20{ }^{\circ} \mathrm{C}$. At test temperature increase up to $100{ }^{\circ} \mathrm{C}$, this difference is leveled off. Both the welding methods are characterized by the same value of critical temperature $\left(-20{ }^{\circ} \mathrm{C}\right)$, which does not change after high tempering. Therefore, the position of cold shortness threshold depends predominantly on grain morphology formation under the conditions of thermodeformational welding cycle.

4. THW of $15 \mathrm{Kh} 1 \mathrm{M} 1 \mathrm{FL}$ steel without preheating ensures high values of mechanical properties of the joints, satisfying the requirements specified in the normative-technical documentation, that forms the basis for commercial application of this process in welding-up defects in casings of turbines and steam fittings.

1. Kozlov, R.A. (1986) Welding of heat-resistant steels. Leningrad: Mashinostroenie.

2. Panov, V.I. (1993) Preheating of welded structures of heavy machine-building. Tyazh. Promyshlennost, 4, 14-17.

3. Panov, V.I. (2007) Universal procedure of repair welding of large-sized massive structures of heavy machine-building. Svarochn. Proizvodstvo, 4, 11-17.

4. Sinadsky, S.E., Panov, V.I. (1985) Autoheating and autoheat treatment in transverse hill welding. Ibid., 11, 3-5.

5. Efimenko, N.G., Orlov, M.V., Levenberg, N.E. et al. Method of multipass welding. USSR author's cert. 1816595. Int. Cl. A1B23K9/16. Publ. 23.05.93.

6. Levenberg, N.E., German, S.I., Fomina, O.P. et al. (1973) About structure of heat-affected zone of welded joints of steels 15Kh1M1FL, 25Kh2NMFA and 20Kh2MFA. Avtomatich. Svarka, 6, 19-21.

7. Cheprasov, D.P. (2006) Structure and phase composition of granular bainite in the region of complete recrystallization of HAZ on low-carbon low-alloy steels. Svarochn. Proizvodstvo, 2, 3-8.

8. Kasatkin, B.S., Kozlovets, O.N. (1992) Macrostructural martensitic-austenitic component in welded joints of high-strength low-alloy steels (Review). Avtomatich. Svarka, 9/10, 3-12.

9. Tsaryuk, A.K. (1979) Peculiarities of development of plastic deformation in processes of welded joint formation: Syn. of Thesis for Cand. of Techn. Sci. Degree. Kiev: PWI

10. Lobanov, L.M., Mikhoduj, O.L., Poznyakov, V.D. et al. (2003) Method of evaluation of effect of residual stresses on formation of longitudinal cold cracks in alloy steel welded joints. The Paton Welding J., 6, 6-10

11. Bernshtejn, M.L. (1977) Structure of deformed metals. Moscow: Metallurgiya.

12. Dyachenko, S.S. (2007) Physical principles of strength and plasticity of metals: Manual. Kharkiv: KhNADU. 


\title{
ANALYSIS OF SOME PHYSICAL AND TECHNICAL CHARACTERISTICS OF ION-PLASMA COATING (TiZr)N ON ROTOR BLADES OF COMPRESSOR OF GAS-TURBINE ENGINE TV3-117
}

\author{
K.A. KORSUNOV and E.A. ASHIKHMINA \\ V. Dal East Ukrainian National University \\ 20 Molodyozhny B1., 91034, Lugansk, Ukraine. E-mail: uni@snu.edu.ua
}

\begin{abstract}
Considered are the results of carried out tests on evaluation of wear resistance of rotor blades of compressor of helicopter engine TV3-117 with ion-plasma coating (TiZr)N, formerly used only in the tool manufacturing. The tests on compressor blades were carried out under the conditions close to the conditions of operation of helicopter engine during take-off conditions. The results of coating test on resistance to corrosion in air-sea atmosphere correspond in average to nine points according to the ten-point scale. The assumption was made that rate of erosion of coating depends on its microhardness and air temperature in compressor unit of the engine. To describe and analyze these dependencies the mathematic method of leveling (method of the least squares) was applied. Quadratic function describes most precisely the practical results. The calculation quadratic curve of the second order correlates well with the experimental curve reflecting the dependence of rate of erosion on microhardness. The obtained working model provides possibility of carrying out the further calculations of service life of blades in different temperature ranges, i.e. evaluation of reliability of aircraft industry objects. 14 Ref., 4 Tables, 3 Figures.
\end{abstract}

Keywords: ion-plasma coating $(\mathrm{TiZr}) \mathrm{w}$, rate of erosion, microhardness, blade of compressor rotor, increase in life of engine TV3-117, method of analytic leveling, dispersion analysis

Blades of the compressor rotor of helicopter engine TV3-117 are the most loaded parts subjected to the effect of static, dynamic and cyclic loads, therefore, they are manufactured of titanium alloys not inferior by their heat, corrosion and erosion resistance to other light alloys.

However during service of the helicopter $\mathrm{Mi}^{-}$ 24 (conditions of sand soils) especially under the conditions of helicopter hover over the ground surface, the abrasive water-air environment of high pressure (more than $4 \mathrm{~atm}$ ) is created in the air path of unit of engine compressor. The absorbed dust particles of different size and geometric shape under the air pressure are collided against the surface of airfoil of rotor blade of compressor, creating a local microshock and, as a result, causing microcracks, spallings, scores, furrows, tears and other defects. In connection with that the strong erosion wear of blades occurs and power of engine can drop by $23-25 \%$. The level and character of erosion wear depend on disperse composition and amount of dust absorbed to the engine [1, 2]. For the further operation of helicopter engine the following blades defects are dangerous: fretting-corrosion on the tail part (Figure 1, $a$ ) and erosion wear along the airfoil (Figure 1,b), which result in gradual fracture of material, i.e. reduction of reliability of machinery and arising of danger of engine surge.

Also, using titanium alloys in the design of compressor of engine the risk of «titanium fires» arises. The presence of friction in the excited air flow (the temperature is above $300{ }^{\circ} \mathrm{C}$ ) results in rapid inflammation of titanium, as a result of which all structural materials, including heatresistant alloys in engine, are burnt out [1, 3].

In connection with the abovementioned, to improve the resistance to chemical and mechanical effects to the blades of compressor rotor manufactured of the alloys based on titanium, the following types of protection are applied:

- purification of fuel and air from the impurities;

- installing of dust protective equipment to the inlet device of the engine;

- development of new alloys with high technical and service characteristics;

- deposition of protective coatings.

The last item is the most challenging, as it does not result in growing cost of fuel, does not require creation of cumbersome designs and application of expensive materials. Deposition of protective coatings on the blades is possible using different methods. According to the values of corrosion resistance $\varphi$ (severity point) and erosion resistance $D$ (severity point) the vacuum ionplasma coatings are more preferable (Table 1). 
Table 1. Protective coatings for the parts of aircraft engines and tools [4-6]

\begin{tabular}{|c|c|c|c|c|c|c|}
\hline $\begin{array}{l}\text { No of } \\
\text { coating }\end{array}$ & Coating & $\begin{array}{l}\text { Method of } \\
\text { deposition }\end{array}$ & Material of coating & Part/material & $\begin{array}{c}\text { Service } \\
\text { characteristics: } T, \\
{ }^{\circ} \mathrm{C} ; \varphi \text { and } D \text {, point }\end{array}$ & Thickness, $\mu \mathrm{m}$ \\
\hline 1 & $\begin{array}{l}\text { Nickel- } \\
\text { cadmium }\end{array}$ & $\begin{array}{l}\text { Electrochemical } \\
\text { (galvanic bath) }\end{array}$ & $\mathrm{Ni}, \mathrm{Cd}$ & $\begin{array}{c}\text { Blade / 15Kh12N2MVFAB-Sh, } \\
\text { 13Kh11N2V2MF }\end{array}$ & $350 ; 2 ; 1$ & $12-20$ \\
\hline \multirow[t]{3}{*}{2} & \multirow[t]{3}{*}{$\begin{array}{l}\text { Vacuum ion- } \\
\text { plasma }\end{array}$} & \multirow{3}{*}{$\begin{array}{c}\text { Ion-plasma } \\
\text { condensation } \\
\text { («Bulat», } \\
\ll \text { Pusk», } \\
\text { MAP-1) }\end{array}$} & TiN, ZrN, TiN-TiAlN & $\begin{array}{l}\text { Blade/VT-20, VT3-1, } \\
\text { 14Kh17N2, VK8, VT-6S }\end{array}$ & $250-400 ; 1-2 ; 2-3$ & \multirow[t]{3}{*}{$0.05-12$} \\
\hline & & & $\begin{array}{c}\text { TiC-TiCN-TiN, } \\
\text { TiN-TiAlN, } \\
\text { TiAlN-TiAlSiN, TiFeN- } \\
\text { TiFeSiN, TiC, TiN- } \\
\text { TiMoN, } \\
\text { TiCN-TiZrN-TiN, TiN- } \\
\text { TiZrN-TiN, } \\
\text { TiN-TiZrN, ZrC }\end{array}$ & $\begin{array}{l}\text { Cutting tool/U8, R6M5, } \\
\text { R9K9, T15K6, U10, U13 }\end{array}$ & $250-400 ; 2 ; 4$ & \\
\hline & & & $\mathrm{TiC}, \mathrm{ZrC}$ & Aircraft unit/SAP-2, VT3-1 & $250-400 ; 2 ; 3$ & \\
\hline 3 & Cermet & Detonation & $\begin{array}{c}\text { VP-AFTs, N-VP-AFTs1 } \\
\text { with nickel sublayer, } \\
\text { WC-C(VK-15) }\end{array}$ & Blade/alloyed steel & $400-450 ; 3 ; 1$ & $80-100$ \\
\hline
\end{tabular}

The aim of this work is investigation and analysis of physical and technical characteristics of ion-plasma multifunctional coating of the type $(\mathrm{TiZr}) \mathrm{N}$ formerly applied only for the tool and offered for protection of titanium alloy VT-8 compressor blades of helicopter engine TV3-117.

The spraying was made on the whole surface of the blade, i.e. on the airfoil and lock part in two layers (thickness 5.0-5.5 $\mu \mathrm{m}$ ) using the machine «Bulat-6». The parameters of modes of deposition of coatings are presented in Table 2. The first layer of the coating was formed by successive bombardment of blade surface by ions of titanium and zirconium in the rarefied medium of nitrogen. In the process of deposition of the first layer the cleaning of the surface and its strengthening with the compounds $\mathrm{ZrN}$ and $\mathrm{TiN}$, partially diffused to the surface of the base, take place. The second layer of the coating has a more complicated composition including strengthening phases based on the refractory compounds $\mathrm{ZrN}, \mathrm{TiN},(\mathrm{TiZr}) \mathrm{N}$, which delay the process of fracture of blade base material caused by chemical

Table 2. Modes of deposition of ion-plasma coating of the (TiZr)N type

\begin{tabular}{||l|c|c|c|c||}
\hline \hline Stage of spraying & $\begin{array}{c}\text { Current of } \\
\text { accelerated } \\
\text { ion flow } \\
I_{\mathrm{f}}, \mathrm{V}\end{array}$ & $\begin{array}{c}\text { Voltage of } \\
\text { accelerated } \\
\text { ion flow } \\
U_{\mathrm{f}}, \mathrm{V}\end{array}$ & $\begin{array}{c}\text { Current of } \\
\text { arc of } \\
\text { evaporator } \\
I_{\mathrm{c}}, \mathrm{A}\end{array}$ & $\begin{array}{c}\text { Voltage of } \\
\text { discharge } \\
U_{\mathrm{c}}, \mathrm{kV}\end{array}$ \\
\hline $\begin{array}{l}\text { Ion etching (pres- } \\
\text { sure of nitrogen } \\
\left.10^{-1} \mathrm{~Pa}\right)\end{array}$ & 3 & 250 & 90 & 1.8 \\
\hline $\begin{array}{l}\text { Spraying of coat- } \\
\text { ing (pressure of ni- } \\
\left.\text { trogen 2.10 } 20^{-1} \mathrm{~Pa}\right)\end{array}$ & 4 & 190 & 110 & 1.5 \\
\hline
\end{tabular}

and mechanical effect of environment during engine operation. The composition of the cathode coating is, vol.\%: $20 \mathrm{Zr}$; $80 \mathrm{Ti}$.

The data of investigations on the corrosion resistance, changes of rate of erosion and microhardness, are given in Table 3 . The corrosion resistance of coting was determined by the effect of fine-sprayed sea water (sea fog) on the blade airfoil at its heating to $300,400,500$ and $600{ }^{\circ} \mathrm{C}$. During test of the coating ( TiZr)N the growth of salt precipitates in the form of white spots occupying up to $2 \%$ of total area of the blade was observed. No oxide-like corrosion damages were detected from the side of shank or blade airfoil. The absence of temper colors on the blade with coating evidences that the coating (TiZr)N at the effect of chemically active environment is sufficiently resistant to thermocyclic loads. The evaluation of salt-like corrosion damages according to the 10-point scale corresponds to 6-7 points, whereas oxide-like ones - to 10 points at the test temperatures mentioned above. According to the calculations the application of ionplasma coating ( $\mathrm{TiZr}$ ) N allows increasing the corrosion resistance of blade shank by $4-5$ times.

Microhardness of coating $(\mathrm{TiZr}) \mathrm{N}$ on the rotor blade of compressor and base material of blades was measured using the device PMT-3 at $50 \mathrm{~g}$ load during $7 \mathrm{~s}$ before deposition of coating, after deposition of coating and every three-hour annealing of blades at $300,400,500$ and $600{ }^{\circ} \mathrm{C}$ both with coating as well as without it. The selection of time of annealing, equal to $3 \mathrm{~h}$, was predetermined by the fact that control time of flight of the helicopter Mi-24, on which the engines TV3-117 are installed, takes in full ammunition (including take-off and landing) not less 
than $2 \mathrm{~h}$. The temperature of air in the compressor unit of engine TV3-117 is $300-400{ }^{\circ} \mathrm{C}$. The increase of operating temperature to $450{ }^{\circ} \mathrm{C}$ in the area of the 12th stage of the compressor is possible. The blades of compressor rotor mounted to the engine in the process of capital repairs undergo the procedure of strengthening (vibro-polishing in fragmentized particles of ball-grinding discs (the size of particle is $5-10 \mathrm{~mm}$ )), therefore microhardness (VT-8 alloy) of such blades is much higher than those of alloy without strengthening and approximates to the values of microhardness of the same alloy but strengthened using method of screw extrusion (4.10-4.28 GPa for the temperature of $700{ }^{\circ} \mathrm{C}$ ) [7]. The measurement of microhardness after thermal tests of blades both with coating as well as without it showed a tendency towards decrease of microhardness at increase of annealing temperature (see Table 3).

For comparison, let us give the following results of investigations given works [8-10] for similar coating $\mathrm{TiN}$ : microhardness of 21.2$27.4 \mathrm{GPa}$, rate of erosion of $19-28 \mathrm{mg} / \mathrm{min}$.

The erosion resistance of coating $(\mathrm{TiZr}) \mathrm{N}$ was determined according to the following procedure. Before and after the test a blade mass was determined by weighing at the accuracy of up to $0.001 \mathrm{~g}$. The stand tests were carried out using fused alumina sand of 100-300 $\mu \mathrm{m}$ dispersion (14A F60), used for bombardment of blades surface under the pressure of $0.30-0.35 \mathrm{MPa}$. Under the conditions of the helicopter flight in the regions of sand soils, the dispersion of particles of absorbed sand was about $200 \mu \mathrm{m}$ and more, the pressure of air in the area of the 12th stage of the compressor of helicopter engine TV3-117 reaches $0.4 \mathrm{MPa}$ (maximum pressure). The testing of blades was carried out without coating and with coating $(\mathrm{TiZr}) \mathrm{N}$, before and after the annealing at the specified temperatures (see $\mathrm{Ta}$ ble 3 ). The rate of erosion was calculated according to the formula [11]

$$
v_{\text {er }}=\frac{m_{0}-m_{1}}{t}(\mathrm{mg} / \mathrm{min}),
$$

where $m_{0}, m_{1}$ is the mass of blade before and after the test, respectively; $t$ is the time of test.

It is seen from Table 3 that the rate of erosion of blade both without coating as well as with

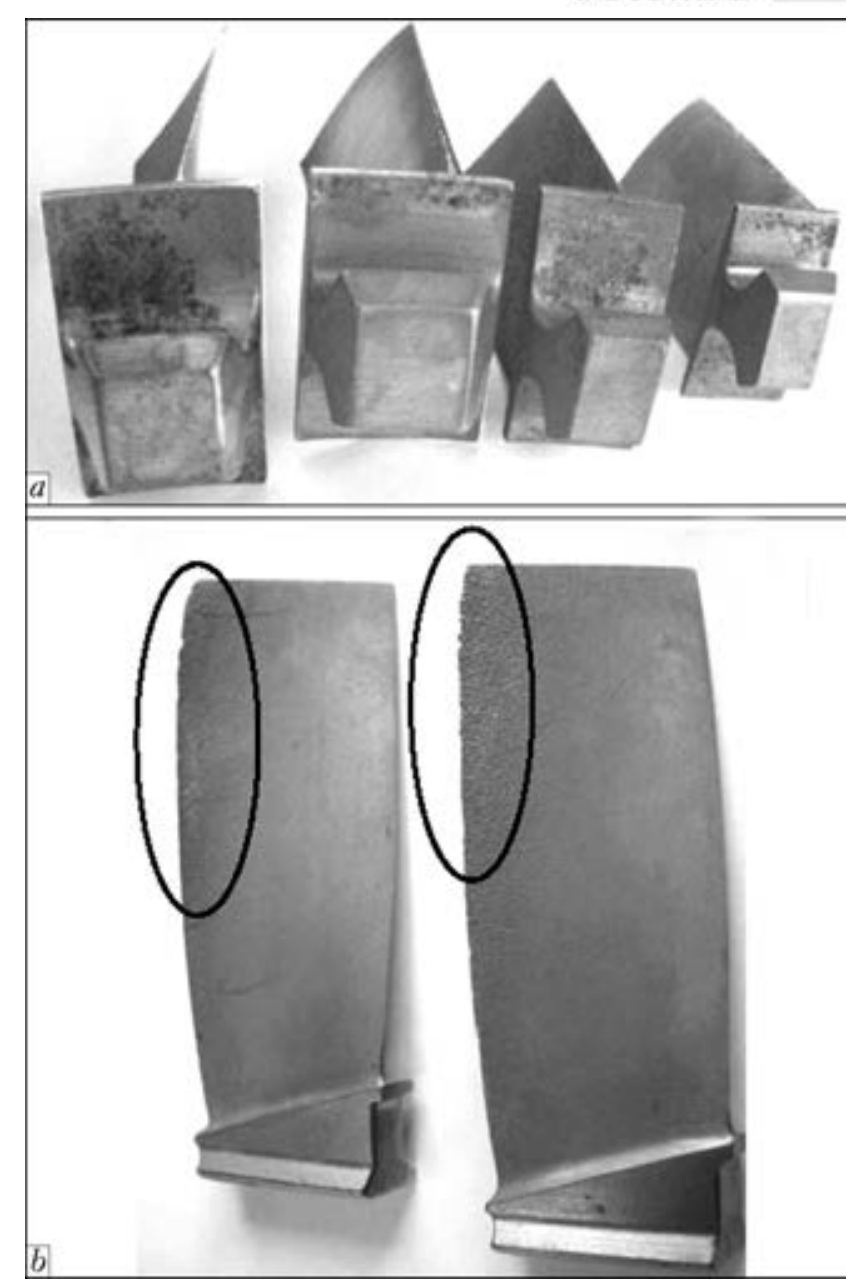

Figure 1. Service defects of rotor blades of compressor of engine TV3-117: $a$ - fretting-corrosion on the locks of blades; $b$ - erosion wear on the outer edge

coating depends on microhardness of material of the blade or coating, and the latter in its turn depends on temperature in the compressor unit during its operation.

In accordance with the obtained test results the rate of erosion of blade with the coating $(\mathrm{TiZr}) \mathrm{N}$ in the range of operating temperatures to $300{ }^{\circ} \mathrm{C}$ is $3.5-5$ times decreased as compared to the blade without coating, which is evidently seen from the plot (Figure 2). Here, the microhardness of coating is negligibly decreased .

In the range of working temperatures of 300$400{ }^{\circ} \mathrm{C}$ the rate of erosion of blade with coating is differed from the values of rate of erosion of blade without coating practically by the same

Table 3. Physical and technical characteristics of compressor rotor blades with coating (TiZr)N (numerator) and without coating (denominator) (base - alloy VT-8)

\begin{tabular}{||l|c|c|c|c|c||}
\hline \multirow{2}{*}{ Characteristic } & \multicolumn{5}{|c|}{ Temperature of annealing, ${ }^{\circ} \mathrm{C}$} \\
\cline { 2 - 6 } & Without heating & 300 & 400 & 500 & 600 \\
\hline Microhardness, $\mathrm{GPa}$ & $34 / 6$ & $32 / 5.5$ & $25 / 4.5$ & $24 / 3.2$ & $5 / 3$ \\
\hline Rate of erosion $v_{\mathrm{er}}, \mathrm{mg} / \mathrm{min}$ & $11 / 38$ & $12 / 61$ & $26 / 63$ & $29 / 168$ & $36 / 347$ \\
\hline Mean value of corrosion resistance $\varphi$, point $(\max 10)$ & $9 / 9$ & $9 / 8$ & $9 / 7$ & $8 / 7$ & $8 / 7$ \\
\hline
\end{tabular}




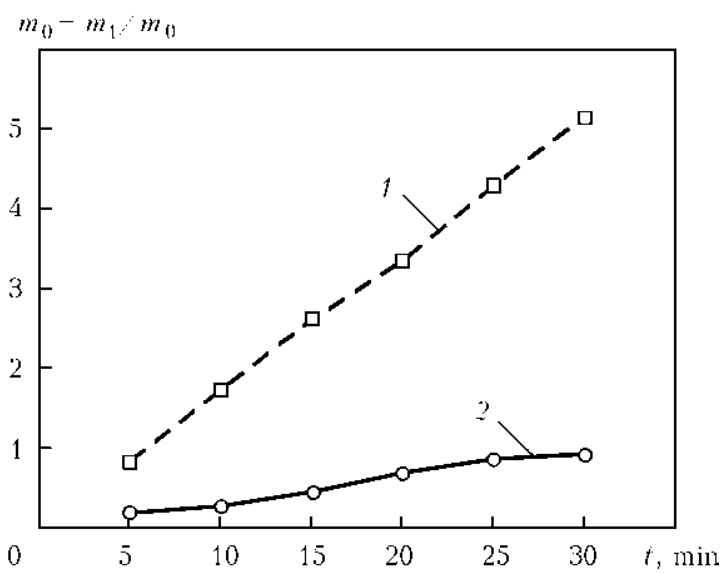

Figure 2. Loss of mass of blade at the effect of erosion environment: 1 - without coating; 2 - with coating $(\mathrm{TiZr}) \mathrm{N}$

value as at the working temperatures up to $300{ }^{\circ} \mathrm{C}$. In its turn it proves the assumption that at such temperatures the structure of coating is sufficiently dense and also resistant to mechanical effects of dust particles getting to the running area of compressor, and the first layer performs the reinforcing functions. Microhardness of coating is decreased (see Table 3), however as is was mentioned above, it does not influence its protective properties.

At increase of operating temperatures to $500{ }^{\circ} \mathrm{C}$ the rate of erosion of the blade without coating, as compared to the blade with coating, is practically 6 times increased as far as tensile strength of titanium alloy VT-8, of which the rotor blade of compressor is manufactured, preserves high values up to $450{ }^{\circ} \mathrm{C}$ and drops abruptly at temperature increase. In this case, the coating (TiZr)N performs also heat protective functions, i.e. partially prevents heating of blade airfoil. In the range $400-500{ }^{\circ} \mathrm{C}$ microhardness of coating like that in the range of up to $300{ }^{\circ} \mathrm{C}$ is decreased negligibly, which in its turn facilitates the preserving of strength characteristics.

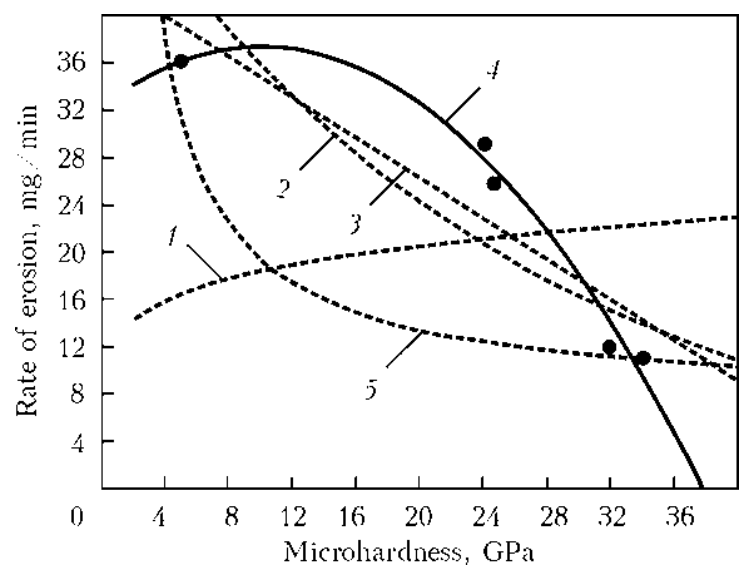

Figure 3. Functions of dependence of rate of erosion of coating $(\mathrm{TiZr}) \mathrm{N}$ on the blades on its microhardness (black spots - experimental values of rate of erosion): 1 - power; 2 - exponential; 3 - linear; 4 - parabola of the second order; 5 - hyperbolic
The further increase of operating temperature to $600{ }^{\circ} \mathrm{C}$ results in heavy erosion wear of blade without coating, the difference of values of rate of erosion of a blade without coating from the blade with coating becomes even more significant. Blade with coating $(\mathrm{TiZr}) \mathrm{N}$, installed to the rotor of compressor of high temperatures, will have a resistance to erosion effect 6-10 times higher than the blade without coating. However microhardness of coating during operation of blade at the temperatures of more than $600{ }^{\circ} \mathrm{C}$ drops abruptly to the level of value of microhardness of material of the blade itself, i.e. titanium alloy VT-8, but meantime preserving the high erosion resistance to the effect of dust atmosphere in the compressor.

Basing on the stated data one can assume the correlation between the following physical and technical values of coating ( TiZr)N: rate of erosion and microhardness, found at different temperatures.

The data of tests of compressor blades according to these values are presented in Figure 3. To confirm the assumed relation the mathematical description of experimental curve is given, which is reduced to determination of the formula of empiric equation using the method of the least squares (method of leveling).

Considering five main functions of dependencies, which are more frequently encountered in the description of experimental curves (Table 4) and, solving the systems of normal equations for them, we obtained the functional dependencies, which describe the field of experimental data with greater or lesser extent of accuracy. Comparing the values of sum of deviations $S_{1}-S_{5}$, one can assume that the experimental curve can be better described by quadratic function of the second order. The verification of equations of models for adequacy was performed using mean error of approximation $\bar{\varepsilon}$, the value of which (less than $12 \%$ ) shows that the model is adequate.

In particular, according to the data of Table 4 , one can speak about the adequacy of the model only for the model described by the equation of parabola of the second order, where the mean error of approximation amounts to $5 \%$. The rest calculation models inadequately reflect the assumed dependence between the selected parameters, i.e. applying them, we obtain the values of rate of erosion with a great error.

Regarding the measurement of closeness of relation at curvilinear dependence, here not a linear coefficient of correlation is used, but correlation of $\eta$ relation, the formula of which is universal at any type of dependence (see Table 4). The closeness of relation of selected signs was evaluated according to the scale of Cheddok: $0.1<\eta<$ $<0.3$ : weak; $0.3<\eta<0.5$ : moderate; $0.5<\eta<$ 
Table 4. Functional dependencies and their analysis according to the experimental data of tests of coating (TiZr)N

\begin{tabular}{|c|c|c|c|c|c|}
\hline \multirow[b]{2}{*}{$\begin{array}{c}\text { Analytical } \\
\text { values }\end{array}$} & \multicolumn{5}{|c|}{ Function (general view/calculation) } \\
\hline & $\begin{array}{c}\text { Power } \\
y(x)=a_{0} x^{a_{1}} \\
y(x)=12.708 x^{0.1587}\end{array}$ & $\begin{array}{c}\text { Exponential } \\
y(x)=a_{0} a_{1}^{x} \\
y(x)=53.3 \cdot 0.961^{x}\end{array}$ & $\begin{array}{c}\text { Linear } \\
y(x)=a_{0}+a_{1} x / \\
y(x)=43.4232-0.8593 x\end{array}$ & $\begin{array}{l}\text { Parabola of the second } \\
\text { order } \\
y(x)=a_{0}+a_{1} x+a_{2} x^{2} \\
y(x)=32.3546+ \\
+0.9871 x-0.0488 x^{2}\end{array}$ & $\begin{array}{c}\text { Hyperbolic } \\
y(x)=a_{0}+a_{1} \frac{1}{x} \\
y(x)=7.3+\frac{12.6413}{x}\end{array}$ \\
\hline$S$ [12] & 697.3 & 187.8 & 90.4 & 7.3 & 492.3 \\
\hline $\bar{\varepsilon}[13]$ & 57 & 25 & 22 & 5 & 56 \\
\hline$\eta[13,14]$ & 0.31 & 1.11 & 0.9 & 0.99 & 1.5 \\
\hline$r_{1}[13,14]$ & Subroot expression $<0$ & 0.78 & 0.9 & 0.99 & Subroot expression $<0$ \\
\hline
\end{tabular}

$<0.7$ : noticeable; $0.7<\eta<0.9$ : high; $0.9<\eta<$ $<1$ : extremely high; $\eta>1$ : relation is absent.

In the power function the moderate relation between the signs is present, in the demonstrative function - the relation is absent, in linear - it is high, in the function of parabola of the second order - it is extremely high, in hyperbolic it is absent. Consequently, the selected function of parabola of the second order reflects the strongest mutual influence of such technological values as rate of erosion and microhardness of coating.

The degree of approximation of calculation data to the real values of empirical series shows a coefficient of accuracy of leveling the curve $r_{1}$ (correlation index), which should be more than 0.95 . The index of correlation (see Table 4) is maximum for the parabola of the second order $\left(r_{1}=0.99\right)$ and more than 0.95 , which proves the proper selection for description of relation of two physical and technical values, its adequacy and high precision of description of test results of the coating.

The calculation values (Table 4) show that dependence of rate of erosion on microhardness of coating can be very precisely described using parabola of the second order.

So, according to the abovementioned, using the blade with proposed two-layer coating $(\mathrm{TiZr}) \mathrm{N}$ in the unit of compressor of aircraft engine one can avoid different operation defects which are often encountered. At the erosion effect on the blade the first layer operates as the reinforcing element preventing initiation of microcracks, spallings and burrs on the coating as a whole. And the second layer of coating due to density and high microhardness protects the blade from impact loads caused by abrasive particles and has an improved resistance to frettingcorrosion. Experimental data showed that even during operation at the elevated temperatures up to $600{ }^{\circ} \mathrm{C}$ the erosion resistance of the blade at the use of coating (TiZr)N almost 10 times increases. And the resistance of blade to the corrosion damages independently of the operation temperature 4-5 times increases as compared to the blade without coating.
The function (parabola of the second order) theoretically derived basing on the practical results determines the dependence of rate of erosion of two-layer coating $(\mathrm{TiZr}) \mathrm{N}$ on its microhardness, reflects close correlation of selected parameters, extremely good correlates (index of correlation is 0.99) with experimental values, which, in turn, allows using the given model during manufacture of parts and units designed for the operation conditions similar to the above-described ones.

1. Maksimov, N.A., Sekistov, V.A. (1977) Aircraft and helicopter engines. Principles of structure and flight operation. Moscow: Voenizdat.

2. Boguslaev, V.A., Muravchenko, F.M., Zhemanyuk, P.D. et al. (2003) Technological control of service characteristics of gas-turbine engine parts. Blades of compressor and ventilator. Pt 1. Zaporozhie: Motor Sich.

3. Rzhavin, Yu.A. (1995) Axial and centrifugal compressors of aircraft engines. Moscow: MAI.

4. Dushkin, A.M., Proshchin, A.B. (1988) Protective coatings on steel blades of compressor. Aviats. Promyshlennost, 7, 13-15.

5. Boldov, V.V., Kordit, E.A., Yakubovich, E.A. (1987) Examination of properties of vacuum-plasma coatings on titanium nitride base. Ibid., 9, 61-62.

6. Bogomolov, V.A., Larina, G.B., Polyanin, B.A. et al. (1988) Zirconium nitride wear-resistant coatings for light alloys. Ibid., 3, 51-53.

7. Kachan, A.Ya., Ovchinnikov, A.V., Pavlenko, D.V. et al. (2012) Technological peculiarities of manufacturing of GTE compressor blades from titanium alloys using screw extrusion. Vestnik Dvigatelestroeniya, 1, 92-97.

8. Khvorostukhin L.A. Nozhnitsky, Yu.A., Bolmanenkov, A.E. (1988) Investigation of erosion strength of ion-plasma coating of titanium nitride. Aviats. Promyshlennost, 6, 59-61.

9. Boldov, V.V., Kordit, E.A., Yakubovich, E.A. (1987) Investigation of properties of vacuum-plasma coatings on titanium nitride base. Ibid., 9, 61-62.

10. Miloserdov, I.V., Paperny, V.L., Makarov, R.V. et al. (1989) Physical-mechanical characteristics of coatings produced by ion bombardment method. Ibid., 12, 39-40.

11. (1960) Methodical guideline on analyses and tests of air craft materials and parts. Issue 960. Moscow: RDI on service and repair of aircraft engineering of air forces.

12. Linnik, Yu.V. (1958) Least-squares method and principles of mathematical-statistical theory of processing of observations. Moscow: Fizmatgiz.

13. Lisiev, V.P. (2006) Theory of probability and mathematical statistics. Moscow: MSU of statistics, economy and informatics.

14. Shanchenko, N.I. (2008) Lectures on econometrics. Ulianovsk: UGTI. 


\section{TODAY'S FOREIGN TRADE COMPANY «INPAT» OF THE E.O. PATON ELECTRIC WELDING INSTITUTE}

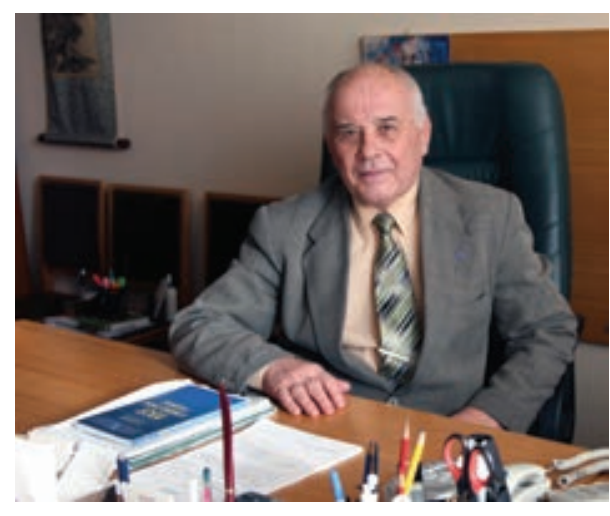

INPAT company of the E.O. Paton Electric Welding Institute (PWI) was founded on June 23, 1989 in accordance with the resolution of the Presidium of AS of UkrSSR. Since the moment of organization and until now the company is headed by Dr. V.I. Galinich, the laureate of the State Prize of Ukraine. The highlyqualified specialists, possessing the knowledge and experience in accompanying as well as in fulfillment of the commercial contracts, are working in the company.

INPAT represents the commercial interests of PWI in Ukraine and at the world markets of welding equipment and technologies on the following trends:

- research and engineering projects;

- trade and purchase, dealer activity, marketing, brokerage, agency activity;

- management of wholesale and retail trade;

- organizing of exhibitions, fairs, auctions, participation in tenders at the territory of Ukraine and abroad;

- advertising-information activity;

- receiving, applying and selling of licenses and patents.

Over this period, PWI with INPAT assistance signed and fulfilled successfully 400 contracts with foreign enterprises and organizations from the USA, Germany, Japan, China, France, South Korea, Great Britain, Russia and some other countries. The most important contracts were signed with such leading foreign companies as General Electric, AIRBUS Industries, TABCO, GEC ALSTHOM, ONERA, TISTO, AEROSPATIALE, University of Pennsylvania, etc.

It is necessary to note especially the many-year beneficial cooperation of INPAT with NASA in the scope of conductance of the International experiment on space welding. Under this subject PWI has already cooperated successfully for several years with the Russian Space Corporation «Energia» with contracts accompany by INPAT. Technology and equipment for flash-butt welding of high-strength aluminium was successfully implemented at the enterprises of rocket construction (welding of frame rings, shells).

Over the recent years the company deals with promotion of the PWI developments to the new challenging markets (India, China, Vietnam). A number of contracts were signed with enterprises and organizations

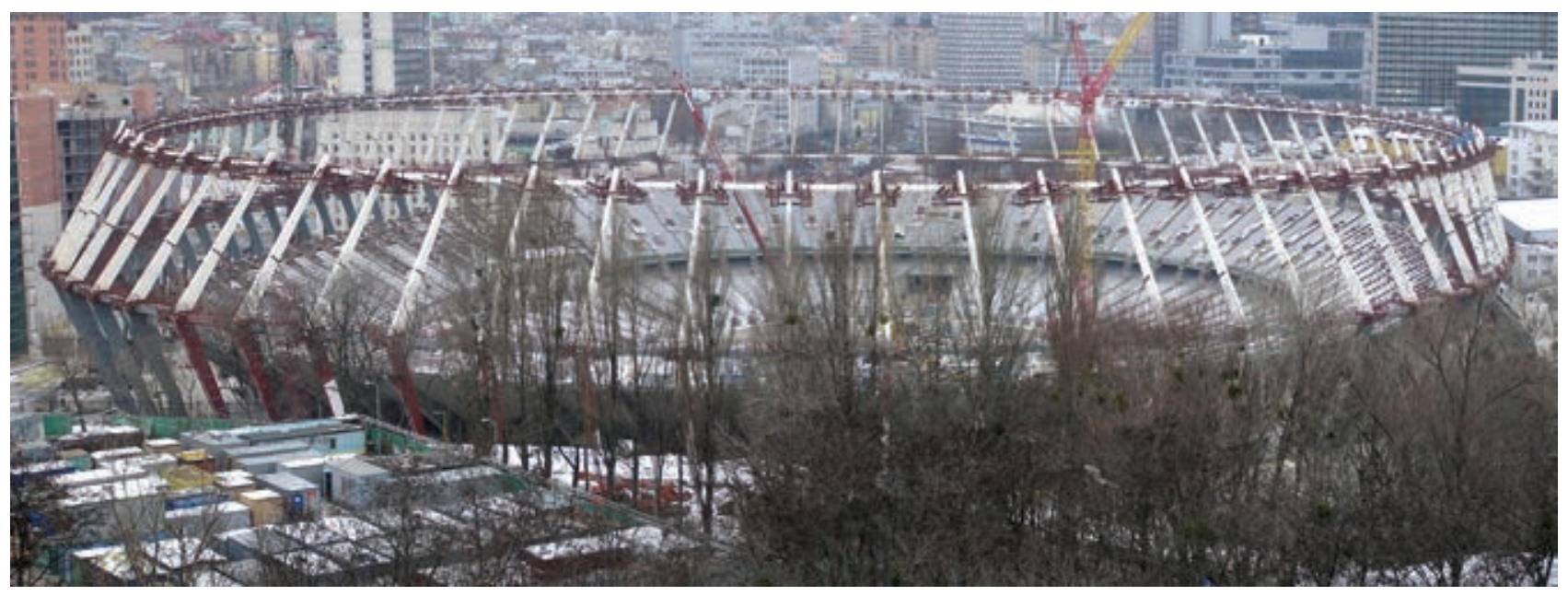



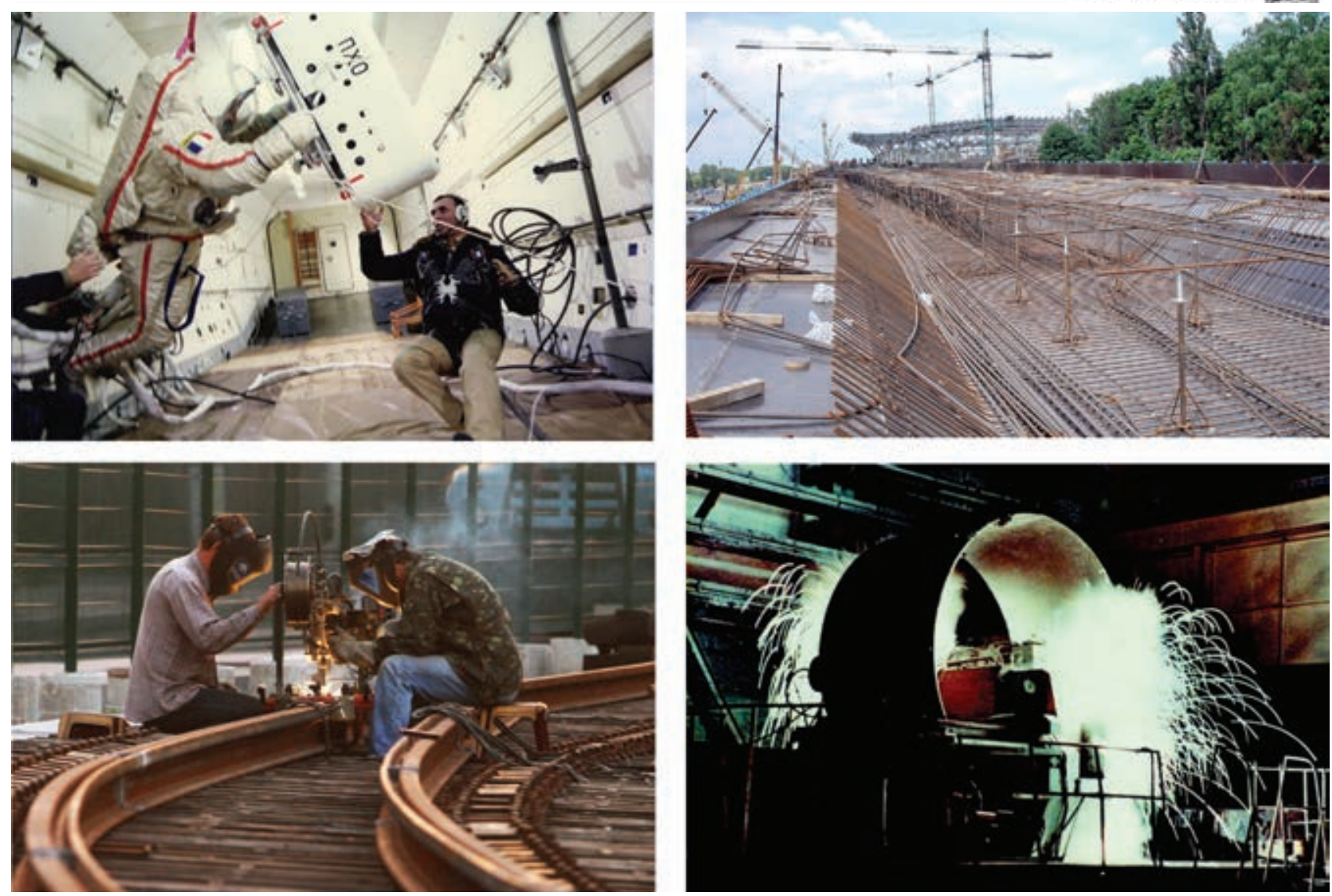

of these countries, the joint venture was established with the Chinese company «Paton-Gaode» for manufacture of flux-cored wires for welding. The agency agreements were signed with Indian and Brasilian partners. In the scope of cooperation with the Indian institutes and enterprises for realization of the PWI developments with participation of INPAT, the exhibition of welding equipment of PWI and Ukrainian enterprises-manufacturers was presented at the International Expo «Welding-India» in February, 2005. The cooperation of the company with the largest Research Welding Institute in India is also progressing.

Within the scope of the intergovernmental agreements about cooperation of the Ukrainian and Vietnamese Academies of Sciences and at a direct participation of INPAT, the Vietnamese Research Center of Transfer of Technologies was established in 2004, the aim of which is the implementation of high technologies of the Ukrainian companies into the economy of Vietnam. The semi-automatic line for manufacture of large-size anchor chains (flash-butt welding), developed and manufactured by the PWI specialists, is successfully operating.

Technology and equipment of embedded electrode welding of INPAT were implemented at the Irkutsk Aluminium Plant (RF) in construction of the $\mathrm{V}$ series of the electrolysis production. More than 16,000 butts were welded in mounting of cathode pins of $80 \times 220 \mathrm{~mm}$ section of electrolytic cells. The welding of cathode pins of $115 \times 230$ and $90 \times 180 \mathrm{~mm}$ section in magnetic fields was also performed at the pilot area of Sayanogorsky Aluminium Plant (RF). The mentioned technology and equipment were also applied in construction of line of a high-speed tram in Kiev (about 1000 butts were made) and in Lvov.

Over the recent years INPAT together with the PWI specialists takes a part in the implementation of technology of live tissues welding, the unique method of joining tissues in surgical practice, developed under the supervision of Prof. Boris Paton. Owing to this technology about 100,000 operations were successfully fulfilled.

The company participated actively in the construction of some objects of the national importance, namely NSC «Olimpiysky», driving-in road to terminal D in Kiev airport «Borispol».

Much work has been done and will be done relying on the experience of team of associates, high scientific and intellectual potential of PWI. 


\title{
PATON PUBLISHING HOUSE
}

\author{
www.patonpublishinghouse,com
}

SUBSCRIPTION

The Patholorial

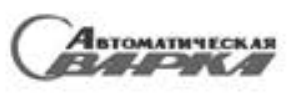

«The Paton Welding Journal» is Published Monthly Since 2000 in English, ISSN 0957-798X.

"Avtomaticheskaya Svarka» Journal (Automatic Welding) is Published

Monthly Since 1948 in Russian, ISSN 005-111X.

«The Paton Welding Journal» is Cover-to-Cover Translation of

Avtomaticheskaya Svarkaw Journal into English.

If You are interested in making subscription directly via Editorial Board, fill, please, the coupon and send application by Fax or E-mail.

The cost of annual subscription via Editorial Board is $\$ 348$ for * The Paton Welding Journals and $\$ 180$ for «Avtomaticheskaya Svarka» Journal.

«The Paton Welding Journals can be also subscribed worldwide from catalogues subscription agency EBSO.

\author{
SUBSCRIPTION COUPON \\ Address for journal delivery \\ Term of subscription since \\ Name, initials \\ Affiliation \\ Position \\ Tel., Fax, E-mail
}

Subscription to the electronic version of «The Paton Welding Journal and «Avtomaticheskaya Svarka can be done at site: URL: www: rucont.ru

We offer the subscription all issues of the Journal in pdf format, starting from 2009. You can subscribe to individual issues or to the entire archive including all issues over a period of 2011-2013. The archives for 2009-2010 are free of charge on www.patonpublishinghouse.com site.
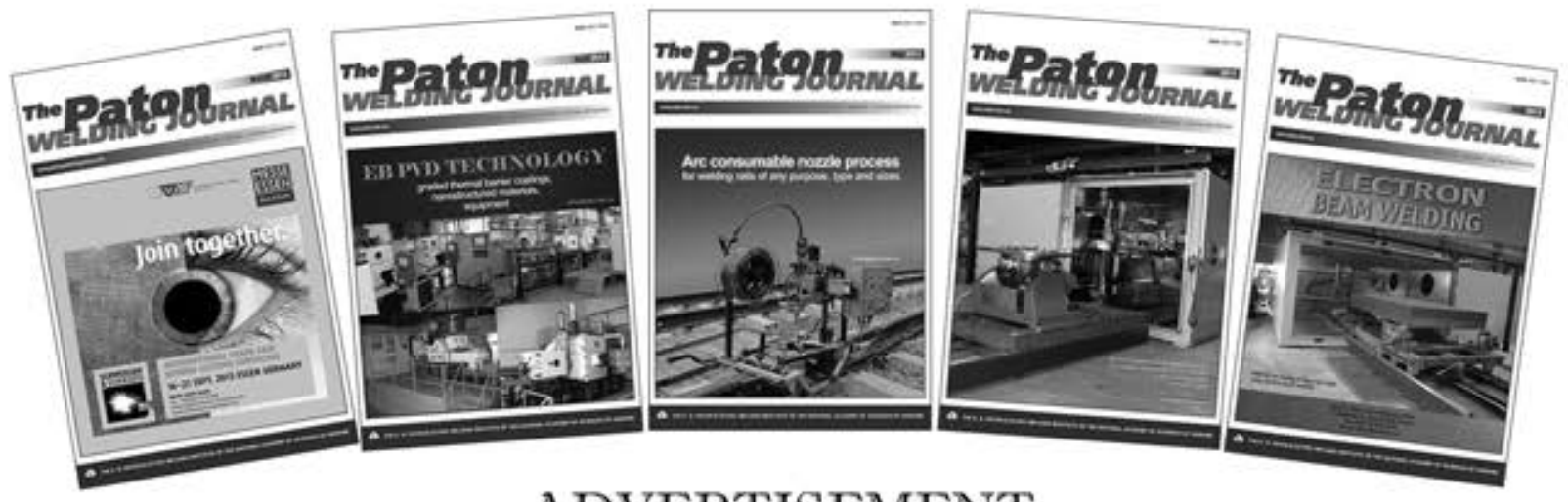

\section{ADVERTISEMENT}

in "Avtomaticheskaya Svarka" and "The Paton Welding Journal"

External cover, fully-colored:

First page of cover $(190 \times 190 \mathrm{~mm})-\$ 700$

Second page of cover $(200 \times 290 \mathrm{~mm})-\$ 550$

Third page of cover

$(200 \times 290 \mathrm{~mm})-\$ 500$

Fourth page of cover

$(200 \times 290 \mathrm{~mm})-\$ 600$

\author{
Internal cover, fully-colored: \\ First/second/third/fourth page \\ of cover $(200 \times 290 \mathrm{~mm})-\$ 400$ \\ Internal insert: \\ Fully-colored $(200 \times 290 \mathrm{~mm})-$ \\ $\$ 340$ \\ Fully-colored (double page A3) \\ $(400 \times 290 \mathrm{~mm})-\$ 500$
}

- Article in the form of advertising is $50 \%$ of the cost of advertising area

- When the sum of advertising contracts exceeds $\$ 1001$, a flexible system of discounts is envisaged

Size of journal after cutting is $200 \times 290 \mathrm{~mm}$

Editorial Board of Journal \&Avtomaticheskaya Svarkas and \&The Paton Welding Journal»

E.O. Paton Electric Welding Institute of the NAS of Ukraine

International Association \&Welding

11, Bozhenko Str., 03680, Kyiv, Ukraine

Tel.: (38044) 20060 16, 2008277 ; Fax: (38044) 2008277,2008145

E-mail: journal@paton.kiev.ua; www.patonpublishinghouse.com 